This is an Accepted Manuscript of an article published by Taylor \& Francis Group in Applied Economics on 7 Nov 2018, available online:

http://www.tandfonline.com/10.1080/00036846.2018.1540848.

\title{
Rational Functions: An Alternative Approach to Asset Pricing
}

Nilanjana Chakraborty a ${ }^{\text {a }}$ Mohammed M Elgammal ${ }^{\text {b,c }}$, David McMillan ${ }^{\mathrm{d}}$

\begin{abstract}
This paper shows that asset prices are linear polynomials of various underlying explanatory factors and asset returns being ratios of these polynomials, are rational functions that do not add linearly when averaging. Hence, average returns should be modeled based on stock prices. However, continuous returns may be treated as approximately linear across time and modeled directly. Our new Rational Function (RF) models, empirically outperform the traditional asset pricing models like the Capital Asset Pricing Model (CAPM) and the Fama-French three and five-factor models for both average and continuous returns. Moreover, the RF theory also provides a model to estimate the asset volumes. The average change in asset volumes together with average returns provide the estimates for average change in market values of assets. Thus, the RF model approach can be used to select assets that provide either highest returns for profit maximization or highest change in market values for wealth maximization for given levels of risk.
\end{abstract}

Keywords: Asset Pricing; Average Returns; Rational Function Model; CAPM; Fama French 3 and 5 Factor Models; Asset Volumes.

JEL Codes: G11, G12

This research did not receive any specific grant from funding agencies in the public, commercial, or not-forprofit sectors.

a. Freelance Researcher, Doctorate in Finance from Indian Institute of Science, Bangalore, India. 
b Department of Finance and Economics, College of Business and Economics, Qatar University (Duhil, Doha, 2713, Qatar).

c. Faculty of Commerce, Menoufia University, Egypt

d. Accounting and Finance Division, Stirling Management School, University of Stirling, Stirling, FK9 4LA, UK. 


\section{Introduction}

Existing asset pricing models are based on a linear relation between expected returns of financial assets and relevant explanatory factors. This includes both theoretically derived models, such as the Capital Asset Pricing Model (CAPM: Sharpe, 1964; Lintner, 1965) and Arbitrage Pricing Theory (Ross, 1976) as well as more recent empirically motivated models beginning with the Fama and French (1993) three factor model and continuing with other factor based models (see, for example, Aharoni et al, 2013; Novy-Marx, 2013; Fama and French, 2015). However, these asset pricing models often fail to provide an accurate description of expected returns when compared to actual values. Indeed, the development of the empirical asset pricing literature arose from the inability of CAPM to explain the cross-sectional differences between the stock returns (starting with the value-growth anomaly of Basu, 1977 and the size anomaly of Banz, 1981). This paper seeks to contribute to the literature by focusing on the basic definition of asset returns and the price-quantity framework that defines any free market. We argue that since an asset return is a quotient of two consecutive asset prices that are themselves polynomials of various factors, the return is a rational function and hence does not add linearly within a portfolio. This motivates one to consider an alternative expected return model that improves our understanding of asset price movements.

Our work adds to the capital asset pricing literature by explaining the discrepancies between the estimations of existing asset pricing models and actual average return values by questioning a basic assumption that lies behind these models. We question whether stock returns add linearly across portfolios or across time and whether they are linearly related to index returns. We address this through a theoretical re-examination of the stock market behavior by considering first an individual security and then the market portfolio. We attempt to explain asset pricing through the Rational Function (RF) model, which asserts that returns do not add linearly when averaging. This means that we should not model returns directly using linear regression techniques but rather model prices and then compute average returns from the estimated prices.

Our RF model further suggests that we should consider other variables in addition to the market index return such as the preceding asset price, asset volume, time trend etc. to model asset prices. Our findings show that the RF model not only outperforms the traditional linear models like the CAPM and the Fama and French 3 and 5 Factor models but follows the actual average returns so closely that it seems that it has finally solved the CAPM enigma. Thus, the CAPM anomalies were 
mainly arising due to averaging errors. Further, apart from the averaging concept, the RF theory also relies on the theoretical link between price and quantity (called trading volume in the stock market) - the two fundamental forces of any free market. This logic is very much in the spirit of earlier endeavors to base asset pricing fundamentals on price-volume relationships (Lo and Wang, 2000, 2006; Wang, 2002). Accordingly, the RF theory leads to a model for estimating asset volumes as well. We have compared the performance of our RF model for volumes with that of the Lo and Wang 2 Factor (LW2F) model and again, the RF model estimates for average change in volumes are found to be more accurate. These findings bring very important implications for the investment managers and the investors as the RF model introduces a powerful technique to study financial assets that can help in making better investment decisions.

The remainder of the paper is organized as follows. Section 2 reviews the popular asset pricing models for estimating returns and volumes, while Section 3 introduces the RF model by establishing its theoretical base and attributes. Section 4 conducts an empirical analysis to compare the performance of the above mentioned models against that of the RF model. Section 5 highlights the practical implications of the RF model while Section 6 concludes the paper.

\section{Literature Review}

According to the Sharpe-Lintner CAPM equation, the relation between the expected return of asset $i$, denoted as $E\left(R_{i}\right)$, and the market risk premium $\beta_{i, m}$ is linear and given by:

$$
E\left(R_{i}\right)=R_{f}+\beta_{i, m}\left[E\left(R_{m}\right)-R_{f}\right]
$$

Asset $i$ represents either an individual stock or a portfolio, while $R_{f}$ and $E\left(R_{m}\right)$ denote the riskfree rate of return and the expected market return, respectively. However, several empirical studies have consistently found that the CAPM average returns are lower than the actual average returns for lower risk assets, whereas they are higher than the actual average returns for higher risk assets (see for example, Jensen, 1968; Blume 1970; Fama and French, 1993, 1996, 2004). This led to the articulation of the prominent Joint Hypothesis Problem by Fama (1970), which attributed the discrepancies between the actual and the CAPM average returns to a flawed asset pricing model and/or market inefficiencies. ${ }^{1}$

\footnotetext{
${ }^{1}$ A related issue is concerned the view that CAPM is an ex ante concept, whereas tests of CAPM are conducted ex post. Roll (1977) concludes that the CAPM tests are invalid because they use inefficient benchmark portfolios.
} 
Fama and French (1993) provided empirical evidence that a single factor encapsulating risk does not adequately explain cross-sectional differences in stock returns. This finding motivated a substantial research agenda on asset pricing that ran alongside a debate regarding the fundamental relation between risk and return (Baker and Haugen, 2012). Fama and French (1993, 1996, 2004) introduced a three-factor model (FF3F) that included a size and value premium to explain variations in stock returns. These two additional factors were included due to their supportive empirical evidence, even though their underlying theoretical rationales remain unclear. Nevertheless, a considerable the amount of subsequent research has been devoted to investigating explanations for these factors (recent examples include Erdos et al., 2011; Dempsey, 2013; Elgammal and McMillan, 2014; Elgammal et al., 2016; Bao et al., 2017).

Various empirical studies examining cross-sectional variations in stock returns have reported patterns unexplained by CAPM, commonly referred to as anomalies. Based on these anomalies, various investment styles have been developed. These investment styles are based on size (Banz 1981; Fama and French, 1993), value/growth (Basu, 1977; Fama and French, 1992, 1993), momentum and reversals (Jegadeesh and Titman 1993; O’ Keeffe and Gallagher, 2017), liquidity (Haugen and Baker, 1996; Datar, Naik, and Radcliffe, 1998), profitability and investment (Fama and French, 2015). However, these models lack a robust economic explanation for their precise nature. Recently, Fama and French (2015) introduced a five-factor model (FF5F) that adds profitability and investment factors to their FF3F model. This model in turn builds on the work of Hou et al. (2015) and Novy-Marx (2013). However, Fama and French (2015) concede that, although, the five-factor model (FF5F) may outperform the three-factor model (FF3F), neither of these models provide a complete description of the expected returns. Indeed, Fama and French (2015) admit that their and other models have difficulty explaining the behavior of small stocks.

Given the above gap, this paper introduces a Rational Function (RF) model which argues that asset returns do not add linearly in a portfolio because returns are rational functions (i.e., ratios) of asset prices which themselves are polynomials of various relevant variables. These relevant variables include asset volumes, preceding asset price, time trends and other market factors in addition to the market return. For identifying the relevant variables, the RF theory draws from the price-volume framework in a free market environment which then logically mirrors the price

Both researchers and practitioners have an innate belief that ex ante risk matters and an ex ante risk premium exists, even if, ex post, such a belief is not empirically validated (Roll and Ross, 1994; Diacogiannis and Feldman, 2011). 
model into a volume model as well. The RF model for volumes addresses another gap in literature that being the lack of attention in modelling volumes as compared to modelling returns. A few others (Lo and Wang, 2000, 2006; Wang, 2002) have also linked both price and volume to economic fundamentals for asset pricing. Lo and Wang (2000) have introduced a two factor (LW2F) model that estimates asset volumes by the volumes of two portfolios, one being the market portfolio and the other being the hedging portfolio. The former is an equal-weighted index while the latter is a share-weighted index. Though Lo and Wang (2000) have estimated asset returns also using their two-portfolio model, they found its performance could not beat the FF3F model. Hence, we consider the LW2F for comparing the performance of the RF volume model only and did not include it for comparison with the RF returns models. Thus, this paper ends by comparing the RF returns models with the CAPM, the FF3F and the FF5F models (which remain the dominant models used in the literature by academics as well as practitioners) and by comparing the RF volume model with the LW2F model.

\section{Rational Function Model (RF): Theoretical Development}

We begin by revisiting the basics of price determination for a publicly traded asset, viz., the demand and supply framework as propounded by Lo and Wang (2000), Wang (2002) etc. Following the laws of increasing marginal cost for the supply curve and decreasing marginal utility for the demand curve (jointly, the laws of diminishing returns), we have an exponential supply curve and a logarithmic demand curve. Here, a fixed quantity of issued stocks limits the supply while the demand for stocks is limited by the amount of money available for investment in the economy. These principles were first stated by Cournot (1838) and further developed by Marshall (1890). Mathematically, we express the exponential supply curve of stock ' $i$ ' on day ' $t$ ' as follows:

$$
p_{s, t}=a_{s}+b_{s}\left[\exp \left(v_{s, t}\right)\right]
$$

where, $p_{s, t}$ is the stock price that corresponds to the stock trading volume $v_{s, t}, a_{s}$ is the minimum price at which the supply curve starts and $b_{s}$ is the linear regression coefficient.

The law of decreasing marginal utility is shaped by the 'willingness' and the 'ability' of investors to buy stocks. According to this law, the elasticity of demand is best expressed by a decreasing logarithmic demand curve where the decrease in utility (or price-willingness) for increasing quantity is sharp at first and hereafter gradually flattens out with further increase in quantity or volume. This has been captured in Equation (3) where the logarithmic demand curve 
for stock $i$ on day $t$ is given as follows:

$$
p_{d, t}=a_{d}-b_{d}\left[\ln \left(v_{d, t}\right)\right]
$$

where, $p_{d, t}$ is the price that corresponds to volume $v_{d, t}, a_{d}$ is the minimum price at which the demand curve starts and $b_{d}$ is the linear regression coefficient. Investors allocate their limited wealth to obtain the greatest satisfaction or utility (See, Samuelson and Nordhaus , 2001). At the point of market equilibrium, Equations (2) and (3) intersect each other, and we have:

$$
p_{s, t}=p_{d, t}=p_{i, t} ; \text { and } v_{s, t}=v_{d, t}=v_{i, t}
$$

Taking an average of Equations (2) and (3) at the point of equilibrium and substituting equation (4) leads us to Equation (5):

$$
p_{i, t}=\left(a_{s}+a_{d}\right) / 2+\left(b_{s} / 2\right)\left[\exp \left(v_{i, t}\right)\right]-\left(b_{d} / 2\right)\left[\ln \left(v_{i, t}\right)\right]
$$

Equation (5) can be further generalized by representing the constants and the slope coefficients by single terms, as follows:

$$
p_{i, t}=a_{i}+b_{i 1}\left[\exp \left(v_{i, t}\right)\right]-b_{i 2}\left[\ln \left(v_{i, t}\right)\right]
$$

Here, $a_{i}$ is a constant, while $b_{i 1}$ and $b_{i 2}$ are the coefficients of the exponential and logarithmic values of the stock volume. This equation, thus, expresses the basic relation between the equilibrium price and the equilibrium volume of a stock ' $i$ '. Next, we consider the situation where numerous stocks are traded simultaneously, which collectively influence the demand and supply of any given stock through various common economic, business or technological factors. In such a case, the prices and volumes of multiple stocks may be correlated. Therefore, we expand our analysis by including a market portfolio $m$, the price of which on day ' $t$ ' is given by:

$$
p_{m, t}=\sum_{j=l^{w}} q_{j} p_{j, t}
$$

where, $j=1$ to $w$, including $i$, thus representing all stocks contained in combination $m$, while $q_{j}$ denotes the corresponding weight of the stock $j$ in combination $m$. Thus,

$$
\sum_{j=1}^{w} q_{j}=1
$$

From Equation (7) we can see that $p_{m, t}$ is a linear aggregate of $p_{i, t}$ and other stock prices on day ' $t$ '. However, the price of some stocks may be correlated with that of stock $i$ and so $p_{i, t}$ would vary in response to a change in the price of any one of these stocks. By representing the relationships between $p_{i, t}$ and those of other stocks (whether linear, non-linear or uncorrelated) into linear functions that describe them most closely and then adding these resulting simultaneous equations, we get a linear relationship between $p_{i, t}$ and $p_{m, t}$. Considering that both $p_{i, t}$ and $p_{i, t-1}$ are correlated with $p_{m, t}$ and $p_{m, t-l}$ on days ' $t$ ' and ' $t-l$ ' respectively, their ratio or the 'rate of change of price' of 
stock ' $i$ ' (i.e. $p_{i, t} / p_{i, t-1}$ ) would also be correlated with the 'rate of change of price' of the market combination $m$ (i.e. $\left.p_{m, t} / p_{m, t-1}\right)^{2}$ This linear relationship between $p_{i, t} / p_{i, t-1}$ and $p_{m, t} / p_{m, t-1}$ can be expressed in a generalized form as follows:

$$
\left(p_{i, t} / p_{i, t-1}\right)=q_{i}+r_{i}\left(p_{m, t} / p_{m, t-1}\right)
$$

Here, $q_{i}$ is the constant and $r_{i}$ is the slope. Although equation (9) looks like a generalized form of the CAPM, its objective is different, in the sense that it aims to estimate asset prices and not returns. Our work can be related to earlier research, which linked capital asset pricing models to the change in the prices. Hagerman and Kim (1976) develop a capital asset-pricing model that relates risk and return under conditions of changing price levels. Similarly, Long (1974) has shown a connection between commodity prices and equilibrium stock prices.

Taking the price equivalent for $p_{i, t}$ and adding the term $\left[q_{i} p_{i, t-1}+r_{i}\left\{\left(p_{m, t} / p_{m, t-1}\right) p_{i, t-1}\right\}\right]$ obtained from equation (9) with equation (6) and generalizing, we get:

$$
\left.\left.p_{i, t}=k_{i}+s_{i 1}\left\{\left(p_{m, t} / p_{m, t-1}\right) p_{i, t-1}\right\}+\right)\right]+s_{i 2} p_{i, t-1}+s_{i 3} \exp \left(v_{i, t}\right)-s_{i 4} \ln \left(v_{i, t}\right)
$$

Equation (10) outlines the relation between the price of an individual stock ' $i$ ', the prices of the market combination ' $m$ ', the preceding price of the stock ' $i$ ' and the volume of stock ' $i$ ' under economic equilibrium in the market.

Besides the asset volume and market return, an asset price may be affected by other market factors, such as firm size, book to market ratios etc. (Fama and French, 1993, 1996, 2004, 2015) as well as time and seasonal trends (Gallant et al., 1992; Chen et al., 2001; Pisedtasalasai and Gunasekarage, 2007). The presence of the time trends in asset pricing can be explained by the seasonality of sales or the regularity of certain anticipated events, such as earnings or dividend announcements. Accordingly, a time trend component can be expressed by the log function of the chronological order of the observation within the data sample (Pisedtasalasai and Gunasekarage, 2007). Incorporating other market factors and the time trend in Equation (10), we get the following resulting equation defining the stock price $p_{i, t}$ :

\footnotetext{
${ }^{2}$ Let us consider a hypothetical market where there are only three stocks trading - stocks 1,2 and 3 . Then, if their daily prices are denoted by the variables $p_{1, t}, p_{2, t}$ and $p_{3, t}$, respectively, and if $p_{1, t}$ is correlated with $p_{2, t}$ and uncorrelated with $p_{3, t}$, we may write: $p_{2, t}=k^{\prime}+b^{\prime}\left(p_{1, t}\right) \ldots$ (i); $p_{3, t}=k^{\prime \prime}+0\left(p_{1, t}\right) \ldots$ (ii); and finally $p_{1, t}=0+\left(p_{1, t}\right)$ ...(iii). Assuming the market combination ' $m$ ' to be a simple average of the three stock prices and averaging the Equations (i), (ii) and (iii), we get: $\left(p_{1, t}+p_{2, t}+p_{3, t}\right) / 3=p_{m, t}=\left(k^{\prime}+k^{\prime \prime}\right) / 3+\left\{\left(1+b^{\prime}\right) / 3\right\}\left(p_{1, t}\right) \ldots$ (iv), where $p_{m, t}$ is the price of the market combination ' $m$ '. The Equation (iv) indicates a linear relationship between $p_{m, t}$ and $p_{l, t}$ which may be generalized as $p_{i, t}=c_{i}+d_{i} p_{m, t} \ldots$ (v). This logic also holds for day' $t-1$ ' when $p_{i, t-l}=c_{i}+d_{i} p_{m, t-1} \ldots$ (vi). From equations (v) and (vi), we may deduce that the ratios $\left(p_{i, t} / p_{i, t-1}\right)$ and $\left(p_{m, t} / p_{m, t-1}\right)$ are also correlated which can be expressed as $\left(p_{i, t} / p_{i, t-1}\right)=q_{i}+r_{i}\left(p_{m, t} / p_{m, t-1}\right) \ldots$ (vii).
} 


$$
p_{i, t}=\alpha_{i}+\beta_{i l}\left\{\left(p_{m, t} / p_{m, t-1}\right) p_{i, t-1}\right\}+\beta_{i 2} p_{i, t-1}+\beta_{i 3} \exp \left(v_{i, t}\right)+\beta_{i 4} \ln \left(v_{i, t}\right)+\beta_{i 5} \ln \left(t_{t}\right)+\beta_{i 6} M F_{i, t}
$$

Here, $M F_{i, t}$ represents other market factors and $\ln \left(t_{t}\right)$ is the time-trend component. Equation (11) reflects a conceptual framework for estimating the price of stock ' $i$ ' using firm, market and time parameters. From the Equation (11), we can clearly infer that the stock return $R_{i, t}$ is not a linear polynomial function of the return of the market combination $R_{m, t}$ but rather a quotient of two polynomials. This follows simply from the definition of return which requires it to be a ratio of the change in the price on day ' $t$ ' to the price on day ' $t-1$ '. Thus, we have:

$$
\begin{aligned}
& {\left[\left\{\alpha_{i}+\beta_{i 1}\left\{\left(p_{m, t} / p_{m, t-1}\right) p_{i, t-1}\right\}+\beta_{i 2} p_{i, t-1}+\beta_{i 3} \exp \left(v_{i, t}\right)+\beta_{i 4} \ln \left(v_{i, t}\right)+\beta_{i 5} \ln \left(t_{t}\right)+\beta_{i 6} M F_{i, t}\right\}-\right.} \\
& \left.\left.\alpha_{i}+\beta_{i 1}\left\{\left(p_{m, t-1} / p_{m, t-2}\right) p_{i, t-2}\right\}+\beta_{i 2} p_{i, t-2}+\beta_{i 3} \exp \left(v_{i, t-1}\right)+\beta_{i 4} \ln \left(v_{i, t-1}\right)+\beta_{i 5} \ln \left(t_{t-1}\right)+\beta_{i 6} M F_{i, t-1}\right\}\right] \\
& R_{i, t} \quad= \\
& {\left[\alpha_{i}+\beta_{i l}\left\{\left(p_{m, t-1} / p_{m, t-2}\right) p_{i, t-2}\right\}+\beta_{i 2} p_{i, t-2}+\beta_{i 3} \exp \left(v_{i, t-1}\right)+\beta_{i 4} \ln \left(v_{i, t-1}\right)+\beta_{i 5} \ln \left(t_{t-1}\right)+\beta_{i 6} M F_{i, t-1}\right]}
\end{aligned}
$$

Equation (12) shows that the relationship between stock return $R_{i, t}$ and market return $R_{m, t}$ is not linear, as suggested by the CAPM, but non-linear because $R_{i, t}$ is a rational function of two consecutive readings of the index return, the preceding asset price, asset volume, time trend and other relevant market factors.

Further, like Equation (11), it can be shown that the asset volume $v_{i, t}$ is given by:

$$
v_{i, t}=\gamma_{i}+\delta_{i 1}\left\{\left(v_{m, t}\left(v_{m, t-1}\right) v_{i, t-1}\right\}+\delta_{i 2} v_{i, t-1}+\delta_{i 3} \exp \left(p_{i, t}\right)+\delta_{i 4} \ln \left(p_{i, t}\right)+\delta_{i 5} \ln \left(t_{t}\right)+\delta_{i 6} M F_{i, t}\right.
$$

Here $v_{m, t}$ is the volume of market combination $m$ on day ' $t$ ' and like $p_{m, t}$ is a weighted aggregate of the volumes of all the stocks trading in the market. This shows that both price and volume of an asset can be estimated using the RF theory.

Klassen and McLaughlin (1996) used cumulative abnormal returns (CARs) obtained during an event period and the number of shares issued by firms multiplied by its preceding share price to arrive at the 'market value' of various environmental events like award and crisis announcements. We have built on this concept by replacing CARs by average returns and the preceding firm value (i.e. number of issued shares multiplied by preceding share price) by average change in volumes, to estimate average change in market value of an asset during a time period. From this, it can be deduced that investors who just wish to maximize profits should focus on maximizing return $R_{i, t}$ but investors who wish to maximize wealth and not just profits (like corporates) should aim at maximizing the change in market value of their portfolio. The change in market value $M V_{i, t}$ is given by the arithmetic product of the change in price (i.e. return) and change in volume and is given as follows: 


$$
M V_{i, t}=\left[\left(1+R_{i, t}\right)\left(1+V_{i, t}\right)\right]
$$

Here, for empirical application of Equations (12) and (14), we take $R_{i, t}=\ln \left(p_{i, t} / p_{i, t-1}\right)$ and $V_{i, t}=$ $\ln \left(v_{i, t} / v_{i, t-1}\right)$. However, we must clarify here that Equations (11) and (13) are conceptual models that need to be refined through empirical validation. In this study, we have considered the variables identified in Equations (11) and (13) and examined their behavior in an empirical context, thus deriving the final RF models from both theoretical rationales and empirical evidence. In developing the final empirical RF model for returns, we distinguish between two types of asset returns - average asset returns and continuous asset returns. This is because average asset returns exhibit greater non-linearity due to the effect of averaging over multiple time intervals and hence these two types of asset returns need to be modeled differently. The next section presents the empirically adjusted RF models for both average and continuous returns and tests their performance in comparison with the existing models like the CAPM, the FF3F and the FF5F. It also presents the empirically adjusted RF model for average change in volumes and compares it with the LW2F. We have not considered continuous change in volumes for single time intervals because volumes are much more volatile than returns and studying them on a continual basis would be of little practical value.

\section{Empirical Models and Methodology}

We test the validity of the RF Models against the Capital Asset Pricing Model (CAPM), the Fama-French 3 Factor model (FF3F) and the Fama French 5 Factor model (FF5F). Our tests utilize twenty-one monthly and daily samples from three international markets (USA, Australia and India) from May 2003 to April 2013. This ten-year time frame provides us with sufficient data for the study, noting, in particular, the unavailability of reliable data on trading volumes for periods much earlier than this, especially for the Indian market.

\subsection{Empirical Models}

The CAPM regression equation is:

$$
R_{i, t}=R_{f, t}+\beta_{i, m}\left(R_{m, t}-R_{f, t}\right)+e_{i t}
$$

while, the FF3F model regression equation is:

$$
R_{i, t}=R_{f, t}+\beta_{i, m}\left(R_{m, t}-R_{f, t}\right)+\beta_{i, s} S M B_{t}+\beta_{i, h} H M L_{t}+e_{i t}
$$

The FF5F model, which we consider only for the US market, is:

$$
R_{i, t}=R_{f, t}+\beta_{i, m}\left(R_{m, t}-R_{f, t}\right)+\beta_{i, s} S M B_{t}+\beta_{i, h} H M L_{t}+\beta_{i, r} R M W_{t}+\beta_{i, c} C M A_{t}+e_{i t}
$$


Here, the expected return of asset ' $i$ ' on day ' $t$ ' is denoted by $R_{i, t}$, while $R_{f, t}$ and $R_{m, t}$ denote the risk-free rate of return and the expected market return on day ' $t$ ' respectively. $S M B_{t}$ (for Small minus Big) is the difference between the returns of the diversified portfolios of small and big size stocks. $H M L_{t}$ (High minus Low) is the difference between the returns of the diversified portfolios of high and low BE/ME (ratio of book equity to market equity) stocks. $R M W_{t}$ (Robust minus Weak) is the difference between the returns of the diversified portfolios of robust and weak profitability. $C M A_{t}$ (Conservative minus Aggressive) is the difference between the returns of the diversified portfolios of low and high investment firms while $e_{i t}$ is a zero-mean residual term. The data for $S M B_{t}, H M L_{t}, R M W_{t}$ and $C M A_{t}$ are obtained from Kenneth French's data library. ${ }^{3}$

As already mentioned, we examine the asset returns in two different formats - average returns and continuous returns. Our preliminary empirical tests indicate that non-linearity due to the rational function nature is quite pronounced in average returns, whether they are averaged across portfolios or across time. Citing other empirical studies, Fama and Macbeth (1973) have reported evidence of stochastic nonlinearities in average returns from period to period. Similarly, Fama and French (2004) have reported evidence that the relationship between average return and market beta was somewhat non-linear. However, since continuous returns are computed as time series of daily or monthly returns based on single time intervals they do not exhibit the non-linear attributes of rational functions. As a result, the continuous returns behave 'approximately' linearly across time. This argument is consistent with the evidence in the literature that continuous returns can be estimated using linear models (please see, Brown and Warner, 1985; Chen and Epstein, 2002). Hence, continuous returns have been modeled directly and not indirectly from prices as we do with average returns (see, Reinganum, 1982; Pandey et al., 1998).

To examine the average returns, the conceptual RFM Equation (11) is refined empirically to simplify it without a loss of information. As discussed above, the RFM average return does not add linearly across time but it is calculated as a ratio of two consecutive average prices obtained for intervals ( $t$ to $t+n-1)$ and ( $t+1$ to $t+n)$, respectively. Our preliminary estimation of the asset prices show that the preceding asset price and the index return can explain asset prices by themselves (with the coefficient of determination, $\mathrm{R}^{2}$ above 93.5\%). Thus, our final empirical

\footnotetext{
${ }^{3}$ We thank Kenneth French for making the data available at: http://mba.tuck.dartmouth.edu/pages/faculty/ken.french/data_library.html
} 
models for estimating asset prices are as given below: ${ }^{4}$

$$
\begin{aligned}
& \mathrm{RF}_{1 \mathrm{a}}: p_{i, t}=\alpha_{i}+\beta_{i}\left[\left\{\left(p_{m, t} / p_{m, t-1}\right) p_{i, t-1}\right\}\right]+e_{i t} \\
& \mathrm{RF}_{1 \mathrm{~b}}: p_{i, t}=\beta_{i}\left[\left\{\left(p_{m, t} / p_{m, t-1}\right) p_{i, t-1}\right\}\right]+e_{i t}
\end{aligned}
$$

The intercept $\alpha_{i}$ is included in Equation (17a) while it is assumed to be zero for equation (17b). In Equation (17a), the intercept $\alpha_{i}$, which is a risk-free component of asset prices, is included for the sake of consistency with the CAPM, FF3F and FF5F models. However, we include a zerointercept version of the model, as this would be the lowest price that an asset could trade at. The zero-intercept model is also consistent with the empirical values of the average risk-free rate of return $R_{f, t}$ that have been negligible or zero in the literature (e.g., Mehra \& Prescott, 1985). According to the RF theory, the risk factor identified for the average returns is the arithmetic product of the market return and the preceding asset price $\left[\left\{\left(p_{m, t} p_{m, t-1}\right) p_{i, t-1}\right\}\right]$ as shown in Equations $(17 \mathrm{a} \& \mathrm{~b})$. The RF theory thus states that there is no direct linear relationship between the average returns and the risk factor, since the average returns are rational functions. However, the assets can be separately sorted based on the risk factors as identified by the CAPM, the FF3F or the FF5F model (or any other model for that matter) and the average returns of the portfolios thus formed could then be estimated using the RF models $\mathrm{RF}_{1 \mathrm{a}}$ and $\mathrm{RF}_{1 \mathrm{~b}}$.

After estimating average returns, we have also estimated average change in asset volumes $\left(V_{i, t}\right)$ as discussed earlier in equation (14). For this, just like average returns, we have computed average change in asset volumes for both LW2F and the RF volume model as a ratio of two consecutive average volumes obtained for intervals ( $t$ to $t+n-1)$ and $(t+1$ to $t+n)$ respectively. The empirical model for estimating the asset volumes is a logical variation of Equation (17b), where we have substituted the price variables with the volume variables as shown below:

$$
\mathrm{RF}_{1 \mathrm{c}}: v_{i, t}=\delta_{i}\left[\left\{\left(v_{m, t} / v_{m, t-1}\right) v_{i, t-1}\right\}\right]+e_{i t}
$$

Here, we have considered only the zero intercept model for estimating asset volumes, because there is no economic compulsion for a positive risk-free level of trading volume for an asset and in reality the asset volumes do dip to zero levels during various trading cycles.

Next, we have compared the $\mathrm{RF}_{1 \mathrm{c}}$ model with the LW2F model. From Lo and Wang (2000) we have taken the LW2F regression Equation as:

$$
v_{i, t}=\delta_{i, 1} v_{m^{\prime}, t}+\delta_{i, 1} v_{h, t}+e_{i t}
$$

\footnotetext{
${ }^{4}$ All results for the preliminary estimation of the asset prices and specification tests between different versions of the model are available upon request.
} 
Here, $v_{m}{ }^{\prime} t$ and $v_{h, t}$ are the volumes of the equally-weighted and share-weighted indices respectively. The volume of the equally-weighted portfolio $v_{m}{ }^{\prime}$, is a simple average of the constituent stock volumes of the index on day ' $t$ '. For $v_{h, t}$, Lo and Wang (2000) had computed the share-weight as the ratio of outstanding shares of a stock to the total number of outstanding shares of all stocks in the index. They then multiplied the share-weights with the stock volume and summed up all these share-weighted volumes to arrive at the volume of the hedging portfolio $v_{h, t}$ on day ' $t$ '. However, as these share weights remain constant for extended time-periods as the number of outstanding shares are constant over considerable time-periods, they tend to become meaningless for daily data being studied for small time windows like we have considered here in this study. Hence, instead of using number of outstanding shares, we have computed the shareweights as ratios of traded volume of a stock to the total traded volume of all the stocks in the index. Further, Lo and Wang (2000) had imposed the constraints that $\left[\delta_{i, 1}+\delta_{i, 2}=1\right]$ and $\left[\Sigma \delta_{i, 1}=\right.$ $\mathrm{J}$ for $i=1$ to $J$ but they had tested the unconstrained version of the model as well and found its results comparable to the constrained version. Hence, we have considered the unconstrained version of the LW2F model here for greater versatility.

The continuous returns behave approximately linearly across time as they are computed from data based on single time intervals and hence do not require averaging. Thus continuous returns can be modeled directly from the relevant firm specific and market specific factors. Our empirical results, detailed below, indeed show that the linear models (CAPM, FF3F and FF5F) are found to provide reasonable estimates (e.g., above $70 \%$ correlation with the actual values) for the continuous returns, although the FF3F and FF5F estimates are marginally more accurate than the CAPM estimates. However, the accuracy of the FF3F and FF5F models for continuous asset returns can be further improved by including three additional factors based on the RF theory, namely, the change in market volume, the time factor and the preceding asset return. In keeping with Equation (11) we replace the term $M F_{i, t}$ (for other market factors) with $S M B_{t}, H M L_{t}, R M W_{t}$ and $C M A_{t}$, enabling us to combine the Fama-French models with the RF theory to give the following equations for continuous asset returns:

$\mathrm{RF}_{2 \mathrm{a}}: R_{i, t}-R_{f, t}=\beta_{i, m}\left(R_{m, \tau}-R_{f, t}\right)+\beta_{i, s} S M B_{t}+\beta_{i, h} H M L_{t}+\beta_{i, v}\left(V_{m, t}\right)+\beta_{i, o}\left(t_{t}\right)^{2}+\beta_{i, l}\left(R_{i, t-l}\right)+e_{i t}$

$\mathrm{RF}_{2 \mathrm{~b}}: R_{i, t}-R_{f, t}=\beta_{i, m}\left(R_{m, \tau}-R_{f, t}\right)+\beta_{i, s} S M B_{t}+\beta_{i, h} H M L_{t}+\beta_{i, r} R M W_{t}+\beta_{i, c} C M A_{t}+\beta_{i, v}\left(V_{m, t}\right)+\beta_{i, o}\left(t_{t}\right)^{2}+\beta_{i, l}\left(R_{i, t-1}\right)+e_{i t}(19 \mathrm{~b})$

Equations (19a) and (19b) are modified versions of the FF3F and FF5F respectively by including the additional variables relevant to the RF theory as noted above. Here, $V_{m, t}=\ln \left(v_{m, t} / v_{m, t}\right.$. 
1) and we have used it instead of change in asset volume $V_{i, t}$ because the latter is dependent on the former as shown in Equation (13). The time factor used for modeling continuous returns is based on the works of Pisedtasalasai and Gunasekarage (2007) and Chen et al. (2001), who show that the time series of trading volumes exhibit quadratic time trends. The continuous returns being single-interval time series like the trading volume data and being connected to the volumes through supply-demand framework, quadratic variations of time ranks have been used in estimating these continuous returns as well, which find support through our empirical results.

Thus, we study asset returns in two different formats as can be seen from Equations (17a and 17b) for $\mathrm{RF}_{1}$ models used for estimating average returns and Equations (19a and 19b) for $\mathrm{RF}_{2}$ models used for estimating continuous returns. We also study average change in asset volumes using Equation (17c). Further, we compute and report two different kinds of actual average returns, denoted actual 1 and actual $_{2}$, for the sake of comparing the performances of the various models. Here, actual ${ }_{1}$ average returns are computed from the ratio of average prices while actual average $^{2}$ returns are computed by averaging the time series of continuous returns. ${ }^{5,6}$ The actual average change in asset volume have been computed like the actual 1 average returns.

\subsection{Methodology}

To test the RF models against the extant models, various sample portfolios have been obtained for three different markets - USA, Australia and India. These markets has been selected to represent financial markets in different developing stages. Our data set different has different time windows to demonstrate the empirical validity of the RF theory. The details of these samples are provided in Table 1. Of the 18 USA samples, the first 11 samples (S1 to S11) are constructed out of the constituent stocks of three indices of various sizes. These include Dow Jones Industrial

\footnotetext{
${ }^{5}$ For computing the RFM average returns, the time series of the estimated prices in the $\mathrm{RF}_{1 \mathrm{a}}$ and $\mathrm{RF}_{1 \mathrm{~b}} \mathrm{models}_{\mathrm{are}}$ averaged from intervals $t$ to $t+n-1$ and from $t+1$ to $t+n$ respectively, and then divided to obtain their ratios. Thus, the actual $_{1}$ average returns, the $\mathrm{RF}_{1 \mathrm{a}}$ average returns and the $\mathrm{RF}_{1 \mathrm{~b}}$ average returns are computed from the ratios of average portfolio prices. However, the actual 2 average returns and the average returns estimated by the CAPM, FF3F and FF5F models are computed by following the standard practice by directly averaging the time series of the continuous returns for each portfolio, from $t+1$ to $t+n$ intervals. The study of average returns is useful for plotting the multiple period risk-return profile of each asset. The actual average change in asset volume have been computed like the actual ${ }_{1}$ average returns.

${ }^{6}$ Different time series of $n$ day-to-day or month-to-month continuous returns over a period of $t+1$ to $t+n$ are computed for different asset portfolios. This format examines the time series of continuous asset returns across increasing time as computed from the same time series of actual portfolio prices that are used for the average returns format. The continuous returns are studied for both actual as well as estimated values as per the CAPM, the FF3F, the FF5F and the RFM Equations. This format is useful in describing the single period contemporaneous asset returns across increasing risk and time.
} 
Average (30 stocks) as on April 30, 2013; 395 stocks constituting the Barron's 400 (B400) index as on August 01, 2013; and 500 stocks constituting the S\&P 500 index as on August 01, 2013. The monthly samples have been obtained for a ten-year period from May 2003 to April 2013, while the daily samples are from December 12, 2012 to April 30, 2013. Further, we have considered another seven samples of the USA stocks, S12 to S18 representing Fama and French portfolios of monthly data constructed by sorting on different financial parameters for the above ten years period. This diversity in portfolio design has been used to demonstrate the robustness of the RF Model to various selection parameters. As both small and large sample analyses of stocks are needed to test out any new asset-pricing model, this paper has considered both.

\section{INSERT TABLE 1}

Two more portfolios were constructed from 100-pooled components of the S\&P ASX 50 and S\&P ASX Mid-cap 50 indices. The Australian samples have been used to study their daily returns for 95 and 120 day time-windows contained within April 12, 2013 to September 30, 2013. Finally, one more sample of 30 stocks constituting the Bombay Stock Exchange (BSE) Sensex as on January 1, 2005 has been collected from the Indian capital market, with monthly returns from January 2002 to November 2009. The samples selected for this study, thus, represent a diversified view of the US, Australian and Indian markets over various time windows and the findings may be taken to be free from any selection bias. ${ }^{7}$

The FF5F model has been tested only for the US market due to data unavailability for the $R M W_{t}$ and the $C M A_{t}$ factors for Australia and India. Kenneth French's data library reports that the daily values of $R_{f, t}$ were negligible for Australia over our sample period and thus the $R_{f, t}$ values are taken to be zero for studying the Australian samples S19 and S20. The Australian FF3F factors $S M B_{t}$ and $H M L_{t}$ were obtained by computing the difference in portfolio returns formed by sorting the 100 companies based on market capitalization and the BE/ME ratio, over the two quarters during April 2013 to September 2013.

The average change in asset volumes have been studied only for samples S1 to S11 and S19 to S21 where we could collect the volume data for the various stocks being considered. We could not

\footnotetext{
${ }^{7}$ The data for the samples S1 to S11 (USA) and S19 and S20 (Australia) were collected from Norgate Investor Services databases. The Australian Size and BE/ME data were provided by the Australian Financial Review. The data for the samples S12 to S18 (USA), and the Fama-French factors for USA and India were collected from Kenneth R. French's data library. The Indian stock market data were collected from the Prowess Database provided by the Centre for Monitoring Indian Economy (CMIE).
} 
do the volume analysis for the Fama-French portfolios S12 to S18 as their volume data are not available.

For the samples S1 to S11 (USA) and S19 to S21 (Australia and India), the stocks in each of these samples were sorted according to risk. The risk factor has been assessed in two ways, first, using the returns variance (for samples S1 to S8 and S19 to S21) and second, idiosyncratic volatility (for samples S9 to S11). More specifically, the returns variance has been measured by the variance of the stock returns through a rolling period of the last 12 observations. Similarly, idiosyncratic volatility has been measured by the variance of the residual $e_{i t}$ through a rolling time frame of the last 12 observations, where the residual $e_{i t}$ is obtained from the difference in actual stock returns and the expected return from the market model:

$$
R_{i, t}=\beta_{i, m} R_{m, t}+e_{i t}
$$

Furthermore, the stocks for the samples S1 to S11 and S19 to S21 were grouped into five subportfolios P1 to P5, according to risk. Each sub-portfolio contains 6 stocks for the DJIA, 79 stocks for the B400, 100 stocks for the S\&P500, 20 stocks for the Australian samples and 6 stocks for the BSE Sensex. P1 consists of the lowest risk stocks while P5 contains the highest risk stocks. We also examine the full sample portfolio (P-full) consisting of all stocks. After sorting, actual stock prices were reconstructed from actual stock returns using a common base number (e.g., 100) to avoid any sudden or abrupt changes in prices after each sorting.

The seven samples S12 to S18 are the Fama-French samples of all actively traded US stocks. Sample S12 consists of all actively traded US stocks sorted into five industry-based sub-portfolios: consumer, manufacturing, hi-technology, health and others as P1 to P5 respectively. We have studied the value-weighted returns of these five sub-portfolios as well as the aggregate of these sub-portfolios, P-full. The value-weighted returns are converted to time series of prices from a base price of 100. Samples S13 to S18 consist of six sub-portfolios, P1 to P6, of value-weighted returns sorted on the basis of two-variables. First, the stocks have been sorted into two size portfolios and then each split further into three portfolios based on another financial parameter like investment, long term reversal (based on prior 13-60 returns), momentum (based on prior 2-12 returns), operating profit, short term reversal (based on prior 1-1 returns) and value. The breakpoint for the size variable is the median NYSE market equity, whereas the breakpoints for the other variables are the $30^{\text {th }}$ and the $70^{\text {th }}$ NYSE percentiles. As before, we converted the time series of value-weighted returns to time series of prices from a base of 100 for further analysis. 
The above samples were analyzed using the CAPM, FF3F, FF5F (for the US samples only), $\mathrm{RF}_{1}$ (17a \& 17b) and $\mathrm{RF}_{2}$ (18a \& 18b) models for both average and continuous returns. To obtain homogenous estimates from the $\mathrm{RF}_{1 \mathrm{a}}$ model across the sub-portfolios, P1 to P5, the intercept $\alpha_{i}$ is computed for the full sample (P-full) and used for estimating the prices for P1 to P5, for the samples S1 to S12 and S19 to S21. For the samples S13 to S18 (where we do not consider the aggregate portfolio), the intercept $\alpha_{i}$ is the arithmetic average of the intercepts of all the six subportfolios. In this way, we have a common intercept value for all the sub-portfolios in a given sample so that we can compare their performance. The empirical accuracy of estimated results from the CAPM, FF3F, FF5F and the RF models have been compared with each other based on their correlations with the actual returns as well as their sum of squared errors (SSE). ${ }^{8}$ We have also carried out the volume analyses for the fourteen samples S1 to S11 and S19 to S21 using RF (17c) and LW2F models and compared their results.

\subsection{Empirical Results and Discussion}

Tables $2 \mathrm{a}, 2 \mathrm{~b}$ and $2 \mathrm{c}$ report the slopes estimated by $\mathrm{RF}_{1 \mathrm{a}}, \mathrm{RF}_{1 \mathrm{~b}}$ and $\mathrm{RF}_{1 \mathrm{c}}$ models for the different samples. As can be seen, the values of $\beta_{i}$ for the $\mathrm{RF}_{1 \mathrm{a}}$ and $\mathrm{RF}_{1 \mathrm{~b}}$ models are stable. In fact, for the $\mathrm{RF}_{1}$ models, the values of $\beta_{i}$ are all positive and are all very close to 1.00 . This is maybe because empirically, the change in the asset price $p_{i, t}$ is nearly equal to the change in market price $p_{m, t .}{ }^{9}$ All the $\beta_{i}$ coefficients have very high $t$-values for both $\mathrm{RF}_{1 \mathrm{a}}$ and $\mathrm{RF}_{1 \mathrm{~b}}$ models in Tables $2 \mathrm{a} \& 2 \mathrm{~b}$. This implies that the arithmetic product of market return and the preceding asset price is the most important factor in estimating the asset prices or average asset returns. Another noteworthy finding from Table $2 \mathrm{a}$ is that the $t$-statistics of the intercepts $\alpha_{i}$ for the $\mathrm{RF}_{1 \mathrm{a}}$ model are all insignificant and the intercepts themselves have quite small values (roughly within a range of $-0.9 \%$ to $+1.9 \%$ of the average asset prices). This supports the view that the zero intercept $\mathrm{RF}_{1 \mathrm{~b}}$ model is both accurate and sufficient in determining the estimates of asset prices. This is consistent with other empirical evidence, whereby the risk-free rate of return $R_{f, t}$ has been found to be negligible or zero ( see,

\footnotetext{
${ }^{8}$ Obviously, our analysis has generated a large number of results that cannot be reasonably reported here. Thus, we report only the important results [i.e. the regression results of Equations (17a), (17b), (17c) and (19b); the results of correlation analysis and the SSE values for average returns and average change in volumes; results of correlation analysis for continuous returns; and finally the improvements in accuracy of estimation of continuous returns due to Equation (18b)]. Other results are available upon request.

${ }^{9}$ We also estimate the CAPM and the FF3F for all samples and the FF5F for the US data. However, we do not report the results for the space limitation. All results are available upon request. The estimated values of CAPM's $\beta_{i, m}$ increase with risk for portfolios sorted by risk, however; the values of $\beta_{i, m}$ for other portfolios do not follow any systematic pattern. The values of $\beta_{i, m}$, estimated by FF3F, FF5F, $\mathrm{RF}_{2 \mathrm{a}}$ and $\mathrm{RF}_{2 \mathrm{~b}}$ models are generally increasing across risk-sorted portfolios.
} 
Fama and French, 2015). Moreover, we believe that a common intercept $\alpha_{i}$ could give erroneous results for long time series data since it would be large compared to the initial prices and small compared to the later prices.

\section{INSERT TABLES 2a, 2b AND 2c}

From Table $2 \mathrm{c}$ we can see the results of regressing $\mathrm{RF}_{1 \mathrm{c}}$ Equation $(17 \mathrm{c}$ ) for estimating asset volumes where the values of $\delta_{i}$ coefficients are all positive but increase or decrease randomly across the sub-portfolios that have been formed according to increasing risk as well as other financial parameters. Unlike the price slopes which are all nearly equal to 1 , the volume slopes lie between a range of 0.45 to 1.27 . However, like the price slopes, the volume slopes also have high t-statistics indicating that $\left\{\left(v_{m, t} / v_{m, t-1}\right) v_{i, t-1}\right\}$ is the most important as well as a sufficient factor in estimating asset volumes.

The results of regressing the $\mathrm{RF}_{2 \mathrm{~b}}$ equation (19b) are reported in Table 3 . The regression results indicate that the $\beta_{i, m}$ values are generally significant and increasing with risk (lying in a range of 0.5 to 1.5 ) which show that the market return is very important in explaining continuous asset returns . Again, while the $t$-statistics for $\beta_{i, m}$ maybe the largest, it was noted that the $t$-statistics of the RF factors: change in index volume $\left(\beta_{i, v}\right)$, time trend $\left(\beta_{i, o}\right)$ and preceding asset return $\left(\beta_{i, l}\right)$ are not dissimilar to those of the FF3F and FF5F factors. This indicates that the RF factors are also important contributors in the assessment of continuous returns.

\section{INSERT TABLE 3}

Next, we compare estimated average returns from different models with the actual average returns to test the accuracy of each model. As mentioned earlier, two types of actual average returns have been computed: actual 1 and actual $_{2}$, where the former are computed, from the ratios of two consecutive average prices, while the latter have been computed by directly averaging the time series of continuous returns. Therefore, the $\mathrm{RF}_{1 \mathrm{a}}$ and $\mathrm{RF}_{1 \mathrm{~b}}$ average returns are computed like actual $_{1}$ average returns while the CAPM, FF3F and FF5F average returns have been computed like actual $_{2}$ average returns. We may mention here that the actual ${ }_{1}$ average returns are more accurate measurements of the empirical average returns. This is because the asset returns are non-linear rational functions (i.e., ratios) of asset prices. This may be illustrated by the fact that $[(b / a)+(c / b)$ $\neq[(b+c) /(a+b)]$, where $\mathrm{a}, \mathrm{b}$ and $\mathrm{c}$ are the prices of an asset for three consecutive time intervals. Hence, direct averages like actual 2 average returns that follow the left hand side of the above equation are not correct measures of the ratios of average prices that are shown on the right hand 
side of the above equation. This non-linear rational function characteristic of the asset returns becomes more prominent, the more they are averaged out across portfolios or across time. However, we have considered both actual ${ }_{1}$ and actual ${ }_{2}$ types of average returns for the sake of comparison among the results.

Thus, we have obtained both actual and estimated average returns for the sub-portfolios P1 to P5 and P-full (i.e., P6 for samples S13 to S18). ${ }^{10}$. Tables $4 \mathrm{a}$ and $4 \mathrm{~b}$ show that the estimates of $\mathrm{RF}_{1}$ models for average returns consistently have the highest correlations with the actual average returns, whether actual 1 or actual 2 , with all above 90\%. The correlations for the CAPM and FF3F models are not only much smaller than those for the $\mathrm{RF}_{1}$ models, but are quite unpredictable taking different signs in different samples. The correlations of the FF5F estimates are higher those of than both the CAPM and the FF3F estimates but are still consistently lower than those of the $\mathrm{RF}_{1}$ estimates. Moreover, the correlations of the FF5F model with actual average returns are negative for samples S1, S2 and S12 and only $3.23 \%$ with actual ${ }_{1}$ and $7.16 \%$ with actual 2 for the sample S8. The highest correlation of FF5F estimates with actual 1 average returns is $93.81 \%$ (93.58\% with actual $_{2}$ ) for $\mathrm{S} 16$, whereas all the correlations of the $\mathrm{RF}_{1}$ models with actual average returns are above $90 \%$ and consistently higher than those of FF5F. Moreover, the RF 1 models have the lowest Sum of Squared Errors (SSE) between the actual and the estimated average returns. This demonstrates that the average returns estimated by the $\mathrm{RF}_{1}$ models are the most accurate.

\section{INSERT TABLES 4a AND 4b}

Figure 1 plots the actual 1 average returns and their estimates from the CAPM, FF3F, FF5F and $\mathrm{RF}_{1 \mathrm{~b}}$ model. ${ }^{11}$ These plots highlight the greater accuracy of the RFM and the non-linear behavior of actual returns across the market beta. In fact, the negative correlation with actual values that can be observed for the CAPM, FF3F and FF5F models arises as these models impose a linear relation. Thus, even though the CAPM, the FF3F and the FF5F models might have identified the important and relevant factors influencing the asset returns, they are unable to capture the complete empirical reality for average asset returns. These results show that the average asset returns are basically non-linear in nature across market risk and other financial attributes. Thus, it follows that though the index price might be the most important variable in computing asset returns, by itself it cannot

\footnotetext{
${ }^{10}$ The values of the actual ${ }_{1}$ average returns and the CAPM betas are available upon request.

11 The plots of $\mathrm{RF}_{1 \mathrm{a}}$ are very like those of $\mathrm{RF}_{1 \mathrm{~b}}$, but we plot the latter, as this version is simpler and more accurate, especially for long time-span data. However all results are available upon request.
} 
provide the important improvements brought in by the non-linearity of the rational function treatment and other factors used in the RF theory.

\section{INSERT Figure 1}

These findings support the arguments against the CAPM (see, for example, Blume and Friend 1973; Fama and MacBeth, 1973; Stambaugh, 1982; Fama and French, 1992; Fama and French, 2004; Dempsey, 2013). Further, our results also find lacunae in the empirical models like FF3F and FF5F in estimating average returns. One of the reasons for the difference in findings between our work and previous studies may be due to different sampling strategies. Previous studies often consider much longer samples and over these longer periods the gradual long term increase in the market returns is found to be reflected similarly and linearly in the large portfolios. However, this fails to encapsulate the dynamics of market behavior or to reflect the practical situation where investors may hold smaller portfolios and over smaller holding periods. It is in this context that our findings are particularly pertinent.

A further key implication of the $\mathrm{RF}_{1}$ models arises from the nature of our results, which show that although the sorting factors do not affect the accuracy of the $\mathrm{RF}_{1}$ models they might influence the level of average returns. We find that although risk, as measured by either return variance or idiosyncratic volatility, does not influence average returns in any specific way, it is reasonable to believe that other market factors like size, investment, reversals, momentum, operating profits etc. might influence the magnitude of average returns. However, since the CAPM, FF3F and FF5F models do not provide accurate estimates of average returns, the $\mathrm{RF}_{1}$ model can be used instead once the stocks have been sorted based on the relevant financial factors.

As already mentioned, we have studied not only asset returns but also asset volumes. We have reported the correlations and the Sum of Squared Errors (SSE) between the actual and the estimated average change in volumes in Table $4 \mathrm{c}$. It can be seen that the correlations for $\mathrm{RF}_{1 \mathrm{c}}$ are all positive and quite high with all the values being above $90 \%$ except for sample S21, where the correlation is $85.5 \%$ for the Indian market. The t-statistics of all these correlations are also very high indicating that these correlations are significant and hence the estimates of the average change in volumes by the $\mathrm{RF}_{1 \mathrm{c}}$ model are reasonably accurate. The correlations of the $\mathrm{RF}_{1 \mathrm{c}}$ are higher than those of the LW2F for ten samples and slightly lower for four samples. However, it can be seen that the correlations of the LW2F are not consistent and takes on both negative and positive values, indicating that sometimes the LW2F estimates can be misleading. Looking at the SSE values, it 
can be seen that all the SSE values of the $\mathrm{RF}_{1 \mathrm{c}}$ model are lower than those for the LW2F model (being improvements in the range of $65.9 \%$ to $99.7 \%$ ) indicating that the $\mathrm{RF}_{1 \mathrm{c}}$ estimates are more accurate.

\section{INSERT TABLE 4c}

We now consider the continuous returns, which behave approximately linearly across time and hence have been modeled directly through linear regression relationships as shown in equations (19a) and (19b). Table 5 reports that the correlations between the actual continuous returns and the $\mathrm{RF}_{2 \mathrm{a}}$ estimates are marginally, but consistently, higher than those of the CAPM and the FF3F estimates. Similarly, the correlations between the actual continuous returns and the $\mathrm{RF}_{2 \mathrm{~b}}$ estimates are marginally, but consistently, higher than those of the FF5F estimates. Thus, the results in Tables 5 show that the $\mathrm{RF}_{2 \mathrm{~b}}$ estimates are the most accurate for continuous returns.

\section{INSERT TABLE 5}

Similar conclusions are provided by the average Sum of Squared Errors (SSE) between the actual and the estimated continuous returns reported in Table 6 which shows that the $\mathrm{RF}_{2 \mathrm{~b}}$ model outperforms the CAPM, FF3F and the FF5F models in estimating continuous returns. In detail, the $\mathrm{RF}_{2 \mathrm{~b}}$ model is better than the FF5F model within a range of $3.88 \%$ to $8.86 \%$ while it outperforms the CAPM estimates by $13.64 \%$ to $89.42 \%$. The two bottom rows of Table 6 show paired $t$-tests for no improvement in the average SSE for the continuous returns estimated by different models. The $\mathrm{p}$-values of the paired $t$-tests show that the null hypothesis for $\mathrm{RF}_{2 \mathrm{~b}}$ model average estimates of continuous returns over the CAPM and the FF5F average estimates of continuous returns can be rejected safely at $p$-values of $8.4 \mathrm{E}-05 \%$ and $3.0 \mathrm{E}-09 \%$ respectively indicating that the $\mathrm{RF}_{2 \mathrm{~b}}$ model estimates for continuous returns are the most accurate.

\section{INSERT TABLE 6}

\section{Practical Implications}

One of the main contributions of this paper is that it has developed separate models for estimating average and continuous returns. The findings of this study indicate that the behavior of actual average returns across increasing level of risk (both returns variance and idiosyncratic volatility) is non-linear. Further, for portfolios sorted on financial factors like industry, size, investment, profitability, momentum, reversals etc. risk, as measured by the market-beta, does not increase uniformly across the sub-portfolios. This can be seen clearly in Figure 1, from the plots 


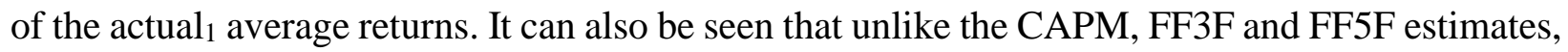
the $\mathrm{RF}_{1 \mathrm{~b}}$ average returns consistently follow the actual $l_{1}$ average returns. This is because of the nonlinear nature and the multiplicity of factors used in estimating asset prices by the $\mathrm{RF}_{1}$ models. The CAPM and the FF3F models are linear and thus are unable to capture the curvilinear behavior of the actual average returns. The FF5F model generates better estimates of average returns than the CAPM and the FF3F models but is still less accurate than the $\mathrm{RF}_{1}$ models.

Tables 4a) and 4b) report that the CAPM, FF3F and FF5F models sometimes generate estimates that have negative correlations with both actual ${ }_{1}$ and actual ${ }_{2}$ average returns. This can sometimes lead to misleading inferences. On the other hand, the $\mathrm{RF}_{1}$ models generate estimates that consistently have correlations of above $90 \%$ with the actual average returns. This clearly shows that the $\mathrm{RF}_{1}$ models are more accurate tools that can be used to evaluate investments over multiple time-periods and can help in making choices that are more efficient in terms of returns and risks. Another key implication from our work is that sorting factors, such as size, value and momentum, might be used to build portfolios that can generate higher average returns however, the analysis of such portfolios, and the generation of estimated returns should be conducted through the RF approach, which provides greater accuracy. This combination of approaches allows us to accurately identify and select portfolios that have higher mean-variance efficiency for average asset returns. Furthermore, the $\mathrm{RF}_{2 \mathrm{~b}}$ model for continuous returns can help investors in making better single time-period assessments of their investments through more accurate monitoring of the changing asset returns on a contemporaneous basis.

The RF theory also provides a reasonably accurate model to estimate average change in asset volume $V_{i, t}$, as can be seen from Table $4 \mathrm{c}$, where the $\mathrm{RF}_{1 \mathrm{c}}$ estimates are found to be more accurate than the LW2F estimates. The average change in asset volume $V_{i, t}$, together with average return $R_{i, t}$ indicate the average change in market value $M V_{i, t}$ of an asset. Since change in asset volume $V_{i, t}$ shows the change in liquidity of an asset thereby indicating the ease of realizing the return for that asset, it is an important factor. The $M V_{i, t}$ of an asset being an arithmetic product of return and change in volume, flows from both $R_{i, t}$ and $V_{i, t}$. Hence, investors who want to maximize wealth instead of just profits, should choose assets that give maximum mean $M V_{i, t}$ for minimum variances in $R_{i, t}$ and $V_{i, t}$ for a given time period. 


\section{Summary and Conclusions}

A significant part of the existing literature emphasizes that the estimates of the market premium as obtained from the CAPM do not match actual values. While much of the subsequent research has sought to remedy this through additional factors, no model has yet been able to provide a sufficiently accurate description of the data nor the theoretical reasons underlying the above anomaly. In this paper, we argue that this discrepancy arises from the assumption that asset returns add linearly when averaging within a portfolio or across time. Returning to the basics involved in estimating asset prices, we present an alternative model for estimating average returns based upon the concept of Rational Functions (i.e., an asset return is a ratio of polynomials). In addition, we distinguish between the modeling requirements of average returns and continuous returns. For estimating continuous returns, we identify three factors - change in index volume, time and the preceding asset return that can be used in combination with an existing factor model (e.g., FF5F) to improve its performance. We also provide a model to estimate average change in volume which together with average return provides estimate for average change in market value of an asset. Further, we empirically test the Rational Function (RF) model for both average and continuous returns and compare them with the CAPM, FF3F and FF5F models using twenty-one samples based on both monthly and daily data from three markets: USA, Australia and India.

Our empirical results show that the RF models provide the most accurate descriptions of actual returns compared to all the established asset pricing models. This is because the RF models are able to capture the non-linear dynamics within the behavior of average returns and introduce additional relevant factors for estimating continuous returns. The charts of the average returns indicate that the risk-return-efficient investments should be carefully selected from such charts as average returns plot nonlinear across risk and sometimes the lower risk assets offer higher returns. Stocks can be sorted on various relevant financial parameters like size, profitability etc. and then the average returns for the portfolios should be estimated by the RF model. The RF estimates of the average change in volumes are also more accurate than the estimates of an extant asset volume model. These results prove the empirical authenticity of the RF theory and affirm that price and volume are two complementary forces of the market. Thus, the market value of an asset flows through both of these factors and for maximizing the former, both the latter variables are important.

Our contribution is not limited to introducing and testing the RF models but also to differentiating between the behaviors of the average and continuous returns and modelling them 
separately. However, we recognize that further empirical testing is required to substantiate the RF theory. Hence, it would be interesting to consider this approach with more comprehensive empirical datasets from different markets. It is also possible that additional factors that influence the asset price will be unearthed, together with their underlying theoretical rationales. This in turn would allow the RF models to be further refined and improved. However, even now, the RF theory and the preliminary empirical evidence provided here indicate that the RF models are of both academic interest as well as of practical value to the investment community.

\section{References}

Aharoni, G., Grundy, B., Zeng, Q. (2013) "Stock returns and the Miller Modigliani valuation formula: revisiting the Fama French analysis", Journal of Financial Economics, 110, 347-357.

Banz, R. W. (1981) "The Relationship Be-tween Return and Market Value of Common Stocks", Journal of Financial Economics, Vol. 9(1), pp. 3-18.

Bao, T. (2017) "A generalized CAPM model with asymmetric power distributed errors with an application to portfolio construction", Economic Modelling, http://dx.doi.org/10.1016/j.econmod.2017.03.035

Basu, S. (1977) "Investment Performance of Common Stocks in Relation to Their Price- Earnings Ratios: A Test of the Efficient Market Hypothesis", Journal of Finance, Vol.12 No.3, pp. 129-56.

Black, F., Scholes, M. (1973) "The Pricing of Options and Corporate Liabilities", Journal of Political Economy, Vol. 81, pp. 637-654.

Blume, M.E., (1970) "Portfolio Theory: A Step Towards its Practical Application", Journal of Business, Vol. 43(2), pp. 152-174.

Blume, M.E., Friend, I. (1973) "A New Look at the Capital Asset Pricing Model”, Journal of Finance, Vol.28, pp. 19-33.

Brown, S., Warner, J. (1985) "Using Daily Stock Returns: The Case of Event Studies”, Journal of Financial Economics, Vol.14, pp 3-31.

Chen, G., Firth, M., Rui, O.M. (2001) “The Dynamic Relation between Stock Returns, Trading Volumes and Volatility", Financial Review, pp. 153-173.

Chen, Z., Epstein, L. (2002) "Ambiguity, Risk, and Asset Returns in Continuous Time”, Econometrica, Vol. 70(4), pp.1403-1443.

Datar, V., Naik, N., Radcliffe, R. (1998) "Liquidity and Stock Returns: An Alternative Test", Journal of Financial Markets Vol.1, pp. 203-219.

Dempsey, M. (2013) "The Capital Asset Pricing Model (CAPM): The History of a Failed Revolutionary Idea in Finance?", Abacus, Vol.49, pp. 44-50.

Diacogiannis, G., \& Feldman, D. (2013) "Linear beta pricing with inefficient benchmarks". The Quarterly Journal of Finance, 3(01), 1350004.

Elgammal, M. M., McMillan, D. (2014) "Value Premium and Default Risk", Journal of Asset Management, Vol.15, pp. 48-61.

Elgammal, M. M., Bas, T., Gough, O., Shah, N. \& Stefan Van Dellen (2016) "Do financial distress and liquidity crises affect value and size premiums?", Applied Economics, Vol.48 (39), pp. 3734-3751. DOI: $10.1080 / 00036846.2016 .1145345$

Erdos, P., Ormos, M., Zibriczky, D. (2011) “Non-parametric and semi-parametric asset pricing”, Economic Modelling, Vol.28, pp. 1150-1162.

Fama, E.F., (1970) "Efficient capital markets: A review of theory and empirical work", Journal of Finance, 25(2), pp.383-417. 
Fama, E.F., French, K.R. (1992) “The Cross-Section of Expected Stock Returns”, Journal of Finance, Vol. 47, pp. 427-65.

Fama, E.F., French, K.R. (1993) "Common Risk Factors in the Returns on Stocks and Bonds", Journal of Financial Economics, Vol. 33, pp. 3-56.

Fama, E. F., \& French, K. R. (1996) "The CAPM is wanted, dead or alive", Journal of Finance, 51(5), pp.1947-1958.

Fama, E.F., French, K.R. (2004) "The Capital Asset Pricing Model: Theory and Evidence”, The Journal of Economic Perspectives, Vol.18, pp. 25-46.

Fama, E. F., French, K.R. (2015) “A five-factor asset pricing model”, Journal of Financial Economics, Vol. 116, pp. 1-22.

Fama, E.F., MacBeth, J.D. (1973) "Risk, Return, and Equilibrium: Empirical Tests", Journal of Political Economy, Vol. 81, pp. 607-36.

Gallant, R.A., Rossi, P.E., Tauchen, G. (1992) "Stock Prices and Volume", Review of Financial Studies, Vol. 5, pp. 199-242.

Hagerman, R., \& Kim, E. (1976) "Capital Asset Pricing with Price Level Changes", Journal of Financial and Quantitative Analysis, 11(3), 381-391. doi:10.2307/2330414

Haugen, R.A., Baker, N.L. (1996) "Commonality in the Determinants of Expected Stock Returns", Journal of Financial Economics, Vol. 41, pp. 401-439.

Hou, K., Xue, C. and Zhang, L., (2015) "Digesting anomalies: An investment approach." The Review of Financial Studies, Vol. 28(3), pp.650-705.

Jegadeesh, N., Titman, S. (1993) "Returns to Buying Winners and Selling Losers: Implications for Stock Market Efficiency", Journal of Finance, Vol. 48:1, pp. 65-91.

Jensen, M.C. (1968) "The Performance of Mutual Funds in the Period 1945-1964", Journal of Finance, Vol. 23(2), pp. 389-416.

Klassen, R., McLaughlin, C., (1996) "The Impact of Environmental Management on Company Performance", Management Science, Vol. 42(8), pp. 1199-1214.

Lintner, J.V. (1965) "The Valuation of Risk Assets and the Selection of Risky Investments in Stock Portfolios and Capital Budgets", Review of Economics and Statistics, Vol. 47, pp. 13-37.

Long, J. B. (1974) "Stock prices, inflation, and the term structure of interest rates", Journal of Financial Economics, 1(2), 131-170.

Lo, L.W., Wang, J. (2000) "Trading Volume: Definitions, Data analysis and Implications of Portfolio Theory", The Review of Financial Studies, Vol. 13, pp. 257-300.

Lo, L.W., Wang, J. (2006) "Trading Volume: Implications of an Intertemporal Capital Asset Pricing Model", The Journal of Finance, Vol. 61(6), pp. 2805-2840.

Mehra, R., \& Prescott, E. C. (1985) “The equity premium: A puzzle”, Journal of monetary Economics, Vol. 15(2), pp. 145-161.

Novy-Marx, R., (2013) "The other side of value: The gross profitability premium", Journal of Financial Economics, 108, 1-28

O' Keeffe, C., Gallagher, Liam A. (2017) "The winner-loser anomaly: recent evidence from Greece”, Applied Economics, Vol. 49 (47), pp. 4718-4728.

Pandey, V., Kohers, T., \& Kohers, G. (1998) "Deterministic nonlinearity in the stock returns of major European equity markets and the United States", Financial Review, 33(1), 45-64.

Pisedtasalasai, A., Gunasekarage, A. (2007) "Causal and Dynamic Relationship among Stock Returns, Return Volatility and Trading Volume: Evidence from Emerging markets in South-East Asia", Asia Pacific Financial Markets, Vol.14, pp. 277-297.

Reinganum, M. R. (1982) “A direct test of Roll's conjecture on the firm size effect”, The Journal of Finance, 37(1), 27-35.

Roll, R. (1977) “A Critique of the Asset Pricing Theory's Tests”, Journal of Financial Economics, Vol. 4, pp. 129-176.

Roll, R., Ross, S.A. (1994) "On the Cross-Sectional Relation between Expected Returns and Betas", Journal of Finance, Vol.49, pp. 101-121. 
Ross, S. (1976) “The arbitrage theory of capital asset pricing”, Journal of Economic Theory, Vol. 13 (3), pp. 341-360.

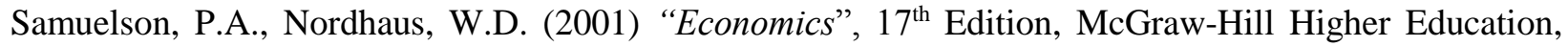
2001.

Sharpe, W.F. (1964) "Capital Asset Prices: A Theory of Market Equilibrium under Conditions of Risk", Journal of Finance, Vol. 19, pp. 425-42.

Stambaugh, R.F. (1982) "On the Exclusion of Assets from Tests of the Two-Parameter Model: A Sensitivity Analysis", Journal of Financial Economics, Vol.10, pp. 237-68.

Wang, J. (2002) "Trading Volume and Asset Prices", Annals of Economics and Finance, Vol. 3, pp. 299359. 
Table 1: Portfolios Description

\begin{tabular}{|c|c|c|c|c|c|c|c|c|c|}
\hline $\begin{array}{l}\text { S. } \\
\text { No. }\end{array}$ & Portfolios & Market & Data from & to & $\begin{array}{l}\text { Type of } \\
\text { Returns }\end{array}$ & $\begin{array}{c}\text { Number of } \\
\text { time intervals }\end{array}$ & Sorting Factor(s) & $\begin{array}{l}\text { Market } \\
\text { Proxy }\end{array}$ & Names \\
\hline 1 & 30 components of DJIA as on April 30, 2013 & USA & 30-May-03 & 30-Apr-13 & Monthly & 120 & Returns Variance & DJIA & S1 \\
\hline 2 & 30 components of DJIA as on April 30, 2013 & USA & 30-May-03 & 30-Apr-13 & Monthly & 120 & Returns Variance & S\&P 500 & $\mathrm{~S} 2$ \\
\hline 3 & 30 components of DJIA as on April 30, 2013 & USA & 30-Jun-05 & 30-Apr-13 & Monthly & 95 & Returns Variance & DJIA & S3 \\
\hline 4 & 30 components of DJIA as on April 30, 2013 & USA & 30-Jun-05 & 30-Apr-13 & Monthly & 95 & Returns Variance & S\&P 500 & S4 \\
\hline 5 & 30 components of DJIA as on April 30, 2013 & USA & 12-Dec-12 & 30-Apr-13 & Daily & 95 & Returns Variance & DJIA & S5 \\
\hline 6 & 30 components of DJIA as on April 30, 2013 & USA & 12-Dec-12 & 30-Apr-13 & Daily & 95 & Returns Variance & S\&P 500 & S6 \\
\hline 7 & 396 components of B400 as on August 1, 2013 & USA & 12-Dec-12 & 30-Apr-13 & Daily & 95 & Returns Variance & S\&P 500 & S7 \\
\hline 8 & 500 components of S\&P 500 as on August 1, 2013 & USA & 12-Dec-12 & 30-Apr-13 & Daily & 95 & Returns Variance & S\&P 500 & S8 \\
\hline 9 & 30 components of DJIA as on April 30, 2013 & USA & 30-May-03 & 30-Apr-13 & Monthly & 120 & Idiosyncratic Volatility & S\&P 500 & S9 \\
\hline 10 & 396 components of B400 as on August 1, 2013 & USA & 12-Dec-12 & 30-Apr-13 & Daily & 95 & Idiosyncratic Volatility & S\&P 500 & S10 \\
\hline 11 & 500 components of S\&P 500 as on August 1, 2013 & USA & 12-Dec-12 & 30-Apr-13 & Daily & 95 & Idiosyncratic Volatility & S\&P 500 & S11 \\
\hline 12 & Fama-French 5 Portfolios of All USA stocks & USA & 30-May-03 & 30-Apr-13 & Monthly & 120 & Industry & S\&P 500 & S12 \\
\hline 13 & Fama-French 6 Portfolios of All USA stocks & USA & 30-May-03 & 30-Apr-13 & Monthly & 120 & Size \& Investment & S\&P 500 & S13 \\
\hline 14 & Fama-French 6 Portfolios of All USA stocks & USA & 30-May-03 & 30-Apr-13 & Monthly & 120 & Size \& Long term reversals & S\&P 500 & S14 \\
\hline 15 & Fama-French 6 Portfolios of All USA stocks & USA & 30-May-03 & 30-Apr-13 & Monthly & 120 & Size and Momentum & S\&P 500 & S15 \\
\hline 16 & Fama-French 6 Portfolios of All USA stocks & USA & 30-May-03 & 30-Apr-13 & Monthly & 120 & Size and Operating profits & S\&P 500 & S16 \\
\hline 17 & Fama-French 6 Portfolios of All USA stocks & USA & 30-May-03 & 30-Apr-13 & Monthly & 120 & Size \& Short term reversals & S\&P 500 & S17 \\
\hline 18 & Fama-French 6 Portfolios of All USA stocks & USA & 30-May-03 & $30-A p r-13$ & Monthly & 120 & Size and BE/ME ratio & S\&P 500 & S18 \\
\hline 19 & $\begin{array}{c}100 \text { components of S\&P ASX } 50 \text { and S\&P ASX } \\
\text { Mid-Cap } 50 \text { as on May 15, } 2013\end{array}$ & Australia & 20-May-13 & 30-Sep-13 & Daily & 95 & Returns Variance & $\begin{array}{l}\text { ASX All } \\
\text { Ordinaries }\end{array}$ & S19 \\
\hline 20 & $\begin{array}{c}100 \text { components of S\&P ASX } 50 \text { and S\&P ASX } \\
\text { Mid-Cap } 50 \text { as on May 15, } 2013\end{array}$ & Australia & 12-Apr-13 & $30-$ Sep-13 & Daily & 120 & Returns Variance & $\begin{array}{l}\text { ASX All } \\
\text { Ordinaries }\end{array}$ & S20 \\
\hline 21 & $\begin{array}{l}30 \text { components of BSE Sensex as on January } 1 \text {, } \\
2005\end{array}$ & India & 31-Jan-02 & 30-Nov-09 & Monthly & 95 & Returns Variance & BSE Sensex & S21 \\
\hline
\end{tabular}


Table 2a: Slope coefficients and t-stats of the RFM Equation (17a - with intercept):

$$
\boldsymbol{R F}_{1 a:}: p_{i, t}=\alpha_{i}+\beta_{i}\left[\left\{\left(p_{m, t} p_{m, t-1}\right) p_{i, t-1}\right\}\right]+e_{i t}
$$

\begin{tabular}{|c|c|c|c|c|c|c|c|}
\hline \multirow{2}{*}{$\begin{array}{l}\text { Sample } \\
\text { Portfolios }\end{array}$} & \multicolumn{3}{|c|}{ Slope coefficients across P1 to P-full } & \multirow{2}{*}{$\begin{array}{c}\text { Sample } \\
\text { Portfolios }\end{array}$} & \multicolumn{3}{|c|}{ Slope coefficients across P1 to P-full } \\
\hline & Sub portfolios & $\alpha_{\mathrm{i}}$ & $\beta_{i}$ & & Sub portfolios & $\alpha_{i}$ & $\beta_{i}$ \\
\hline \multirow{6}{*}{ S1 } & P1 & & $1.00(49.902)$ & \multirow{6}{*}{ S10 } & $\mathrm{P} 1$ & & $0.99(135.59)$ \\
\hline & P2 & & $1.00(110.85)$ & & P2 & & $0.98(89.093)$ \\
\hline & P3 & & $0.99(101.55)$ & & P3 & & $0.98(75.988)$ \\
\hline & P4 & & $0.97(62.040)$ & & P4 & & $0.96(58.225)$ \\
\hline & P5 & & $0.98(61.915)$ & & P5 & & $0.96(44.426)$ \\
\hline & P-full & $0.35(0.46)$ & $0.99(170.84)$ & & P-full & $1.92(1.60)$ & $0.98(81.112)$ \\
\hline \multirow{6}{*}{ S2 } & P1 & & $0.99(39.986)$ & \multirow{6}{*}{ S11 } & P1 & & $1.00(144.28)$ \\
\hline & P2 & & $0.99(97.915)$ & & $\mathrm{P} 2$ & & $1.00(149.26)$ \\
\hline & P3 & & $0.99(97.491)$ & & P3 & & $0.99(145.45)$ \\
\hline & P4 & & $0.98(65.704)$ & & P4 & & $0.98(82.446)$ \\
\hline & P5 & & $0.99(65.846)$ & & P5 & & $0.96(50.963)$ \\
\hline & P-full & $0.11(0.14)$ & $0.99(153.73)$ & & P-full & $0.46(0.66)$ & $0.99(145.11)$ \\
\hline \multirow{6}{*}{ S3 } & P1 & & $1.00(45.441)$ & \multirow{6}{*}{ S12 } & P1 & & $1.00(151.91)$ \\
\hline & $\mathrm{P} 2$ & & $1.00(97.870)$ & & P2 & & $0.99(102.36)$ \\
\hline & P3 & & $0.99(93.150)$ & & P3 & & $0.99(121.94)$ \\
\hline & P4 & & $0.98(59.949)$ & & P4 & & $1.00(72.912)$ \\
\hline & P5 & & $0.99(51.117)$ & & P5 & & 0.99 (113.85) \\
\hline & P-full & $-0.45(-0.69)$ & $1.00(176.79)$ & & P-full & $0.03(0.11)$ & $1.00(431.53)$ \\
\hline \multirow{6}{*}{ S4 } & P1 & & $0.99(35.812)$ & \multirow{6}{*}{ S13 } & P1 & & $0.99(84.023)$ \\
\hline & P2 & & $0.99(85.160)$ & & P2 & & 0.99 (97.351) \\
\hline & P3 & & $0.99(90.832)$ & & P3 & $0.79(0.51)$ & 0.98 (67.908) \\
\hline & P4 & & $0.98(62.910)$ & & P4 & & $1.00(176.53)$ \\
\hline & P5 & & $1.00(53.596)$ & & P5 & & $1.00(300.28)$ \\
\hline & P-full & $-0.29(-0.35)$ & $1.00(139.63)$ & & P-full & & $0.99(176.97)$ \\
\hline \multirow{6}{*}{ S5 } & P1 & & $0.99(81.714)$ & \multirow{6}{*}{ S14 } & P1 & & $0.98(58.832)$ \\
\hline & P2 & & $1.01(77.688)$ & & P2 & & 0.99 (102.56) \\
\hline & P3 & & 0.98 (99.304) & & P3 & $1.32(0.78)$ & 0.99 (93.675) \\
\hline & P4 & & $1.01(81.851)$ & & P4 & & $0.99(70.892)$ \\
\hline & P5 & & $0.97(45.708)$ & & P5 & & $1.00(236.99)$ \\
\hline & P-full & $-0.14(-0.30)$ & $1.00(221.37)$ & & P-full & & $0.99(106.76)$ \\
\hline \multirow{6}{*}{ S6 } & P1 & & $0.98(61.889)$ & \multirow{6}{*}{ S15 } & P1 & & $0.97(74.616)$ \\
\hline & P2 & & $1.00(86.040)$ & & P2 & & 0.99 (105.38) \\
\hline & P3 & & $0.97(93.221)$ & & P3 & $1.81(1.04)$ & $1.00(74.499)$ \\
\hline & P4 & & $1.00(83.234)$ & & P4 & & $0.97(66.420)$ \\
\hline & P5 & & $0.97(47.608)$ & & P5 & & $0.99(263.86)$ \\
\hline & P-full & $0.28(0.44)$ & $0.99(161.76)$ & & P-full & & $1.00(102.37)$ \\
\hline \multirow{6}{*}{ S7 } & P1 & & $0.99(119.27)$ & & P1 & & $0.98(65.503)$ \\
\hline & P2 & & $0.98(97.872)$ & & P2 & & 0.99 (101.19) \\
\hline & P3 & & $0.97(69.931)$ & & P3 & $0.83(0.71)$ & 0.99 (92.163) \\
\hline & P4 & & $0.97(59.854)$ & S16 & P4 & & $1.00(118.36)$ \\
\hline & P5 & & $0.96(42.219)$ & & P5 & & $1.00(276.27)$ \\
\hline & P-full & $1.92(1.58)$ & $0.98(80.612)$ & & P-full & & $0.99(252.70)$ \\
\hline & P1 & & $1.00(128.44)$ & & P1 & & $0.98(66.220)$ \\
\hline & P2 & & $0.99(152.71)$ & & P2 & & $0.99(92.274)$ \\
\hline 88 & P3 & & $0.99(106.11)$ & S17 & P3 & & $0.98(72.263)$ \\
\hline 58 & P4 & & $0.98(83.984)$ & ' & P4 & $1.29(0.71)$ & 0.99 (88.608) \\
\hline & P5 & & $0.97(50.929)$ & & P5 & & $1.00(245.88)$ \\
\hline & P-full & $0.46(0.66)$ & $0.99(145.04)$ & & P-full & & $0.99(116.70)$ \\
\hline & P1 & & $0.96(55.165)$ & & P1 & & $0.99(74.678)$ \\
\hline & $\mathrm{P} 2$ & & $1.00(123.48)$ & & $\mathrm{P} 2$ & & 0.98 (91.969) \\
\hline S9 & P3 & & $0.96(62.214)$ & S18 & P3 & & $0.98(74.880)$ \\
\hline 39 & P4 & & 0.99 (80.148) & S18 & P4 & $0.87(0.70)$ & 0.99 (209.34) \\
\hline & P5 & & $0.97(52.576)$ & & P5 & & 0.99 (196.31) \\
\hline & P-full & $0.20(0.23)$ & $0.99(149.50)$ & & P-full & & $1.01(92.183)$ \\
\hline
\end{tabular}


Table 2a contd.: Slope coefficients and $t$-stats of the RFM Equation (17a - with intercept): $R_{1 a}: \quad p_{i, t}=\alpha_{i}+\beta_{i}\left[\left\{\left(p_{m, t} / p_{m, t-1}\right) p_{i, t-1}\right\}\right]+e_{i t}$

\begin{tabular}{|c|c|c|c|}
\hline Sample & \multicolumn{3}{|c|}{ Slope coefficients across P1 to P-full } \\
\hline Portfolios & Sub portfolios & $\alpha_{\mathrm{i}}$ & $\beta_{i}$ \\
\hline \multirow{5}{*}{ S19 } & P1 & & $0.98(50.475)$ \\
& P2 & & $0.99(113.25)$ \\
& P3 & & $1.00(66.014)$ \\
& P4 & & $1.00(107.45)$ \\
& P5 & & $1.00(60.653)$ \\
& P-full & $-1.06(-1.31)$ & $1.00(142.21)$ \\
\hline \multirow{5}{*}{ S20 } & P1 & & $1.01(67.880)$ \\
& P2 & & $0.99(108.21)$ \\
& P3 & & $1.00(81.172)$ \\
& P4 & & $0.99(91.064)$ \\
& P5 & & $0.99(59.589)$ \\
& P-full & $-1.05(-1.22)$ & $1.00(135.29)$ \\
\hline \multirow{5}{*}{ S21 } & P1 & & $0.96(79.087)$ \\
& P2 & & $0.99(94.814)$ \\
& P3 & & $1.00(115.54)$ \\
& P4 & & $1.00(85.058)$ \\
& P5 & & $0.99(69.505)$ \\
& P-full & $0.09(0.21)$ & $0.99(227.75)$ \\
\hline
\end{tabular}


Table 2b: Slope coefficients and t-stats of the RFM Equation (17b - without intercept):

$\boldsymbol{R F}_{1 b}: p_{i, t}=\boldsymbol{\beta}_{i}\left[\left\{\left(p_{m, t} \boldsymbol{p}_{m, t-1}\right) p_{i, t-1}\right\}\right]+e_{i t}$

\begin{tabular}{|c|c|c|c|c|c|c|c|c|c|c|c|c|c|c|c|c|}
\hline \multirow{2}{*}{$\begin{array}{c}\text { Sample } \\
\text { Portfolios }\end{array}$} & \multicolumn{2}{|c|}{$\begin{array}{l}\text { Slope coefficients across } \\
\text { P1 to P-full } \\
\end{array}$} & \multirow{2}{*}{$\begin{array}{l}\text { Sample } \\
\text { Portfolios }\end{array}$} & \multicolumn{3}{|c|}{$\begin{array}{l}\text { Slope coefficients across } \\
\text { P1 to P-full }\end{array}$} & \multirow{2}{*}{$\begin{array}{l}\text { Sample } \\
\text { Portfolios }\end{array}$} & \multicolumn{2}{|c|}{$\begin{array}{l}\text { Slope coefficients across P1 } \\
\text { to P-full }\end{array}$} & \multirow{2}{*}{$\begin{array}{l}\text { Sample } \\
\text { Portfolios }\end{array}$} & \multicolumn{3}{|c|}{$\begin{array}{l}\text { Slope coefficients across P1 } \\
\text { to P-full }\end{array}$} & \multirow{2}{*}{$\begin{array}{l}\text { Sample } \\
\text { Portfolios }\end{array}$} & \multicolumn{2}{|c|}{$\begin{array}{l}\text { Slope coefficients across } \\
\text { P1 to P-full }\end{array}$} \\
\hline & $\begin{array}{c}\text { Sub } \\
\text { portfolios }\end{array}$ & $\beta_{i}$ & & $\begin{array}{c}\text { Sub } \\
\text { portfolios }\end{array}$ & & $\beta_{i}$ & & $\begin{array}{c}\text { Sub } \\
\text { portfolios }\end{array}$ & $\beta_{i}$ & & $\begin{array}{c}\text { Sub } \\
\text { portfolios }\end{array}$ & & $\beta_{i}$ & & $\begin{array}{c}\text { Sub } \\
\text { portfolios }\end{array}$ & $\beta_{i}$ \\
\hline \multirow{6}{*}{ S1 } & P1 & $1.00(471.85)$ & \multirow{6}{*}{ S6 } & P1 & 0.99 & (1654.1) & \multirow{6}{*}{ S11 } & P1 & $1.00(5012.7)$ & \multirow{6}{*}{ S16 } & P1 & 1.00 & $(382.21)$ & \multirow{6}{*}{ S21 } & P1 & 0.98 (213.95) \\
\hline & $\mathrm{P} 2$ & $1.00(538.63)$ & & $\mathrm{P} 2$ & 1.00 & (2586.9) & & $\mathrm{P} 2$ & $1.00(5289.7)$ & & $\mathrm{P} 2$ & 1.00 & $(492.61)$ & & $\mathrm{P} 2$ & 0.99 (262.05) \\
\hline & P3 & $1.00(605.99)$ & & P3 & 1.00 & (2773.9) & & P3 & $1.00(4573.9)$ & & P3 & 1.00 & $(420.93)$ & & P3 & $1.00(278.81)$ \\
\hline & P4 & 0.99 (391.94) & & P4 & 1.00 & (2306.4) & & P4 & $1.00(3075.3)$ & & P4 & 1.00 & $(717.52)$ & & P4 & 0.99 (248.63) \\
\hline & P5 & 0.99 (287.34) & & P5 & 1.00 & (1573.8) & & P5 & $0.99(2320.0)$ & & P5 & 1.00 & $(1639.3)$ & & P5 & 0.99 (167.51) \\
\hline & P-full & 0.99 (1238.0) & & P-full & 1.00 & (4918.6) & & P-full & $1.00(5365.0)$ & & P-full & 1.00 & $(1339.5)$ & & P-full & 0.99 (612.95) \\
\hline \multirow{6}{*}{ S2 } & P1 & $1.00(381.42)$ & \multirow{6}{*}{ S7 } & P1 & 0.99 & (4468.4) & \multirow{6}{*}{$\mathrm{S} 12$} & P1 & $1.00(680.51)$ & \multirow{6}{*}{ S17 } & P1 & 1.00 & $(318.36)$ & & & \\
\hline & P2 & $1.00(474.89)$ & & P2 & 1.00 & (3246.3) & & P2 & $1.00(479.14)$ & & P2 & 1.00 & $(464.61)$ & & & \\
\hline & P3 & $1.00(582.88)$ & & P3 & 1.00 & (2850.2) & & P3 & $1.00(598.82)$ & & P3 & 1.00 & $(426.21)$ & & & \\
\hline & P4 & 0.99 (416.24) & & P4 & 1.00 & (2092.7) & & P4 & $1.00(402.58)$ & & P4 & 0.99 & (424.75) & & & \\
\hline & P5 & $0.99(303.81)$ & & P5 & 1.00 & (1605.3) & & P5 & $0.99(530.94)$ & & P5 & 1.00 & (1326.5) & & & \\
\hline & P-full & 0.99 (1121.8) & & P-full & 1.00 & (2995.6) & & P-full & $1.00(2532.6)$ & & P-full & 1.00 & $(654.61)$ & & & \\
\hline \multirow{6}{*}{ S3 } & P1 & $0.99(396.20)$ & \multirow{6}{*}{ S8 } & P1 & 1.00 & (3932.7) & \multirow{6}{*}{ S13 } & P1 & $1.00(369.70)$ & \multirow{6}{*}{ S18 } & P1 & 1.00 & $(421.14)$ & & & \\
\hline & P2 & $1.00(467.18)$ & & P2 & 1.00 & (5533.1) & & P2 & $1.00(481.73)$ & & P2 & 1.00 & (456.74) & & & \\
\hline & P3 & $1.00(533.59)$ & & P3 & 1.00 & (4015.8) & & P3 & $1.00(424.10)$ & & P3 & 1.00 & $(375.93)$ & & & \\
\hline & P4 & 0.99 (328.83) & & $\mathrm{P} 4$ & 1.00 & (3073.3) & & P4 & $1.00(1058.1)$ & & $\mathrm{P} 4$ & 1.00 & (1138.8) & & & \\
\hline & P5 & 0.99 (228.41) & & P5 & 0.99 & (2063.0) & & P5 & $1.00(1768.1)$ & & P5 & 1.00 & $(1152.5)$ & & & \\
\hline & P-full & 0.99 (1164.5) & & P-full & 1.00 & (5353.9) & & P-full & $1.00(1083.3)$ & & P-full & 1.00 & $(538.96)$ & & & \\
\hline \multirow{6}{*}{ S4 } & P1 & 0.99 (315.91) & \multirow{6}{*}{ S9 } & P1 & 0.99 & (476.39) & & P1 & $1.00(308.03)$ & & P1 & 0.99 & $(2549.3)$ & & & \\
\hline & P2 & $1.00(405.38)$ & & $\mathrm{P} 2$ & 1.00 & (560.68) & & P2 & $1.00(477.37)$ & & P2 & 1.00 & $(3271.4)$ & & & \\
\hline & P3 & $1.00(520.12)$ & & P3 & 0.99 & (502.39) & S14 & $\mathrm{P} 3$ & $1.00(450.33)$ & S19 & P3 & 0.99 & $(2547.1)$ & & & \\
\hline & $\mathrm{P} 4$ & 0.99 (344.51) & & $\mathrm{P} 4$ & 0.99 & (401.12) & $\mathrm{S} 14$ & P4 & $1.00(496.31)$ & 319 & $\mathrm{P} 4$ & 1.00 & $(2147.1)$ & & & \\
\hline & P5 & 0.99 (239.13) & & P5 & 0.99 & (288.13) & & P5 & $1.00(1439.6)$ & & P5 & 0.99 & (1129.9) & & & \\
\hline & P-full & $1.00(919.87)$ & & P-full & 0.99 & (1069.1) & & P-full & $1.00(615.43)$ & & P-full & 0.99 & (3994.0) & & & \\
\hline & P1 & 0.99 (2178.2) & & P1 & 0.99 & (5081.4) & & P1 & $1.00(290.60)$ & & P1 & 1.00 & $(2996.2)$ & & & \\
\hline & $\mathrm{P} 2$ & $1.00(2329.3)$ & & $\mathrm{P} 2$ & 0.99 & (3312.8) & & $\mathrm{P} 2$ & $1.00(493.12)$ & & $\mathrm{P} 2$ & 1.00 & (3388.7) & & & \\
\hline$S_{5}$ & P3 & $1.00(2958.7)$ & S10 & P3 & 1.00 & (2536.8) & S15 & P3 & $1.00(391.74)$ & S20 & P3 & 0.99 & $(2801.2)$ & & & \\
\hline SJ & P4 & $1.00(2280.6)$ & S10 & P4 & 0.99 & (2140.7) & נIJ & P4 & $0.99(352.85)$ & 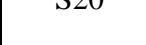 & P4 & 1.00 & (1972.0) & & & \\
\hline & P5 & $0.99(1518.1)$ & & P5 & 1.00 & (1701.1) & & P5 & $1.00(1326.8)$ & & P5 & 1.00 & $(1155.0)$ & & & \\
\hline & P-full & $1.00(6797.1)$ & & P-full & 1.00 & (3011.5) & & P-full & $1.00(580.35)$ & & P-full & 1.00 & $(3972.8)$ & & & \\
\hline
\end{tabular}


Table 2c: Slope coefficients and t-stats of the RFM Equation $(17 \mathrm{c}$ - volume estimation):

$\boldsymbol{R F}_{1 c}: v_{i, t}=\delta_{i}\left[\left\{\left(v_{m, t} / v_{m, t-1}\right) v_{i, t-1}\right\}\right]+e_{i t}$

\begin{tabular}{|c|c|c|c|c|c|c|c|c|}
\hline \multirow{2}{*}{$\begin{array}{l}\text { Sample } \\
\text { Portfolios }\end{array}$} & \multicolumn{2}{|c|}{$\begin{array}{l}\text { Slope coefficients } \\
\text { across P1 to P-full }\end{array}$} & \multirow{2}{*}{$\begin{array}{l}\text { Sample } \\
\text { Portfolios }\end{array}$} & \multicolumn{2}{|c|}{$\begin{array}{l}\text { Slope coefficients } \\
\text { across P1 to P-full }\end{array}$} & \multirow{2}{*}{$\begin{array}{l}\text { Sample } \\
\text { Portfolios }\end{array}$} & \multicolumn{2}{|c|}{$\begin{array}{c}\text { Slope coefficients across } \\
\text { P1 to P-full }\end{array}$} \\
\hline & $\begin{array}{c}\text { Sub } \\
\text { portfolios }\end{array}$ & $\delta_{i}$ & & $\begin{array}{c}\text { Sub } \\
\text { portfolios }\end{array}$ & $\delta_{i}$ & & $\begin{array}{c}\text { Sub } \\
\text { portfolios }\end{array}$ & $\delta_{i}$ \\
\hline \multirow{6}{*}{$\mathrm{S} 1$} & $\mathrm{P} 1$ & $1.11(42.54)$ & \multirow{6}{*}{ S6 } & $\mathrm{P} 1$ & $1.03(56.93)$ & \multirow{6}{*}{ S11 } & $\mathrm{P} 1$ & $1.02(31.70)$ \\
\hline & $\mathrm{P} 2$ & $0.86(20.81)$ & & $\mathrm{P} 2$ & $1.02(48.11)$ & & $\mathrm{P} 2$ & $1.22(45.12)$ \\
\hline & P3 & $1.27(69.49)$ & & P3 & $0.97(49.80)$ & & P3 & $0.89(57.38)$ \\
\hline & $\mathrm{P} 4$ & $0.96(42.12)$ & & $\mathrm{P} 4$ & $0.96(55.16)$ & & $\mathrm{P} 4$ & $0.89(54.59)$ \\
\hline & P5 & 0.88 (28.43) & & P5 & $0.92(51.70)$ & & P5 & $0.90(59.24)$ \\
\hline & P-full & $1.15(55.20)$ & & P-full & $0.96(73.89)$ & & P-full & $0.91 \quad(71.38)$ \\
\hline \multirow{6}{*}{$\mathrm{S} 2$} & P1 & $1.13(43.84)$ & \multirow{6}{*}{ S7 } & $\mathrm{P} 1$ & $1.13(47.02)$ & \multirow{6}{*}{ S19 } & P1 & $1.00(20.36)$ \\
\hline & $\mathrm{P} 2$ & $0.90(22.75)$ & & $\mathrm{P} 2$ & 1.07 (35.13) & & $\mathrm{P} 2$ & $0.80(13.45)$ \\
\hline & P3 & $1.27(72.35)$ & & P3 & $1.19(36.63)$ & & P3 & $0.72(10.31)$ \\
\hline & $\mathrm{P} 4$ & $1.00(52.11)$ & & $\mathrm{P} 4$ & $1.11(22.35)$ & & $\mathrm{P} 4$ & $0.84(18.32)$ \\
\hline & P5 & 0.89 (25.30) & & P5 & 0.88 (99.53) & & P5 & 0.88 (18.92) \\
\hline & P-full & $1.16(66.36)$ & & P-full & $0.90(77.65)$ & & P-full & $1.00(20.36)$ \\
\hline \multirow{6}{*}{$\mathrm{S} 3$} & P1 & $0.99(30.46)$ & \multirow{6}{*}{ S8 } & P1 & $1.19(42.46)$ & \multirow{6}{*}{$\mathrm{S} 20$} & P1 & $0.77(21.82)$ \\
\hline & $\mathrm{P} 2$ & 0.87 (18.62) & & $\mathrm{P} 2$ & $1.03(15.72)$ & & $\mathrm{P} 2$ & 0.99 (23.69) \\
\hline & P3 & $1.24(51.65)$ & & P3 & $1.00(81.88)$ & & P3 & $0.86(15.51)$ \\
\hline & $\mathrm{P} 4$ & 0.92 (37.90) & & P4 & $0.93(45.24)$ & & $\mathrm{P} 4$ & $0.92(30.57)$ \\
\hline & P5 & $0.83(25.16)$ & & P5 & $0.91 \quad(70.27)$ & & P5 & $0.96(29.22)$ \\
\hline & P-full & $1.00(29.57)$ & & P-full & $0.92(52.99)$ & & P-full & $0.77(21.82)$ \\
\hline \multirow{6}{*}{$\mathrm{S} 4$} & P1 & $1.05(45.33)$ & \multirow{6}{*}{ S9 } & P1 & $1.05(43.86)$ & \multirow{6}{*}{$\mathrm{S} 21$} & P1 & $1.27(9.77)$ \\
\hline & $\mathrm{P} 2$ & $0.90(20.43)$ & & $\mathrm{P} 2$ & $0.92(38.56)$ & & $\mathrm{P} 2$ & $0.45(6.05)$ \\
\hline & P3 & $1.25(59.40)$ & & P3 & $0.92(43.62)$ & & P3 & $0.73(15.00)$ \\
\hline & $\mathrm{P} 4$ & $0.97(49.49)$ & & $\mathrm{P} 4$ & 0.97 (29.33) & & $\mathrm{P} 4$ & $0.66(10.45)$ \\
\hline & P5 & $0.91(34.30)$ & & P5 & $0.76(23.37)$ & & P5 & $0.53(33.72)$ \\
\hline & P-full & $1.03(34.71)$ & & P-full & $0.95(44.26)$ & & P-full & $0.83(8.94)$ \\
\hline \multirow{4}{*}{ S5 } & P1 & $1.02(49.55)$ & \multirow{4}{*}{$\mathrm{S} 10$} & P1 & $1.18(82.83)$ & & & \\
\hline & $\mathrm{P} 2$ & $1.04(46.18)$ & & $\mathrm{P} 2$ & $1.05(65.96)$ & & & \\
\hline & P3 & $0.96(44.20)$ & & P3 & $1.03(62.53)$ & & & \\
\hline & $\mathrm{P} 4$ & 0.96 (47.72) & & P4 & $0.92(61.92)$ & & & \\
\hline
\end{tabular}


Table 3: Slope coefficients and their t-stats for the Combined RFM Equation (18b):

$R F_{2 b}: R_{i, t}-R_{f, t}=\beta_{i, m}\left(R_{m, t}-R_{f, t}\right)+\beta_{i, s} S M B_{t}+\beta_{i, h} H M L_{t}+\beta_{i, r} R M W_{t}+\beta_{i, c} C M A_{t}+\beta_{i, v}\left[\ln \left(v_{m, t} / v_{m, t-1}\right)\right]+\beta_{i, o}\left(t_{t}\right)^{2}+\beta_{i, l}\left(R_{i, t-1}\right)+e_{i t}$

\begin{tabular}{|c|c|c|c|c|c|c|c|c|c|}
\hline \multirow{2}{*}{$\begin{array}{c}\text { Sample } \\
\text { Portfolios }\end{array}$} & \multicolumn{9}{|c|}{ Slope coefficients across P1 to P-full } \\
\hline & $\begin{array}{c}\text { Sub } \\
\text { portfolios }\end{array}$ & $\beta_{i, m}$ & $\beta_{i, s}$ & $\beta_{i, h}$ & $\beta_{i, r}$ & $\beta_{i, c}$ & $\beta_{i, v}$ & $\beta_{i, o}$ & $\beta_{i, l}$ \\
\hline \multirow{6}{*}{$\mathrm{S} 1$} & P1 & $0.82(13.88)$ & $-0.19(-2.19)$ & $-0.09(-1.01)$ & $0.28(1.919)$ & $0.15(1.007)$ & $-0.010(-2.04)$ & $-4.23(-0.11)$ & $0.02(0.331)$ \\
\hline & $\mathrm{P} 2$ & $0.77(13.82)$ & $0.03(0.352)$ & $-0.06(-0.74)$ & $0.17(1.285)$ & $0.18(1.215)$ & $-0.005(-1.26)$ & $7.86(2.193)$ & $-0.03(-0.51)$ \\
\hline & P3 & $0.99(17.52)$ & $0.07(0.866)$ & $0.11(1.216)$ & $-0.2(-1.78)$ & $-0.08(-0.54)$ & $0.0054(1.136)$ & $0.00(0.931)$ & $0.05(1.140)$ \\
\hline & $\mathrm{P} 4$ & $1.14(14.12)$ & $0.16(1.338)$ & $-0.01(-0.05)$ & $-0.38(-1.89)$ & $-0.37(-1.71)$ & $-0.009(-1.31)$ & $1.58(0.312)$ & $0.0001(0.003)$ \\
\hline & P5 & $1.42(14.18)$ & $0.46(2.995)$ & $0.56(3.525)$ & $-0.25(-1.03)$ & $-0.28(-1.04)$ & $-0.002(-0.26)$ & $-1.33(-2.12)$ & $-0.001 \quad(-0.03)$ \\
\hline & P-full & $1.02(43.50)$ & $0.10(2.881)$ & $0.08(2.114)$ & $-0.11(-2.02)$ & $-0.04(-0.68)$ & $-0.003(-1.97)$ & $3.35(0.226)$ & $-0.001(-0.09)$ \\
\hline \multirow{6}{*}{$\mathrm{S} 2$} & P1 & $0.77(11.68)$ & $-0.30(-2.99)$ & $-0.05(-0.49)$ & $0.37(2.219)$ & $0.29(1.654)$ & $-0.011(-1.81)$ & $-6.06(-0.14)$ & $0.0012(0.021)$ \\
\hline & $\mathrm{P} 2$ & 0.78 (13.65) & $-0.08(-1.02)$ & $-0.04(-0.45)$ & $0.34(2.341)$ & $0.33(2.193)$ & $-0.005(-0.96)$ & $7.55(2.092)$ & $-0.071(-1.32)$ \\
\hline & P3 & $0.98(16.75)$ & $-0.07(-0.81)$ & 0.12 (1.319) & $-0.04(-0.28)$ & $0.13(0.853)$ & 0.0067 (1.218) & $2.35(0.637)$ & $0.019(0.480)$ \\
\hline & $\mathrm{P} 4$ & 1.18 (14.39) & $-0.04(-0.34)$ & $0.01 \quad(0.084)$ & $-0.14(-0.66)$ & $-0.06(-0.29)$ & $-0.000(-0.04)$ & $-5.10(-9.98)$ & $-0.06(-1.21)$ \\
\hline & P5 & $1.44(14.30)$ & 0.21 & $0.56(3.513)$ & $0.06(0.248)$ & $0.11(0.406)$ & $0.0090(0.949)$ & $-1.58(-2.49)$ & $-0.02(-0.48)$ \\
\hline & P-full & $1.03(36.05)$ & $-0.06(-1.44)$ & $0.09(2.250)$ & $0.089(1.218)$ & $0.20(2.600)$ & $0.0004(0.180)$ & $-7.76(-0.43)$ & $-0.04(-1.99)$ \\
\hline \multirow{6}{*}{ S3 } & P1 & $0.80(12.92)$ & $-0.24(-2.34)$ & $-0.07(-0.73)$ & $0.31(1.894)$ & $0.16(0.947)$ & $-0.014(-2.48)$ & $1.49(0.206)$ & $0.01 \quad(0.108)$ \\
\hline & $\mathrm{P} 2$ & $0.77(13.00)$ & 0.08 (0.769) & $-0.10(-0.98)$ & 0.18 (1.196) & $0.25(1.482)$ & $-0.006(-1.18)$ & $1.62(2.313)$ & $-0.04(-0.64)$ \\
\hline & P3 & 1.01 (16.54) & $0.09(0.921)$ & $0.07(0.712)$ & $-0.24(-1.49)$ & $-0.02(-0.12)$ & $0.0056(0.980)$ & $4.79(0.673)$ & $0.04(0.929)$ \\
\hline & $\mathrm{P} 4$ & 1.19 (13.37) & $0.012(0.086)$ & $-0.02(-0.15)$ & $-0.44(-1.90)$ & $-0.20(-0.81)$ & $-0.010(-1.24)$ & $-1.31(-0.12)$ & $-0.01 \quad(-0.14)$ \\
\hline & P5 & $1.42(14.34)$ & $0.622(3.752)$ & $0.96(5.382)$ & $-0.06(-0.26)$ & $-0.88(-3.13)$ & $0.0084(0.927)$ & $-1.87(-1.64)$ & $3.42(0.000)$ \\
\hline & P-full & $1.02(46.13)$ & $0.083(2.249)$ & $0.14(3.622)$ & $-0.06(-1.10)$ & $-0.08(-1.37)$ & $-0.003(-1.48)$ & $1.28(0.499)$ & $-0.01 \quad(-0.49)$ \\
\hline \multirow{6}{*}{ S4 } & P1 & $0.7541(10.80)$ & $-0.37(-3.08)$ & $0.003(0.023)$ & $0.41 \quad(2.152)$ & $0.26(1.257)$ & $-0.013(-1.97)$ & $1.29(0.157)$ & $-0.01 \quad(-0.09)$ \\
\hline & $\mathrm{P} 2$ & $0.77(12.63)$ & $-0.06(-0.63)$ & $-0.04(-0.44)$ & $0.35(2.144)$ & $0.37(2.110)$ & $-0.003(-0.59)$ & $1.55(2.150)$ & $-0.07(-1.19)$ \\
\hline & P3 & 0.98 (16.09) & $-0.08(-0.84)$ & 0.12 (1.134) & $-0.01 \quad(-0.10)$ & $0.16(0.890)$ & $0.0044(0.726)$ & $3.02(0.415)$ & $0.017(0.388)$ \\
\hline & $\mathrm{P} 4$ & $1.22(14.00)$ & $-0.23(-1.59)$ & $0.04(0.284)$ & $-0.16(-0.69)$ & $0.05(0.208)$ & $0.0005(0.068)$ & $-4.57(-0.45)$ & $-0.06(-1.28)$ \\
\hline & P5 & 1.38 (13.33) & 0.36 (1.989) & $1.03(5.504)$ & $0.23(0.823)$ & $-0.58(-1.91)$ & $0.0150(1.473)$ & $-2.20(-1.81)$ & $-0.02(-0.38)$ \\
\hline & P-full & $1.01(33.10)$ & $-0.11(-2.06)$ & $0.21 \quad(3.884)$ & $0.15(1.824)$ & $0.10(1.129)$ & $0.0010(0.349)$ & $-4.42(-0.12)$ & $-0.04(-1.92)$ \\
\hline \multirow{6}{*}{ S5 } & P1 & $0.884(11.73)$ & $-0.09(-0.78)$ & $-0.46(-2.67)$ & $0.02(0.078)$ & $0.49(2.293)$ & $0.0028(1.345)$ & $-1.52(-1.17)$ & $-0.18(-2.86)$ \\
\hline & $\mathrm{P} 2$ & $0.982(12.19)$ & $0.008(0.069)$ & $0.27(1.512)$ & $-0.07(-0.25)$ & $-0.10(-0.45)$ & $-0.001 \quad(-0.67)$ & $1.47(1.052)$ & $0.03(0.431)$ \\
\hline & P3 & $1.01(15.84)$ & $-0.03(-0.32)$ & $-0.09(-0.64)$ & $-0.12(-0.55)$ & 0.36 (1.989) & $-0.001(-0.72)$ & $3.53(0.318)$ & $0.08(1.550)$ \\
\hline & $\mathrm{P} 4$ & 1.02 (13.69) & $0.173(1.466)$ & $0.08(0.473)$ & $-0.37(-1.43)$ & $-0.67(-3.13)$ & $-0.002(-1.05)$ & $2.65(2.028)$ & $-0.07(-1.39)$ \\
\hline & P5 & 0.99 (9.009) & $0.025(0.144)$ & $0.94(3.757)$ & $-0.18(-0.47)$ & $-0.94(-3.00)$ & $0.0023(0.788)$ & $1.117(0.586)$ & $-0.12(-1.82)$ \\
\hline & P-full & $0.98(39.19)$ & $0.008(0.222)$ & $0.14(2.576)$ & $-0.15(-1.73)$ & $-0.18(-2.61)$ & $-5.174(-0.07)$ & $8.201(1.880)$ & $-0.04(-1.76)$ \\
\hline \multirow{5}{*}{ S6 } & P1 & $0.73(9.194)$ & $-0.16(-1.16)$ & $-0.56(-2.79)$ & $0.06(0.215)$ & $0.74(2.872)$ & $0.0036(1.218)$ & $-1.43(-0.95)$ & $-0.16(-2.18)$ \\
\hline & $\mathrm{P} 2$ & $0.94(14.51)$ & $-0.15(-1.33)$ & 0.17 (1.047) & $0.21(0.840)$ & 0.29 (1.389) & $-0.000(-0.31)$ & $1.06(0.854)$ & 0.05 (0.989) \\
\hline & P3 & 0.95 (18.35) & $-0.18(-2.00)$ & $-0.22(-1.67)$ & $0.13(0.653)$ & $0.75(4.514)$ & $0.0017(0.884)$ & $3.95(0.039)$ & $0.09(2.128)$ \\
\hline & $\mathrm{P} 4$ & 0.89 (11.91) & $0.04(0.347)$ & $-0.015(-0.08)$ & $-0.25(-0.85)$ & $-0.35(-1.45)$ & $-0.003(-1.25)$ & $2.48(1.730)$ & $-0.02(-0.42)$ \\
\hline & P5 & 0.87 (8.327) & $-0.09(-0.49)$ & $0.84(3.227)$ & $-0.02(-0.05)$ & $-0.61(-1.83)$ & $0.0011 \quad(0.303)$ & $1.02(0.514)$ & $-0.10(-1.50)$ \\
\hline
\end{tabular}


Table 3 (contd.): Slope coefficients and their t-stats for the Combined RFM Equation (18b):

$\boldsymbol{R F}_{2 b}: \boldsymbol{R}_{i, t}-\boldsymbol{R}_{f, t}=\beta_{i, m}\left(\boldsymbol{R}_{m, t}-\boldsymbol{R}_{f, t}\right)+\beta_{i, s} S M B_{t}+\beta_{i, h} H M L_{t}+\beta_{i, r} R M W_{t}+\beta_{i, c} C M A_{t}+\beta_{i, v}\left[\ln \left(v_{m, t} / v_{m, t-1}\right)\right]+\beta_{i, o}\left(t_{t}\right)^{2}+\beta_{i, l}\left(R_{i, t-1}\right)+e_{i t}$

\begin{tabular}{|c|c|c|c|c|c|c|c|c|c|}
\hline \multirow[b]{2}{*}{$\begin{array}{c}\text { Sample } \\
\text { Portfolios }\end{array}$} & \multicolumn{9}{|c|}{ Slope coefficients across P1 to P-full } \\
\hline & $\begin{array}{c}\text { Sub } \\
\text { portfolios }\end{array}$ & $\beta_{i, m}$ & $\beta_{i, s}$ & $\beta_{i, h}$ & $\beta_{i, r}$ & $\beta_{i, c}$ & $\beta_{i, v}$ & $\beta_{i, o}$ & $\beta_{i, l}$ \\
\hline \multirow{6}{*}{ S7 } & $\mathrm{P} 1$ & $0.89(29.54)$ & $0.26(5.022)$ & $-0.36(-4.85)$ & $-0.16(-1.39)$ & $0.27(2.852)$ & $0.0007(0.687)$ & $-4.22(-0.74)$ & $0.0131(0.516)$ \\
\hline & P2 & $0.98(25.19)$ & $0.57(8.412)$ & $-0.35(-3.66)$ & $-0.12(-0.82)$ & $0.17(1.398)$ & $-0.001(-0.79)$ & $3.47(0.472)$ & $0.0397(1.426)$ \\
\hline & P3 & $0.96(23.35)$ & $0.68(9.517)$ & $-0.40(-3.94)$ & $-0.44(-2.76)$ & $0.01(0.108)$ & $-0.000(-0.37)$ & $1.78(0.230)$ & $-0.005(-0.19)$ \\
\hline & P4 & $1.03(21.24)$ & $0.91 \quad(10.75)$ & $-0.29(-2.46)$ & $-0.39(-2.12)$ & $-0.15(-0.96)$ & $-0.004(-2.32)$ & $-2.04(-0.22)$ & $0.0280(0.957)$ \\
\hline & P5 & $1.06(16.20)$ & $1.20(10.59)$ & $-0.24(-1.51)$ & $-0.25(-0.84)$ & $0.28(1.370)$ & $-0.006(-2.81)$ & $8.81(0.715)$ & $-0.021(-0.61)$ \\
\hline & P-full & $0.98(31.76)$ & $0.72(13.46)$ & $-0.33(-4.32)$ & $-0.26(-2.21)$ & $0.12(1.240)$ & $-0.002(-2.13)$ & $1.45(0.249)$ & $0.0139(0.665)$ \\
\hline \multirow{6}{*}{ S8 } & P1 & $0.85(26.21)$ & $0.03(0.693)$ & $-0.17(-2.19)$ & $0.01(0.147)$ & 0.49 (4.737) & $0.0013(1.112)$ & $1.33(2.152)$ & $-0.011 \quad(-0.37)$ \\
\hline & $\mathrm{P} 2$ & $0.96(32.85)$ & $0.16(3.253)$ & $-0.10(-1.43)$ & $0.12(1.131)$ & $0.35(3.793)$ & $3.25(0.029)$ & $-7.40(-0.13)$ & $0.0164(0.694)$ \\
\hline & P3 & $1.05(27.92)$ & $0.26(3.984)$ & $-0.03(-0.35)$ & $-0.11 \quad(-0.76)$ & $0.04(0.360)$ & $-0.000(-0.03)$ & $1.60(0.225)$ & $0.0192(0.737)$ \\
\hline & P4 & $1.1(30.83)$ & $0.3(5.315)$ & $0.146(1.580)$ & $-0.07(-0.48)$ & $-0.15(-0.96)$ & $-0.002(-1.48)$ & $-4.14(-0.59)$ & 0.0254 (1.099) \\
\hline & P5 & $1.05(20.40)$ & $0.5(6.506)$ & $0.616(4.755)$ & $0.08(0.402)$ & $-0.39(-2.36)$ & $-0.006(-3.17)$ & $-5.67(-0.05)$ & $-0.017(-0.56)$ \\
\hline & P-full & $1.01(43.27)$ & $0.27(6.848)$ & 0.087 (1.497) & $0.01(0.095)$ & $0.08(1.038)$ & $-0.001 \quad(-1.57)$ & $1.85(0.419)$ & $0.0069(0.408)$ \\
\hline \multirow{6}{*}{ S9 } & P1 & 0.94 (15.58) & $-0.11(-1.26)$ & $-0.03(-0.39)$ & $0.43(2.764)$ & $0.21(1.239)$ & $-0.000(-0.15)$ & $-4.27(-1.12)$ & $-0.095(-2.01)$ \\
\hline & P2 & $0.95(19.05)$ & $-0.21(-2.79)$ & $0.02(0.353)$ & $0.34(2.692)$ & $0.32(2.336)$ & $-0.003(-0.71)$ & 5.58 (1.748) & $-0.021(-0.52)$ \\
\hline & P3 & $0.86(13.92)$ & $-0.06(-0.69)$ & $0.06(0.719)$ & $0.11(0.746)$ & $0.25(1.463)$ & $-0.003(-0.55)$ & $-3.59(-0.92)$ & $-0.017(-0.35)$ \\
\hline & P4 & $1.02(12.17)$ & $-0.12(-0.96)$ & $-0.0(-0.08)$ & $-0.25(-1.20)$ & $0.27(1.177)$ & $-0.011(-1.48)$ & $8.48(0.164)$ & $-0.019(-0.37)$ \\
\hline & P5 & $1.41(12.54)$ & $0.07(0.422)$ & $0.49(2.811)$ & $-0.01 \quad(-0.05)$ & $-0.06(-0.21)$ & $0.03(2.462)$ & $-1.65(-0.23)$ & $-0.021(-0.43)$ \\
\hline & P-full & $1.05(34.16)$ & $-0.08(-1.83)$ & 0.07 (1.668) & $0.09(1.200)$ & $0.22(2.607)$ & 0.0025 & $-3.53(-0.18)$ & $-0.045(-2.03)$ \\
\hline \multirow{6}{*}{$\mathrm{S} 10$} & P1 & $0.92(33.36)$ & $0.25(5.241)$ & $-0.34(-5.01)$ & $-0.20(-1.89)$ & $0.25(2.895)$ & $-0.000(-0.11)$ & $-2.09(-0.40)$ & $0.0058(0.261)$ \\
\hline & P2 & $0.97(26.06)$ & $0.56(8.764)$ & $-0.37(-4.00)$ & $-0.26(-1.83)$ & $0.14(1.252)$ & $-0.000(-0.65)$ & $4.30(0.061)$ & $0.0089(0.336)$ \\
\hline & P3 & 0.98 (21.75) & $0.77(9.840)$ & $-0.34(-3.00)$ & $-0.30(-1.73)$ & $0.00(0.040)$ & $0.0003(0.207)$ & $1.32(1.547)$ & $0.0039(0.132)$ \\
\hline & P4 & $1.01(19.50)$ & $0.85(9.451)$ & $-0.22(-1.73)$ & $-0.27(-1.35)$ & $-0.15(-0.90)$ & $-0.005(-2.83)$ & $-1.29(-1.33)$ & $0.0326(1.011)$ \\
\hline & P5 & $1.04(16.59)$ & $1.17(10.72)$ & $-0.35(-2.23)$ & $-0.23(-0.95)$ & $0.37(1.858)$ & $-0.006(-2.68)$ & $9.35(0.792)$ & $-0.011(-0.33)$ \\
\hline & P-full & $0.9(31.85)$ & $0.72(13.41)$ & $-0.32(-4.23)$ & $-0.25(-2.11)$ & $0.13(1.294)$ & $-0.002(-2.20)$ & $1.37(0.236)$ & $0.0147(0.701)$ \\
\hline \multirow{6}{*}{ S11 } & P1 & $0.91(30.31)$ & $0.06(1.312)$ & $-0.13(-1.74)$ & $0.01(0.081)$ & 0.37 (3.934) & $0.0004(0.412)$ & $7.22(1.272)$ & $-0.000(-0.01)$ \\
\hline & $\mathrm{P} 2$ & $0.98(31.37)$ & $0.15(2.901)$ & $-0.08(-1.06)$ & $0.016(0.137)$ & $0.28(2.800)$ & $0.0003(0.325)$ & $1.64(0.277)$ & $0.0017(0.073)$ \\
\hline & P3 & $1.04(31.50)$ & $0.21(3.744)$ & $0.02(0.274)$ & $-0.05(-0.35)$ & $0.06(0.581)$ & $-0.000(-0.27)$ & $6.19(0.986)$ & $0.0233(0.995)$ \\
\hline & P4 & $1.12(32.40)$ & $0.44(7.368)$ & $0.07(0.827)$ & $-0.08(-0.62)$ & $0.02(0.242)$ & $-0.001(-1.24)$ & $-3.81(-0.58)$ & $0.0110(0.508)$ \\
\hline & P5 & $1.00(18.85)$ & $0.51(5.568)$ & $0.54(4.087)$ & $0.13(0.635)$ & $-0.36(-2.15)$ & $-0.005(-2.87)$ & $-1.04(-0.10)$ & $-0.021(-0.65)$ \\
\hline & P-full & $1.01(43.19)$ & $0.28(6.834)$ & $0.08(1.412)$ & $0.01(0.051)$ & $0.08(1.040)$ & $-0.001 \quad(-1.59)$ & $1.97(0.446)$ & $0.0065(0.386)$ \\
\hline \multirow{5}{*}{ S12 } & P1 & $0.82(21.99)$ & $0.28(4.962)$ & $-0.14(-2.41)$ & $0.27(2.820)$ & $0.26(2.533)$ & $0.0025(0.713)$ & $6.77(2.809)$ & $0.0034(0.106)$ \\
\hline & P2 & $1.00(14.27)$ & $0.10(0.952)$ & $0.033(0.304)$ & $0.12(0.667)$ & $-0.43(-2.24)$ & $-0.000(-0.03)$ & $3.61(0.813)$ & $0.0337(0.738)$ \\
\hline & P3 & $1.06(24.79)$ & $0.38(5.813)$ & $-0.50(-7.61)$ & $-0.12(-1.17)$ & $-0.07(-0.60)$ & $-0.006(-1.58)$ & $2.81(1.052)$ & $0.0101 \quad(0.372)$ \\
\hline & P4 & $0.66(9.246)$ & $-0.12(-1.14)$ & $-0.14(-1.29)$ & $-0.32(-1.76)$ & $0.15(0.759)$ & $-0.000(-0.05)$ & $1.23(2.675)$ & $-0.057(-0.91)$ \\
\hline & P5 & $1.15(23.69)$ & $0.031(0.418)$ & $0.55(7.206)$ & $-0.17(-1.35)$ & $0.05(0.366)$ & 0.0071 & $-2.49(-0.81)$ & $-0.047(-1.73)$ \\
\hline
\end{tabular}


\begin{tabular}{l|l|l|l|l|l|l|l|l|l|l} 
P-full & $0.94(88.96)$ & $0.13(7.992)$ & $-0.07(-4.36)$ & $-0.03(-1.30)$ & $0.001(0.035)$ & $7.89(0.078)$ & $4.37(6.511)$ & $0.0005(0.065)$ \\
\hline
\end{tabular}

Table 3 (contd.): Slope coefficients and their t-stats for the Combined RFM Equation (18b):

$\boldsymbol{R F}_{2 b}: \boldsymbol{R}_{i, t}-\boldsymbol{R}_{f, t}=\beta_{i, m}\left(\boldsymbol{R}_{m, t}-\boldsymbol{R}_{f, t}\right)+\beta_{i, s} S M B_{t}+\beta_{i, h} H M L_{t}+\beta_{i, r} R M W_{t}+\beta_{i, c} C M A_{t}+\beta_{i, v}\left[\ln \left(v_{m, t} / v_{m, t-1}\right)\right]+\beta_{i, o}\left(t_{t}\right)^{2}+\beta_{i, l}\left(R_{i, t-1}\right)+e_{i t}$

\begin{tabular}{|c|c|c|c|c|c|c|c|c|c|}
\hline \multirow{2}{*}{$\begin{array}{c}\text { Sample } \\
\text { Portfolios }\end{array}$} & \multicolumn{9}{|c|}{ Slope coefficients across P1 to P-full } \\
\hline & $\begin{array}{c}\text { Sub } \\
\text { portfolios }\end{array}$ & $\beta_{i, m}$ & $\beta_{i, s}$ & $\beta_{i, h}$ & $\beta_{i, r}$ & $\beta_{i, c}$ & $\beta_{i, v}$ & $\beta_{i, o}$ & $\beta_{i, l}$ \\
\hline \multirow{6}{*}{ S13 } & $\mathrm{P} 1$ & $1.05(53.81)$ & $1.11(36.16)$ & $0.04(1.450)$ & $-0.22(-4.45)$ & $0.40(7.467)$ & $0.0044(2.348)$ & $1.57(1.260)$ & $0.0134(1.350)$ \\
\hline & $\mathrm{P} 2$ & $0.91(48.89)$ & $0.96(32.89)$ & $0.13(4.491)$ & $-0.01(-0.32)$ & $0.05(1.078)$ & $-0.001(-1.04)$ & $3.87(3.248)$ & $-0.024(-2.18)$ \\
\hline & P3 & $1.00(54.52)$ & $1.03(35.96)$ & $-0.06(-1.95)$ & $-0.25(-5.42)$ & $-0.49(-9.69)$ & $-0.000(-0.28)$ & $9.77(0.839)$ & $0.0179(1.807)$ \\
\hline & $\mathrm{P} 4$ & $0.94(47.94)$ & $0.06(2.029)$ & $-0.11(-3.40)$ & $-0.04(-0.91)$ & $0.55(10.36)$ & $-0.004(-2.35)$ & $2.42(1.934)$ & $0.0154(1.005)$ \\
\hline & P5 & $0.96(49.95)$ & $-0.004(-0.15)$ & $-0.03(-1.02)$ & $-0.01 \quad(-0.39)$ & $0.10(2.001)$ & $0.0020(1.126)$ & $3.45(2.831)$ & $-0.021(-1.39)$ \\
\hline & P6 & $1.00(43.99)$ & $0.13(3.801)$ & $-0.01 \quad(-0.21)$ & $-0.02(-0.42)$ & $-0.52(-8.45)$ & $0.0004(0.188)$ & $3.41(2.370)$ & $0.0187(1.169)$ \\
\hline \multirow{6}{*}{$\mathrm{S} 14$} & $\mathrm{P} 1$ & $1.13(32.08)$ & $1.21(22.07)$ & $0.17(3.150)$ & $-0.33(-3.63)$ & $0.22(2.314)$ & $0.0034(1.028)$ & $-2.15(-0.09)$ & $0.0001(0.009)$ \\
\hline & $\mathrm{P} 2$ & $0.92(32.73)$ & 0.94 (21.39) & $0.12(2.875)$ & $-0.05(-0.69)$ & $0.03(0.403)$ & $0.0015(0.589)$ & $4.54(2.538)$ & $-0.042(-2.55)$ \\
\hline & P3 & $1.0(29.22)$ & 0.97 (17.10) & $-0.006(-0.11)$ & $-0.00(-0.03)$ & $-0.49(-4.99)$ & $-0.000(-0.19)$ & $4.19(1.823)$ & $0.0489(2.528)$ \\
\hline & $\mathrm{P} 4$ & $1.04(20.44)$ & 0.17 (2.156) & $0.16(2.020)$ & $-0.38(-2.95)$ & $0.50(3.621)$ & $0.0056(1.168)$ & $2.70(0.084)$ & $-0.105(-3.34)$ \\
\hline & P5 & $0.92(46.94)$ & $0.02(0.835)$ & $0.16(5.292)$ & $0.02(0.446)$ & $-0.01(-0.22)$ & $0.0008(0.444)$ & $4.68(3.762)$ & $-0.022(-1.49)$ \\
\hline & P6 & $0.9(22.67)$ & 0.07 (1.032) & $-0.26(-3.84)$ & $0.008(0.078)$ & $-0.47(-3.96)$ & $-0.002(-0.62)$ & $3.16(1.143)$ & $0.0537(1.721)$ \\
\hline \multirow{6}{*}{ S15 } & $\mathrm{P} 1$ & $1.18(13.78)$ & $1.09(8.195)$ & $0.31 \quad(2.283)$ & $-0.47(-2.14)$ & $-0.37(-1.59)$ & $0.0019(0.239)$ & $2.2(0.423)$ & $0.0856(2.449)$ \\
\hline & $\mathrm{P} 2$ & $0.96(36.51)$ & $0.94(22.84)$ & 0.12 (2.809) & $-0.08(-1.22)$ & $-0.16(-2.22)$ & $-0.000(-0.31)$ & $3.94(2.348)$ & $0.0170(1.136)$ \\
\hline & P3 & $0.99(20.41)$ & $1.0(13.99)$ & $-0.16(-2.08)$ & $-0.11(-0.91)$ & $-0.06(-0.48)$ & $-0.002(-0.55)$ & $3.56(1.154)$ & $-0.005(-0.20)$ \\
\hline & $\mathrm{P} 4$ & $1.2(13.90)$ & $-0.0(-0.43)$ & 0.38 (2.610) & $-0.45(-1.87)$ & $-0.50(-1.96)$ & $0.0231(2.667)$ & $2.27(0.388)$ & $-0.000(-0.01)$ \\
\hline & P5 & $0.95(35.06)$ & 0.07 (1.693) & 0.055 (1.298) & 0.07 (1.062) & $0.05(0.798)$ & $-0.000(-0.18)$ & $5.1(2.971)$ & $-0.020(-1.00)$ \\
\hline & P6 & $0.94(16.50)$ & $0.31(3.576)$ & $-0.25(-2.76)$ & $0.05(0.372)$ & $-0.09(-0.60)$ & $-0.006(-1.24)$ & $1.93(0.538)$ & $0.0497(1.258)$ \\
\hline \multirow{6}{*}{ S16 } & $\mathrm{P} 1$ & $1.0(61.70)$ & $1.07(42.27)$ & $-0.12(-4.83)$ & $-0.63(-15.0)$ & $-0.02(-0.36)$ & $-0.001(-1.11)$ & $1.2(1.267)$ & $0.0048(0.579)$ \\
\hline & $\mathrm{P} 2$ & $0.93(47.41)$ & 0.96 (31.17) & $0.16(5.123)$ & 0.07 (1.392) & $-0.07(-1.21)$ & $0.0007(0.403)$ & $3.11(2.481)$ & $-0.007(-0.67)$ \\
\hline & P3 & $1.01(45.20)$ & $1.11(31.73)$ & $0.11(3.213)$ & $0.32(5.495)$ & $-0.16(-2.56)$ & $0.0011(0.516)$ & $2.21(1.546)$ & $0.0305(2.448)$ \\
\hline & $\mathrm{P} 4$ & $0.9(36.36)$ & $0.09(2.381)$ & 0.07 (1.688) & $-0.82(-11.9)$ & $-0.15(-2.04)$ & $0.0036(1.437)$ & $3.2(1.936)$ & 0.0267 (1.591) \\
\hline & P5 & $1.03(54.36)$ & $0.04(1.384)$ & 0.08 (2.848) & $-0.01 \quad(-0.24)$ & $-0.06(-1.21)$ & $-0.001(-1.03)$ & 2.75 (2.299) & $0.0124(0.926)$ \\
\hline & P6 & $0.94(59.62)$ & $0.05(2.263)$ & $-0.16(-6.40)$ & $0.25(6.258)$ & $0.02(0.415)$ & $0.0005(0.383)$ & $3.72(3.723)$ & $-0.020(-1.52)$ \\
\hline \multirow{6}{*}{$\mathrm{S} 17$} & $\mathrm{P} 1$ & $1.2(24.88)$ & $1.11(14.61)$ & $0.003(0.041)$ & $-0.48(-3.82)$ & $-0.23(-1.72)$ & $0.0080(1.719)$ & $2.1(0.680)$ & $0.0233(1.084)$ \\
\hline & $\mathrm{P} 2$ & $0.99(42.60)$ & $0.96(26.44)$ & $0.12(3.432)$ & $-0.12(-2.04)$ & $-0.24(-3.77)$ & $-0.000(-0.23)$ & $3.69(2.507)$ & $0.0068(0.534)$ \\
\hline & P3 & $0.94(21.82)$ & $0.9(14.33)$ & $0.02(0.222)$ & $-0.16(-1.47)$ & $-0.09(-0.78)$ & $-0.005(-1.40)$ & $6.70(0.245)$ & $0.0520(2.162)$ \\
\hline & $\mathrm{P} 4$ & $1.2(17.72)$ & $0.13(1.178)$ & $0.10(0.915)$ & $-0.33(-1.84)$ & $-0.33(-1.70)$ & $0.0089(1.334)$ & $-3.08(-0.69)$ & $-0.003(-0.08)$ \\
\hline & P5 & 0.95 (37.59) & $0.11(2.928)$ & $-0.04(-1.11)$ & $0.07(1.196)$ & $-0.02(-0.28)$ & $0.0014(0.589)$ & $4.91(3.052)$ & $-0.023(-1.18)$ \\
\hline & P6 & $0.92(17.33)$ & $0.07(0.875)$ & $-0.02(-0.19)$ & $0.008(0.059)$ & $-0.16(-1.13)$ & $-0.004(-0.98)$ & $5.65(1.665)$ & $0.0489(1.257)$ \\
\hline \multirow{4}{*}{ S18 } & $\mathrm{P} 1$ & $0.99(53.56)$ & $1.08(37.56)$ & $-0.35(-12.4)$ & $-0.36(-7.61)$ & $-0.21(-4.25)$ & $-0.001(-0.62)$ & $2.89(2.481)$ & $0.0136(1.356)$ \\
\hline & $\mathrm{P} 2$ & $0.9(54.67)$ & $1.0(38.07)$ & 0.08 (3.004) & $-0.05(-1.21)$ & $-0.05(-1.26)$ & $-0.000(-0.06)$ & 2.33 (2.139) & $-0.001(-0.11)$ \\
\hline & P3 & $1.01(53.86)$ & 0.99 (33.69) & $0.54(18.30)$ & $0.02(0.351)$ & $0.13(2.693)$ & $0.0017(0.999)$ & $1.08(0.906)$ & $-0.004(-0.51)$ \\
\hline & $\mathrm{P} 4$ & $0.95(53.86)$ & $0.06(2.198)$ & $-0.34(-12.4)$ & $0.07(0.833)$ & $0.02(0.584)$ & $0.0006(0.377)$ & $4.20(3.747)$ & $-0.003(-0.23)$ \\
\hline
\end{tabular}


Table 4a: Correlations and Sum of Squared Errors (SSE) between Actual ${ }_{1}$ Average Returns (calculated as ratios of average prices) and Estimated Average Returns across P1 to P-full:

\begin{tabular}{|c|c|c|c|c|c|c|c|c|c|c|c|c|c|c|c|}
\hline \multirow{2}{*}{$\begin{array}{c}\text { Sample } \\
\text { Portfolios }\end{array}$} & \multicolumn{3}{|c|}{ CAPM } & \multicolumn{3}{|c|}{ FF3F } & \multicolumn{3}{|c|}{ FF5F } & \multicolumn{3}{|c|}{$\mathrm{RF}_{1 \mathrm{a}}$} & \multicolumn{3}{|c|}{$\mathrm{RF}_{1 \mathrm{~b}}$} \\
\hline & Correlation & t-stats & SSE & Correlation & t-stats & SSE & Correlation & t-stats & SSE & Correlation & t-stats & SSE & Correlation & t-stats & SSE \\
\hline $\mathrm{S} 1$ & $-81.74 \%$ & -2.46 & $1.01 \mathrm{E}-04$ & $-81.68 \%$ & -2.45 & $1.27 \mathrm{E}-04$ & $-55.51 \%$ & -1.16 & $9.22 \mathrm{E}-05$ & $99.58 \%$ & 18.77 & $1.25 \mathrm{E}-06$ & $99.57 \%$ & 18.72 & $1.22 \mathrm{E}-06$ \\
\hline $\mathrm{S} 2$ & $-79.49 \%$ & -2.27 & $9.59 \mathrm{E}-05$ & $-81.55 \%$ & -2.44 & $1.19 \mathrm{E}-04$ & $-60.03 \%$ & -1.30 & $9.53 \mathrm{E}-05$ & $99.58 \%$ & 18.95 & $1.21 \mathrm{E}-06$ & $99.58 \%$ & 18.94 & $1.19 \mathrm{E}-06$ \\
\hline S3 & $-79.36 \%$ & -2.26 & $1.20 \mathrm{E}-04$ & $-68.78 \%$ & -1.64 & $1.15 \mathrm{E}-04$ & $77.48 \%$ & 2.12 & $5.40 \mathrm{E}-05$ & $99.36 \%$ & 15.25 & $1.20 \mathrm{E}-06$ & $99.36 \%$ & 15.24 & $1.23 \mathrm{E}-06$ \\
\hline $\mathrm{S} 4$ & $-77.19 \%$ & -2.10 & $1.08 \mathrm{E}-04$ & $-60.82 \%$ & -1.33 & $1.05 \mathrm{E}-04$ & $83.23 \%$ & 2.60 & $5.14 \mathrm{E}-05$ & $99.36 \%$ & 15.27 & $1.22 \mathrm{E}-06$ & $99.36 \%$ & 15.26 & $1.24 \mathrm{E}-06$ \\
\hline S5 & $46.82 \%$ & 0.92 & $2.31 \mathrm{E}-07$ & $44.88 \%$ & 0.87 & $2.24 \mathrm{E}-07$ & $72.15 \%$ & 1.80 & $1.61 \mathrm{E}-07$ & $98.91 \%$ & 11.65 & $1.45 \mathrm{E}-08$ & $98.92 \%$ & 11.67 & $1.38 \mathrm{E}-08$ \\
\hline S6 & $52.44 \%$ & 1.07 & $9.67 \mathrm{E}-07$ & $50.13 \%$ & 1.00 & $7.77 \mathrm{E}-07$ & $72.49 \%$ & 1.82 & $4.96 \mathrm{E}-07$ & $98.90 \%$ & 11.60 & $9.18 \mathrm{E}-09$ & $98.90 \%$ & 11.57 & 8.93E-09 \\
\hline S7 & $33.23 \%$ & 0.61 & $2.19 \mathrm{E}-07$ & $30.46 \%$ & 0.55 & $1.78 \mathrm{E}-07$ & $49.76 \%$ & 0.99 & $7.41 \mathrm{E}-08$ & $93.80 \%$ & 4.69 & $1.08 \mathrm{E}-08$ & $93.73 \%$ & 4.66 & 7.84E-09 \\
\hline S8 & $-75.70 \%$ & -2.01 & $5.35 \mathrm{E}-07$ & $-65.33 \%$ & -1.49 & $3.37 \mathrm{E}-07$ & $3.23 \%$ & 0.06 & $9.99 \mathrm{E}-08$ & $91.13 \%$ & 3.83 & $1.89 \mathrm{E}-08$ & $91.11 \%$ & 3.83 & $1.86 \mathrm{E}-08$ \\
\hline S9 & $-46.40 \%$ & -0.91 & $4.16 \mathrm{E}-05$ & $-43.23 \%$ & -0.83 & $4.84 \mathrm{E}-05$ & $58.83 \%$ & 1.26 & $2.60 \mathrm{E}-05$ & $99.50 \%$ & 17.27 & $5.26 \mathrm{E}-07$ & $99.50 \%$ & 17.26 & $5.19 \mathrm{E}-07$ \\
\hline S10 & $7.28 \%$ & 0.13 & $2.95 \mathrm{E}-07$ & $-0.01 \%$ & -0.00 & $2.92 \mathrm{E}-07$ & $37.54 \%$ & 0.70 & $1.70 \mathrm{E}-07$ & $96.00 \%$ & 5.94 & $1.70 \mathrm{E}-08$ & $95.95 \%$ & 5.90 & $1.32 \mathrm{E}-08$ \\
\hline S11 & $-31.71 \%$ & -0.58 & $3.36 \mathrm{E}-07$ & $-5.48 \%$ & -0.09 & $2.01 \mathrm{E}-07$ & $63.98 \%$ & 1.44 & $7.88 \mathrm{E}-08$ & $94.81 \%$ & 5.16 & $1.49 \mathrm{E}-08$ & $94.79 \%$ & 5.16 & $1.45 \mathrm{E}-08$ \\
\hline S12 & $-76.81 \%$ & -2.08 & $8.86 \mathrm{E}-05$ & $-81.77 \%$ & -2.46 & $9.39 \mathrm{E}-05$ & $-17.56 \%$ & -0.31 & $8.37 \mathrm{E}-05$ & $99.69 \%$ & 21.82 & $2.50 \mathrm{E}-07$ & $99.69 \%$ & 21.82 & $2.49 \mathrm{E}-07$ \\
\hline S13 & $34.61 \%$ & 0.74 & $5.29 \mathrm{E}-05$ & $54.86 \%$ & 1.14 & $2.91 \mathrm{E}-05$ & $86.78 \%$ & 3.03 & $2.97 \mathrm{E}-05$ & $99.33 \%$ & 14.88 & $2.36 \mathrm{E}-07$ & $99.33 \%$ & 17.20 & $3.16 \mathrm{E}-07$ \\
\hline S14 & $23.42 \%$ & 0.48 & $5.46 \mathrm{E}-05$ & $39.60 \%$ & 0.75 & $3.11 \mathrm{E}-05$ & $65.04 \%$ & 1.48 & $3.50 \mathrm{E}-05$ & $99.00 \%$ & 12.15 & $2.90 \mathrm{E}-07$ & $99.01 \%$ & 14.14 & $4.36 \mathrm{E}-07$ \\
\hline S15 & $-22.79 \%$ & -0.47 & $6.01 \mathrm{E}-05$ & $19.88 \%$ & 0.35 & $3.52 \mathrm{E}-05$ & $89.06 \%$ & 3.39 & $3.94 \mathrm{E}-05$ & $99.76 \%$ & 24.94 & $1.41 \mathrm{E}-07$ & $99.77 \%$ & 29.43 & $2.94 \mathrm{E}-07$ \\
\hline S16 & $-15.68 \%$ & -0.32 & $5.78 \mathrm{E}-05$ & $27.98 \%$ & 0.50 & $3.45 \mathrm{E}-05$ & $93.81 \%$ & 4.69 & $2.90 \mathrm{E}-05$ & $99.61 \%$ & 19.52 & $2.88 \mathrm{E}-07$ & $99.61 \%$ & 22.65 & $3.77 \mathrm{E}-07$ \\
\hline S17 & $-36.48 \%$ & -0.78 & $5.33 \mathrm{E}-05$ & $0.40 \%$ & 0.01 & $3.95 \mathrm{E}-05$ & $65.85 \%$ & 1.52 & $3.54 \mathrm{E}-05$ & $99.59 \%$ & 19.18 & $2.99 \mathrm{E}-07$ & $99.61 \%$ & 22.66 & $3.76 \mathrm{E}-07$ \\
\hline S18 & $35.51 \%$ & 0.76 & $4.71 \mathrm{E}-05$ & $55.35 \%$ & 1.15 & $2.18 \mathrm{E}-05$ & $74.98 \%$ & 1.96 & $2.61 \mathrm{E}-05$ & $99.03 \%$ & 12.34 & $2.60 \mathrm{E}-07$ & $99.05 \%$ & 14.41 & $3.45 \mathrm{E}-07$ \\
\hline S19 & $27.37 \%$ & 0.49 & 7.37E-07 & $28.12 \%$ & 0.51 & $8.28 \mathrm{E}-07$ & & & & $99.32 \%$ & 14.77 & $9.89 \mathrm{E}-09$ & $99.33 \%$ & 14.88 & $1.13 \mathrm{E}-08$ \\
\hline $\mathrm{S} 20$ & $65.35 \%$ & 1.50 & $2.18 \mathrm{E}-07$ & $75.89 \%$ & 2.02 & $2.73 \mathrm{E}-07$ & & & & $96.31 \%$ & 6.20 & $2.86 \mathrm{E}-08$ & $96.29 \%$ & 6.18 & $2.98 \mathrm{E}-08$ \\
\hline $\mathrm{S} 21$ & $39.22 \%$ & 0.74 & $9.64 \mathrm{E}-05$ & $17.13 \%$ & 0.30 & $1.12 \mathrm{E}-04$ & & & & $99.90 \%$ & 39.54 & $7.50 \mathrm{E}-07$ & $99.90 \%$ & 39.54 & $7.46 \mathrm{E}-07$ \\
\hline
\end{tabular}


Table 4b: Correlations and Sum of Squared Errors (SSE) between Actual 2 Average Returns (calculated as averages of time series of continuous returns) and Estimated Average Returns across P1 to P-full:

\begin{tabular}{|c|c|c|c|c|c|c|c|c|c|c|c|c|c|c|c|}
\hline \multirow{2}{*}{$\begin{array}{c}\text { Sample } \\
\text { Portfolios }\end{array}$} & \multicolumn{3}{|c|}{ CAPM } & \multicolumn{3}{|c|}{ FF3F } & \multicolumn{3}{|c|}{ FF5F } & \multicolumn{3}{|c|}{$\mathrm{RF}_{1 \mathrm{a}}$} & \multicolumn{3}{|c|}{$\mathrm{RF}_{1 \mathrm{~b}}$} \\
\hline & Correlation & t-stats & SSE & Correlation & t-stats & SSE & Correlation & t-stats & SSE & Correlation & t-stats & SSE & Correlation & t-stats & SSE \\
\hline $\mathrm{S} 1$ & $-81.86 \%$ & -2.47 & $8.66 \mathrm{E}-05$ & $-82.50 \%$ & -2.53 & $1.13 \mathrm{E}-04$ & $-57.90 \%$ & -1.23 & 7.92E-05 & $99.22 \%$ & 13.78 & $1.62 \mathrm{E}-06$ & $99.22 \%$ & 13.76 & $1.66 \mathrm{E}-06$ \\
\hline $\mathrm{S} 2$ & $-79.65 \%$ & -2.28 & $8.08 \mathrm{E}-05$ & $-82.52 \%$ & -2.53 & $1.03 \mathrm{E}-04$ & $-62.44 \%$ & -1.38 & 8.33E-05 & $99.23 \%$ & 13.92 & $1.23 \mathrm{E}-06$ & $99.23 \%$ & 13.91 & $1.24 \mathrm{E}-06$ \\
\hline S3 & $-79.85 \%$ & -2.30 & $1.02 \mathrm{E}-04$ & $-69.26 \%$ & -1.66 & $9.71 \mathrm{E}-05$ & $77.72 \%$ & 2.14 & 4.09E-05 & $99.23 \%$ & 13.86 & $2.29 \mathrm{E}-06$ & $99.23 \%$ & 13.86 & 2.19E-06 \\
\hline $\mathrm{S} 4$ & $-77.69 \%$ & -2.14 & $8.70 \mathrm{E}-05$ & $-61.39 \%$ & -1.35 & 8.34E-05 & $83.47 \%$ & 2.62 & $3.85 \mathrm{E}-05$ & $99.23 \%$ & 13.87 & $2.22 \mathrm{E}-06$ & $99.23 \%$ & 13.87 & $2.16 \mathrm{E}-06$ \\
\hline S5 & $43.02 \%$ & 0.83 & $2.48 \mathrm{E}-07$ & $41.67 \%$ & 0.79 & $2.37 \mathrm{E}-07$ & $75.61 \%$ & 2.00 & $1.64 \mathrm{E}-07$ & $99.40 \%$ & 15.78 & 7.33E-09 & $99.41 \%$ & 15.81 & 7.05E-09 \\
\hline S6 & $48.78 \%$ & 0.97 & $1.05 \mathrm{E}-06$ & $47.15 \%$ & 0.93 & $8.45 \mathrm{E}-07$ & $75.42 \%$ & 1.99 & 5.33E-07 & $99.40 \%$ & 15.71 & 8.72E-09 & $99.39 \%$ & 15.66 & 7.70E-09 \\
\hline S7 & $34.54 \%$ & 0.64 & $1.85 \mathrm{E}-07$ & $32.29 \%$ & 0.59 & 2.33E-07 & $48.46 \%$ & 0.96 & $1.07 \mathrm{E}-07$ & $93.96 \%$ & 4.76 & $2.35 \mathrm{E}-08$ & $93.90 \%$ & 4.73 & $1.21 \mathrm{E}-08$ \\
\hline S8 & $-73.59 \%$ & -1.88 & $5.12 \mathrm{E}-07$ & $-62.69 \%$ & -1.39 & 3.39E-07 & $7.16 \%$ & 0.12 & $1.00 \mathrm{E}-07$ & $90.74 \%$ & 3.74 & $2.07 \mathrm{E}-08$ & $90.72 \%$ & 3.73 & $1.91 \mathrm{E}-08$ \\
\hline S9 & $-53.91 \%$ & -1.11 & $3.38 \mathrm{E}-05$ & $-49.62 \%$ & -0.99 & $4.08 \mathrm{E}-05$ & $56.43 \%$ & 1.18 & $2.12 \mathrm{E}-05$ & $99.03 \%$ & 12.36 & $1.27 \mathrm{E}-06$ & $99.03 \%$ & 12.37 & $1.29 \mathrm{E}-06$ \\
\hline S10 & $8.35 \%$ & 0.15 & $2.59 \mathrm{E}-07$ & $1.32 \%$ & 0.02 & $3.43 \mathrm{E}-07$ & $35.92 \%$ & 0.67 & $2.00 \mathrm{E}-07$ & $96.02 \%$ & 5.96 & $2.89 \mathrm{E}-08$ & $95.97 \%$ & 5.91 & $1.68 \mathrm{E}-08$ \\
\hline S11 & $-28.20 \%$ & -0.51 & $3.21 \mathrm{E}-07$ & $-1.78 \%$ & -0.03 & $2.11 \mathrm{E}-07$ & $65.80 \%$ & 1.51 & 8.48E-08 & $95.42 \%$ & 5.52 & $1.76 \mathrm{E}-08$ & $95.40 \%$ & 5.51 & $1.58 \mathrm{E}-08$ \\
\hline S12 & $-61.01 \%$ & -1.33 & $6.68 \mathrm{E}-05$ & $-70.00 \%$ & -1.70 & $7.19 \mathrm{E}-05$ & $-10.29 \%$ & -0.18 & $6.30 \mathrm{E}-05$ & $98.12 \%$ & 8.81 & $2.66 \mathrm{E}-06$ & $98.12 \%$ & 8.81 & 2.67E-06 \\
\hline S13 & $43.03 \%$ & 0.95 & $3.55 \mathrm{E}-05$ & $62.87 \%$ & 1.40 & $1.72 \mathrm{E}-05$ & $89.39 \%$ & 3.45 & $1.78 \mathrm{E}-05$ & $98.73 \%$ & 10.77 & $2.97 \mathrm{E}-06$ & $98.74 \%$ & 12.46 & $3.29 \mathrm{E}-06$ \\
\hline S14 & $17.83 \%$ & 0.36 & $4.07 \mathrm{E}-05$ & $31.04 \%$ & 0.57 & $2.33 \mathrm{E}-05$ & $55.67 \%$ & 1.16 & $2.55 \mathrm{E}-05$ & $97.49 \%$ & 7.58 & $2.44 \mathrm{E}-06$ & $97.50 \%$ & 8.77 & $2.94 \mathrm{E}-06$ \\
\hline S15 & $-27.06 \%$ & -0.56 & $4.45 \mathrm{E}-05$ & $16.07 \%$ & 0.28 & $2.57 \mathrm{E}-05$ & $88.51 \%$ & 3.29 & $2.62 \mathrm{E}-05$ & $99.00 \%$ & 12.18 & $2.31 \mathrm{E}-06$ & $99.07 \%$ & 14.59 & $2.96 \mathrm{E}-06$ \\
\hline S16 & $-12.61 \%$ & -0.25 & $4.63 \mathrm{E}-05$ & $30.93 \%$ & 0.56 & $2.67 \mathrm{E}-05$ & $93.58 \%$ & 4.60 & $2.01 \mathrm{E}-05$ & $99.66 \%$ & 20.98 & $1.83 \mathrm{E}-06$ & $99.67 \%$ & 24.40 & $2.11 \mathrm{E}-06$ \\
\hline S17 & $-34.59 \%$ & -0.74 & $3.97 \mathrm{E}-05$ & $3.23 \%$ & 0.06 & $3.01 \mathrm{E}-05$ & $68.76 \%$ & 1.64 & $2.38 \mathrm{E}-05$ & $99.62 \%$ & 19.69 & $2.03 \mathrm{E}-06$ & $99.63 \%$ & 23.34 & $2.43 \mathrm{E}-06$ \\
\hline S18 & $43.75 \%$ & 0.97 & $3.68 \mathrm{E}-05$ & $63.49 \%$ & 1.42 & $1.48 \mathrm{E}-05$ & $80.35 \%$ & 2.34 & $1.80 \mathrm{E}-05$ & $96.63 \%$ & 6.50 & $1.81 \mathrm{E}-06$ & $96.68 \%$ & 7.57 & 2.07E-06 \\
\hline S19 & $25.07 \%$ & 0.45 & 7.72E-07 & $25.78 \%$ & 0.46 & 8.72E-07 & & & & $99.04 \%$ & 12.41 & $1.33 \mathrm{E}-08$ & $99.05 \%$ & 12.49 & $1.39 \mathrm{E}-08$ \\
\hline S20 & $64.65 \%$ & 1.47 & $1.97 \mathrm{E}-07$ & $76.18 \%$ & 2.04 & $2.48 \mathrm{E}-07$ & & & & $96.50 \%$ & 6.37 & $2.27 \mathrm{E}-08$ & $96.48 \%$ & 6.36 & $2.37 \mathrm{E}-08$ \\
\hline $\mathrm{S} 21$ & $42.11 \%$ & 0.80 & $8.41 \mathrm{E}-05$ & $40.19 \%$ & 0.76 & $3.52 \mathrm{E}-05$ & & & & $96.97 \%$ & 6.88 & $4.66 \mathrm{E}-05$ & $96.97 \%$ & 6.88 & $4.62 \mathrm{E}-05$ \\
\hline
\end{tabular}


Table 4c: Correlations and Sum of Squared Errors (SSE) between Actual Average Change in Volumes (calculated as ratios of average volumes) and Estimated Average Change in Volumes across P1 to P-full:

\begin{tabular}{|c|c|c|c|c|c|c|c|}
\hline \multirow{2}{*}{ Names } & \multicolumn{3}{|c|}{ LW2F } & \multicolumn{3}{c|}{$\mathrm{RF}_{1 \mathrm{c}}$} & $\begin{array}{c}\text { Percentage improvement } \\
\text { in SSE between } \mathrm{RF}_{1 \mathrm{c}} \text { and } \\
\text { LW2F }\end{array}$ \\
\cline { 2 - 7 } & Correlation & t-stats & SSE & Correlation & t-stats & SSE & $\begin{array}{c} \\
\text { S1 }\end{array}$ \\
& $75.43 \%$ & 1.99 & $5.25 \mathrm{E}-02$ & $99.12 \%$ & 12.94 & $7.12 \mathrm{E}-04$ & $98.64 \%$ \\
S2 & $75.43 \%$ & 1.99 & $5.25 \mathrm{E}-02$ & $99.13 \%$ & 13.05 & $6.79 \mathrm{E}-04$ & $98.71 \%$ \\
S3 & $-28.30 \%$ & -0.51 & $2.78 \mathrm{E}-02$ & $99.50 \%$ & 17.27 & $4.74 \mathrm{E}-04$ & $98.29 \%$ \\
S4 & $-28.30 \%$ & -0.51 & $2.78 \mathrm{E}-02$ & $99.45 \%$ & 16.52 & $3.35 \mathrm{E}-04$ & $98.79 \%$ \\
S5 & $99.26 \%$ & 14.12 & $7.87 \mathrm{E}-03$ & $98.87 \%$ & 11.42 & $2.39 \mathrm{E}-04$ & $96.96 \%$ \\
S6 & $99.24 \%$ & 14.01 & $7.87 \mathrm{E}-03$ & $98.48 \%$ & 9.82 & $5.15 \mathrm{E}-04$ & $93.45 \%$ \\
S7 & $97.66 \%$ & 7.86 & $4.49 \mathrm{E}-02$ & $94.49 \%$ & 5.00 & $6.72 \mathrm{E}-03$ & $85.03 \%$ \\
S8 & $96.39 \%$ & 6.27 & $1.00 \mathrm{E}-01$ & $98.29 \%$ & 9.24 & $1.64 \mathrm{E}-02$ & $83.57 \%$ \\
S9 & $47.75 \%$ & 0.94 & $7.24 \mathrm{E}-03$ & $90.88 \%$ & 3.77 & $1.65 \mathrm{E}-03$ & $77.18 \%$ \\
S10 & $97.98 \%$ & 8.48 & $3.60 \mathrm{E}-02$ & $99.99 \%$ & 120.27 & $1.19 \mathrm{E}-04$ & $99.67 \%$ \\
S11 & $97.71 \%$ & 7.96 & $3.74 \mathrm{E}-02$ & $94.78 \%$ & 5.15 & $5.25 \mathrm{E}-03$ & $85.95 \%$ \\
S19 & $-76.73 \%$ & -2.07 & $2.19 \mathrm{E}-02$ & $99.79 \%$ & 26.54 & $7.49 \mathrm{E}-05$ & $99.66 \%$ \\
S20 & $-76.68 \%$ & -2.07 & $1.84 \mathrm{E}-02$ & $91.06 \%$ & 3.82 & $2.90 \mathrm{E}-03$ & $84.23 \%$ \\
S21 & $28.70 \%$ & 0.52 & $3.90 \mathrm{E}-01$ & $85.49 \%$ & 2.85 & $1.33 \mathrm{E}-01$ & $65.91 \%$ \\
& & & & & & & \\
\hline
\end{tabular}


Table 5: Correlations between the Actual and the Estimated Continuous Returns:

\begin{tabular}{|c|c|c|c|c|c|c|c|}
\hline \multirow[b]{2}{*}{ Sample } & \multirow[b]{2}{*}{ Models } & \multicolumn{6}{|c|}{ Correlations of Estimated Returns with Actual Returns } \\
\hline & & P1 & $\mathrm{P} 2$ & P3 & P4 & P5 & $\begin{array}{c}\text { P-full or } \\
\text { P6 }\end{array}$ \\
\hline \multirow{5}{*}{ S1 } & CAPM & $83.77 \%$ & $86.53 \%$ & $92.09 \%$ & $89.16 \%$ & $89.04 \%$ & $98.49 \%$ \\
\hline & FF3F & $85.39 \%$ & $86.58 \%$ & $92.44 \%$ & $89.50 \%$ & $91.93 \%$ & $98.73 \%$ \\
\hline & FF5F & $86.26 \%$ & $87.21 \%$ & $92.72 \%$ & $90.07 \%$ & $92.04 \%$ & $98.76 \%$ \\
\hline & $\mathrm{RF}_{2 \mathrm{a}}$ & $86.04 \%$ & $87.21 \%$ & $92.78 \%$ & $89.65 \%$ & $91.82 \%$ & $98.76 \%$ \\
\hline & $\mathrm{RF}_{2 \mathrm{~b}}$ & $86.76 \%$ & $87.59 \%$ & $93.03 \%$ & $90.25 \%$ & $91.95 \%$ & $98.80 \%$ \\
\hline \multirow{5}{*}{$\mathrm{S} 2$} & CAPM & $77.60 \%$ & $84.72 \%$ & $92.12 \%$ & $89.99 \%$ & $89.33 \%$ & $97.67 \%$ \\
\hline & FF3F & $80.42 \%$ & $85.14 \%$ & $92.44 \%$ & $90.00 \%$ & $91.61 \%$ & $97.90 \%$ \\
\hline & FF5F & $82.29 \%$ & $86.91 \%$ & $92.51 \%$ & $90.06 \%$ & $91.57 \%$ & $98.06 \%$ \\
\hline & $\mathrm{RF}_{2 \mathrm{a}}$ & $81.53 \%$ & $86.23 \%$ & $92.62 \%$ & $90.17 \%$ & $91.62 \%$ & $98.00 \%$ \\
\hline & $\mathrm{RF}_{2 \mathrm{~b}}$ & $82.85 \%$ & $87.41 \%$ & $92.68 \%$ & $90.23 \%$ & $91.64 \%$ & $98.13 \%$ \\
\hline \multirow{5}{*}{ S3 } & CAPM & $84.86 \%$ & $88.35 \%$ & $93.32 \%$ & $90.88 \%$ & $89.32 \%$ & $98.83 \%$ \\
\hline & FF3F & $86.51 \%$ & $88.36 \%$ & $93.63 \%$ & $90.90 \%$ & $93.36 \%$ & $99.11 \%$ \\
\hline & FF5F & $87.67 \%$ & $89.04 \%$ & $93.88 \%$ & $91.34 \%$ & $94.25 \%$ & $99.13 \%$ \\
\hline & $\mathrm{RF}_{2 \mathrm{a}}$ & $87.84 \%$ & $89.08 \%$ & $93.88 \%$ & $91.06 \%$ & $93.62 \%$ & $99.13 \%$ \\
\hline & $\mathrm{RF}_{2 \mathrm{~b}}$ & $88.70 \%$ & $89.60 \%$ & $94.09 \%$ & $91.55 \%$ & $94.38 \%$ & $99.16 \%$ \\
\hline \multirow{5}{*}{ S4 } & CAPM & $79.08 \%$ & $86.66 \%$ & $93.41 \%$ & $91.28 \%$ & $89.16 \%$ & $97.68 \%$ \\
\hline & FF3F & $82.05 \%$ & $86.86 \%$ & $93.76 \%$ & $91.52 \%$ & $92.74 \%$ & $98.19 \%$ \\
\hline & FF5F & $84.23 \%$ & $88.49 \%$ & $93.81 \%$ & $91.56 \%$ & $93.32 \%$ & $98.30 \%$ \\
\hline & $\mathrm{RF}_{2 \mathrm{a}}$ & $83.67 \%$ & $87.62 \%$ & $93.79 \%$ & $91.73 \%$ & $93.24 \%$ & $98.28 \%$ \\
\hline & $\mathrm{RF}_{2 \mathrm{~b}}$ & $85.11 \%$ & $88.95 \%$ & $93.87 \%$ & $91.79 \%$ & $93.63 \%$ & $98.38 \%$ \\
\hline \multirow{5}{*}{ S5 } & CAPM & $77.83 \%$ & $85.85 \%$ & $88.97 \%$ & $87.02 \%$ & $76.86 \%$ & $97.84 \%$ \\
\hline & FF3F & $80.28 \%$ & $86.42 \%$ & $89.07 \%$ & $87.46 \%$ & $80.74 \%$ & $98.09 \%$ \\
\hline & FF5F & $81.23 \%$ & $86.46 \%$ & $89.89 \%$ & $88.85 \%$ & $82.68 \%$ & $98.25 \%$ \\
\hline & $\mathrm{RF}_{2 \mathrm{a}}$ & $83.19 \%$ & $86.79 \%$ & $89.41 \%$ & $88.40 \%$ & $81.45 \%$ & $98.20 \%$ \\
\hline & $\mathrm{RF}_{2 \mathrm{~b}}$ & $84.28 \%$ & $86.82 \%$ & $90.38 \%$ & $89.79 \%$ & $83.58 \%$ & $98.37 \%$ \\
\hline \multirow{5}{*}{ S6 } & CAPM & $69.39 \%$ & $89.32 \%$ & $88.98 \%$ & $86.65 \%$ & $77.87 \%$ & $97.16 \%$ \\
\hline & FF3F & $73.02 \%$ & $89.62 \%$ & $89.68 \%$ & $86.68 \%$ & $80.59 \%$ & $97.38 \%$ \\
\hline & FF5F & $75.33 \%$ & $89.93 \%$ & $91.73 \%$ & $87.04 \%$ & $81.46 \%$ & $97.44 \%$ \\
\hline & $\mathrm{RF}_{2 \mathrm{a}}$ & $75.89 \%$ & $89.81 \%$ & $89.80 \%$ & $87.24 \%$ & $81.08 \%$ & $97.33 \%$ \\
\hline & $\mathrm{RF}_{2 \mathrm{~b}}$ & $78.48 \%$ & $90.13 \%$ & $92.17 \%$ & $87.64 \%$ & $82.09 \%$ & $97.41 \%$ \\
\hline \multirow{5}{*}{ S7 } & CAPM & $95.98 \%$ & $93.78 \%$ & $92.97 \%$ & $90.77 \%$ & $86.32 \%$ & $93.81 \%$ \\
\hline & FF3F & $97.02 \%$ & $96.83 \%$ & $96.67 \%$ & $96.28 \%$ & $94.16 \%$ & $97.99 \%$ \\
\hline & FF5F & $97.46 \%$ & $96.94 \%$ & $97.01 \%$ & $96.50 \%$ & $94.50 \%$ & $98.21 \%$ \\
\hline & $\mathrm{RF}_{2 \mathrm{a}}$ & $97.09 \%$ & $96.86 \%$ & $96.67 \%$ & $96.57 \%$ & $94.99 \%$ & $98.10 \%$ \\
\hline & $\mathrm{RF}_{2 \mathrm{~b}}$ & $97.52 \%$ & $97.00 \%$ & $97.01 \%$ & $96.80 \%$ & $95.33 \%$ & $98.32 \%$ \\
\hline \multirow{5}{*}{ S8 } & CAPM & $95.33 \%$ & $97.10 \%$ & $96.74 \%$ & $96.72 \%$ & $91.55 \%$ & $97.92 \%$ \\
\hline & FF3F & $95.36 \%$ & $97.39 \%$ & $97.35 \%$ & $97.85 \%$ & $95.67 \%$ & $98.83 \%$ \\
\hline & FF5F & $96.40 \%$ & $97.79 \%$ & $97.38 \%$ & $97.87 \%$ & $95.93 \%$ & $98.85 \%$ \\
\hline & $\mathrm{RF}_{2 \mathrm{a}}$ & $95.43 \%$ & $97.39 \%$ & $97.37 \%$ & $97.92 \%$ & $96.36 \%$ & $98.87 \%$ \\
\hline & $\mathrm{RF}_{2 \mathrm{~b}}$ & $96.56 \%$ & $97.80 \%$ & $97.40 \%$ & $97.95 \%$ & $96.65 \%$ & $98.89 \%$ \\
\hline \multirow{5}{*}{ S9 } & CAPM & $87.24 \%$ & $90.70 \%$ & $88.32 \%$ & $87.14 \%$ & $86.47 \%$ & $97.41 \%$ \\
\hline & FF3F & $87.66 \%$ & $91.73 \%$ & $88.61 \%$ & $87.23 \%$ & $87.90 \%$ & $97.60 \%$ \\
\hline & FF5F & $88.41 \%$ & $92.75 \%$ & $88.88 \%$ & $87.77 \%$ & $87.98 \%$ & $97.77 \%$ \\
\hline & $\mathrm{RF}_{2 \mathrm{a}}$ & $88.29 \%$ & $91.99 \%$ & $88.85 \%$ & $87.77 \%$ & $88.73 \%$ & $97.71 \%$ \\
\hline & $\mathrm{RF}_{2 \mathrm{~b}}$ & $89.19 \%$ & $92.78 \%$ & $89.12 \%$ & $88.14 \%$ & $88.73 \%$ & $97.86 \%$ \\
\hline \multirow{5}{*}{ S10 } & CAPM & $96.83 \%$ & $94.34 \%$ & $91.85 \%$ & $90.03 \%$ & $86.53 \%$ & $93.85 \%$ \\
\hline & FF3F & $97.69 \%$ & $97.15 \%$ & $96.44 \%$ & $95.38 \%$ & $94.20 \%$ & $98.00 \%$ \\
\hline & FF5F & $98.09 \%$ & $97.37 \%$ & $96.57 \%$ & $95.55 \%$ & $94.69 \%$ & $98.21 \%$ \\
\hline & $\mathrm{RF}_{2 \mathrm{a}}$ & $97.70 \%$ & $97.14 \%$ & $96.42 \%$ & $96.11 \%$ & $94.85 \%$ & $98.11 \%$ \\
\hline & $\mathrm{RF}_{2 \mathrm{~b}}$ & $98.10 \%$ & $97.37 \%$ & $96.57 \%$ & $96.26 \%$ & $95.35 \%$ & $98.33 \%$ \\
\hline
\end{tabular}


Table 5 Contd.: Correlations between the Actual and the Estimated Continuous Returns:

\begin{tabular}{|c|c|c|c|c|c|c|c|}
\hline \multirow[b]{2}{*}{ Sample } & \multirow[b]{2}{*}{ Models } & \multicolumn{6}{|c|}{ Correlations of Estimated Returns with Actual Returns } \\
\hline & & P1 & P2 & P3 & P4 & P5 & $\begin{array}{c}\text { P-full or } \\
\text { P6 }\end{array}$ \\
\hline \multirow{5}{*}{ S11 } & CAPM & $96.86 \%$ & $97.25 \%$ & $97.32 \%$ & $96.58 \%$ & $91.25 \%$ & $97.92 \%$ \\
\hline & FF3F & $96.89 \%$ & $97.48 \%$ & $97.82 \%$ & $98.19 \%$ & $94.86 \%$ & $98.83 \%$ \\
\hline & FF5F & $97.44 \%$ & $97.73 \%$ & $97.83 \%$ & $98.20 \%$ & $95.15 \%$ & $98.85 \%$ \\
\hline & $\mathrm{RF}_{2 \mathrm{a}}$ & $96.91 \%$ & $97.48 \%$ & $97.83 \%$ & $98.22 \%$ & $95.63 \%$ & $98.87 \%$ \\
\hline & $\mathrm{RF}_{2 \mathrm{~b}}$ & $97.49 \%$ & $97.74 \%$ & $97.85 \%$ & $98.22 \%$ & $95.94 \%$ & $98.89 \%$ \\
\hline \multirow{5}{*}{ S12 } & CAPM & $93.52 \%$ & $89.80 \%$ & $93.39 \%$ & $78.37 \%$ & $94.26 \%$ & $99.48 \%$ \\
\hline & FF3F & $94.56 \%$ & $89.85 \%$ & $96.75 \%$ & $79.13 \%$ & $96.66 \%$ & $99.72 \%$ \\
\hline & FF5F & $95.22 \%$ & $90.44 \%$ & $96.80 \%$ & $80.27 \%$ & $96.68 \%$ & $99.73 \%$ \\
\hline & $\mathrm{RF}_{2 \mathrm{a}}$ & $94.85 \%$ & $89.78 \%$ & $96.77 \%$ & $80.14 \%$ & $96.76 \%$ & $99.72 \%$ \\
\hline & $\mathrm{RF}_{2 \mathrm{~b}}$ & $95.40 \%$ & $90.31 \%$ & $96.83 \%$ & $81.08 \%$ & $96.81 \%$ & $99.73 \%$ \\
\hline \multirow{5}{*}{ S13 } & CAPM & $91.65 \%$ & $92.34 \%$ & $92.67 \%$ & $97.46 \%$ & $99.02 \%$ & $97.76 \%$ \\
\hline & FF3F & $99.13 \%$ & $99.41 \%$ & $99.02 \%$ & $97.53 \%$ & $99.02 \%$ & $98.02 \%$ \\
\hline & FF5F & $99.54 \%$ & $99.43 \%$ & $99.56 \%$ & $99.00 \%$ & $99.08 \%$ & $98.89 \%$ \\
\hline & $\mathrm{RF}_{2 \mathrm{a}}$ & $99.18 \%$ & $99.46 \%$ & $99.11 \%$ & $97.88 \%$ & $99.01 \%$ & $98.12 \%$ \\
\hline & $\mathrm{RF}_{2 \mathrm{~b}}$ & $99.58 \%$ & $99.47 \%$ & $99.57 \%$ & $99.04 \%$ & $99.06 \%$ & $98.90 \%$ \\
\hline \multirow{5}{*}{ S14 } & CAPM & $90.97 \%$ & $91.86 \%$ & $92.69 \%$ & $93.15 \%$ & $98.63 \%$ & $93.27 \%$ \\
\hline & FF3F & $98.62 \%$ & $98.71 \%$ & $97.77 \%$ & $94.19 \%$ & $98.94 \%$ & $94.92 \%$ \\
\hline & FF5F & $98.87 \%$ & $98.72 \%$ & $98.21 \%$ & $95.29 \%$ & $98.94 \%$ & $95.68 \%$ \\
\hline & $\mathrm{RF}_{2 \mathrm{a}}$ & $98.63 \%$ & $98.79 \%$ & $97.93 \%$ & $94.62 \%$ & $98.99 \%$ & $95.05 \%$ \\
\hline & $\mathrm{RF}_{2 \mathrm{~b}}$ & $98.88 \%$ & $98.80 \%$ & $98.35 \%$ & $95.80 \%$ & $98.99 \%$ & $95.71 \%$ \\
\hline \multirow{5}{*}{ S15 } & CAPM & $88.13 \%$ & $92.93 \%$ & $89.97 \%$ & $88.96 \%$ & $98.03 \%$ & $91.44 \%$ \\
\hline & FF3F & $93.52 \%$ & $98.96 \%$ & $96.86 \%$ & $89.39 \%$ & $98.12 \%$ & $92.81 \%$ \\
\hline & FF5F & $94.05 \%$ & $99.01 \%$ & $96.88 \%$ & $90.34 \%$ & $98.15 \%$ & $92.81 \%$ \\
\hline & $\mathrm{RF}_{2 \mathrm{a}}$ & $94.07 \%$ & $98.97 \%$ & $96.87 \%$ & $90.47 \%$ & $98.13 \%$ & $92.90 \%$ \\
\hline & $\mathrm{RF}_{2 \mathrm{~b}}$ & $94.43 \%$ & $99.02 \%$ & $96.90 \%$ & $91.04 \%$ & $98.16 \%$ & $92.93 \%$ \\
\hline \multirow{5}{*}{ S16 } & CAPM & $92.14 \%$ & $92.53 \%$ & $91.54 \%$ & $96.54 \%$ & $99.17 \%$ & $98.65 \%$ \\
\hline & FF3F & $99.00 \%$ & $99.42 \%$ & $99.02 \%$ & $96.90 \%$ & $99.24 \%$ & $99.07 \%$ \\
\hline & FF5F & $99.70 \%$ & $99.43 \%$ & $99.27 \%$ & $98.79 \%$ & $99.24 \%$ & $99.30 \%$ \\
\hline & $\mathrm{RF}_{2 \mathrm{a}}$ & $99.01 \%$ & $99.40 \%$ & $99.04 \%$ & $97.11 \%$ & $99.24 \%$ & $99.00 \%$ \\
\hline & $\mathrm{RF}_{2 \mathrm{~b}}$ & $99.70 \%$ & $99.42 \%$ & $99.32 \%$ & $98.84 \%$ & $99.25 \%$ & $99.27 \%$ \\
\hline \multirow{5}{*}{ S17 } & CAPM & $91.78 \%$ & $93.27 \%$ & $91.13 \%$ & $93.20 \%$ & $98.27 \%$ & $92.96 \%$ \\
\hline & FF3F & $97.44 \%$ & $99.19 \%$ & $97.22 \%$ & $93.42 \%$ & $98.41 \%$ & $93.00 \%$ \\
\hline & FF5F & $97.86 \%$ & $99.30 \%$ & $97.29 \%$ & $93.89 \%$ & $98.40 \%$ & $93.03 \%$ \\
\hline & $\mathrm{RF}_{2 \mathrm{a}}$ & $97.67 \%$ & $99.19 \%$ & $97.37 \%$ & $93.69 \%$ & $98.36 \%$ & $93.17 \%$ \\
\hline & $\mathrm{RF}_{2 \mathrm{~b}}$ & $97.98 \%$ & $99.31 \%$ & $97.44 \%$ & $94.01 \%$ & $98.37 \%$ & $93.26 \%$ \\
\hline \multirow{5}{*}{ S18 } & CAPM & $91.33 \%$ & $92.34 \%$ & $91.02 \%$ & $97.39 \%$ & $98.22 \%$ & $94.00 \%$ \\
\hline & FF3F & $99.23 \%$ & $99.60 \%$ & $99.56 \%$ & $99.19 \%$ & $98.55 \%$ & $98.61 \%$ \\
\hline & FF5F & $99.54 \%$ & $99.61 \%$ & $99.59 \%$ & $99.18 \%$ & $98.55 \%$ & $98.99 \%$ \\
\hline & $\mathrm{RF}_{2 \mathrm{a}}$ & $99.26 \%$ & $99.58 \%$ & $99.57 \%$ & $99.14 \%$ & $98.55 \%$ & $98.64 \%$ \\
\hline & $\mathrm{RF}_{2 \mathrm{~b}}$ & $99.56 \%$ & $99.59 \%$ & $99.60 \%$ & $99.14 \%$ & $98.55 \%$ & $99.02 \%$ \\
\hline \multirow{3}{*}{ S19 } & CAPM & $90.73 \%$ & $94.09 \%$ & $92.13 \%$ & $92.20 \%$ & $86.15 \%$ & $96.90 \%$ \\
\hline & FF3F & $91.66 \%$ & $94.16 \%$ & $92.49 \%$ & $93.09 \%$ & $87.47 \%$ & $97.60 \%$ \\
\hline & $\mathrm{RF}_{2 \mathrm{a}}$ & $91.89 \%$ & $94.56 \%$ & $92.77 \%$ & $93.16 \%$ & $88.04 \%$ & $97.78 \%$ \\
\hline \multirow{3}{*}{$\mathrm{S} 20$} & CAPM & $90.79 \%$ & $93.27 \%$ & $91.12 \%$ & $88.93 \%$ & $81.71 \%$ & $95.93 \%$ \\
\hline & FF3F & $91.34 \%$ & $93.31 \%$ & $92.62 \%$ & $92.50 \%$ & $84.14 \%$ & $97.36 \%$ \\
\hline & $\mathrm{RF}_{2 \mathrm{a}}$ & $91.37 \%$ & $93.37 \%$ & $92.80 \%$ & $92.59 \%$ & $84.30 \%$ & $97.42 \%$ \\
\hline \multirow{3}{*}{ S21 } & CAPM & $87.10 \%$ & $91.21 \%$ & $93.49 \%$ & $93.08 \%$ & $91.94 \%$ & $98.82 \%$ \\
\hline & FF3F & $87.10 \%$ & $91.91 \%$ & $93.91 \%$ & $93.18 \%$ & $93.05 \%$ & $98.93 \%$ \\
\hline & $\mathrm{RF}_{2 \mathrm{a}}$ & $87.37 \%$ & $92.13 \%$ & $94.12 \%$ & $93.52 \%$ & $93.30 \%$ & $99.00 \%$ \\
\hline
\end{tabular}


Table 6: Average SSEs between the Actual and the Estimated Continuous Returns across Risk-Time Format

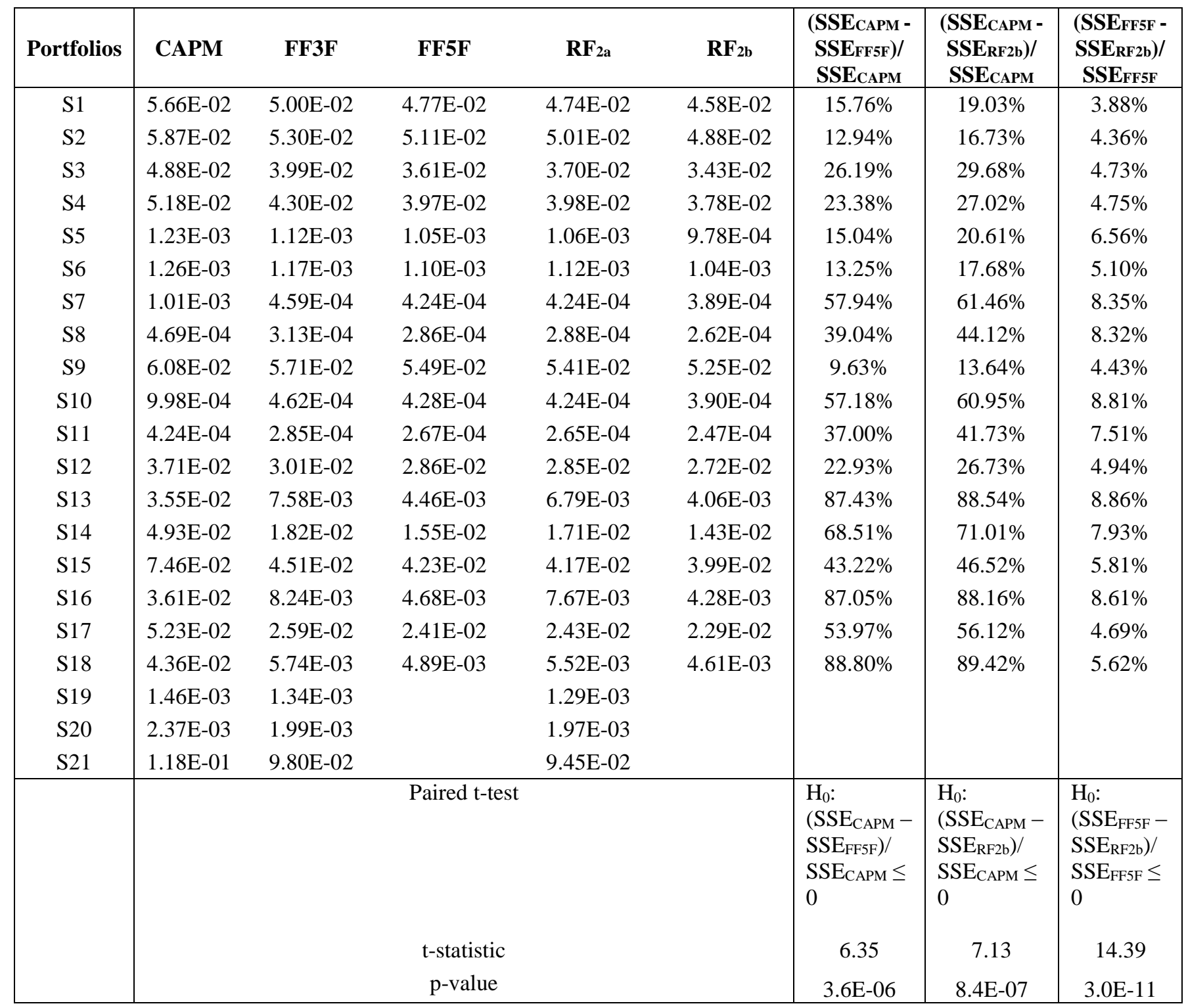


Figure 1: Charts of the Actual ${ }_{1}$ Average Returns and the Estimated Average Returns across Increasing Risk according to CAPM, FF3F, FF5F and $\mathrm{RF}_{1 \mathrm{~b}}$ Equation (17b):

Average Monthly Returns of the Portfolios of S1 from May 2003 to April 2013

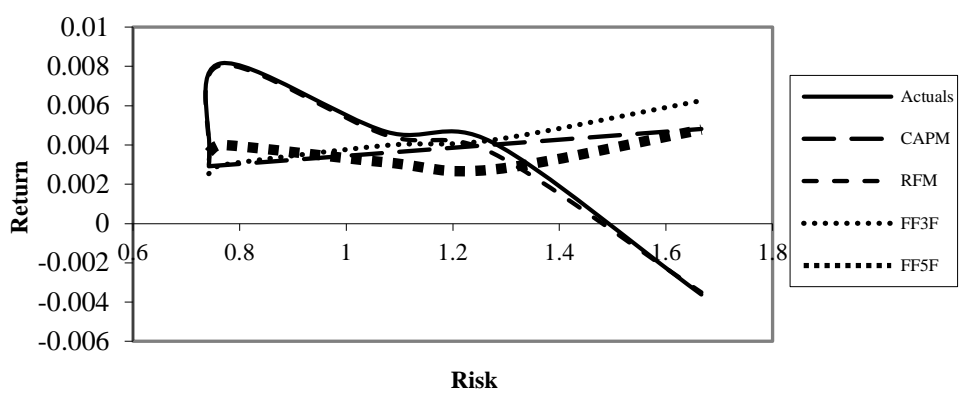

Average Monthly Returns of the Portfolios of S3 from June 2005 to April 2013

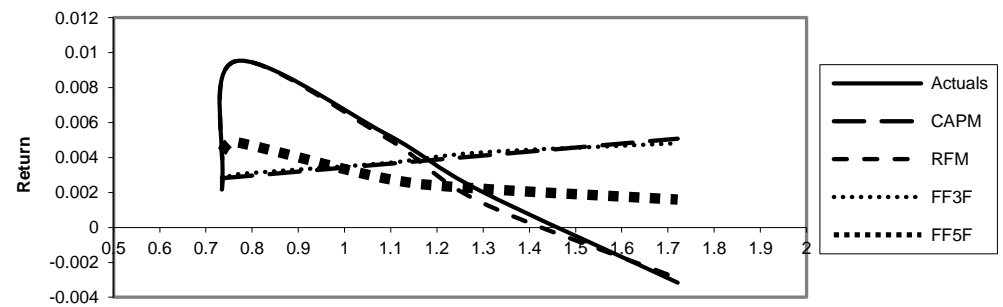

Risk

Average Daily Returns of the Portfolios of S5 from 12 Dec 2012 to 30 April 2013

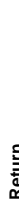

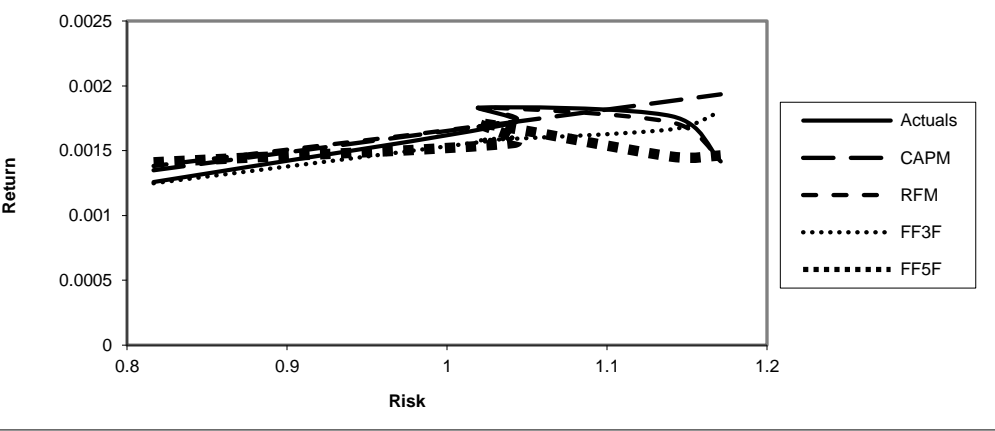

Average Daily Returns of the Portfolios of S7 from 12 Dec 2012 to 30 April 2013

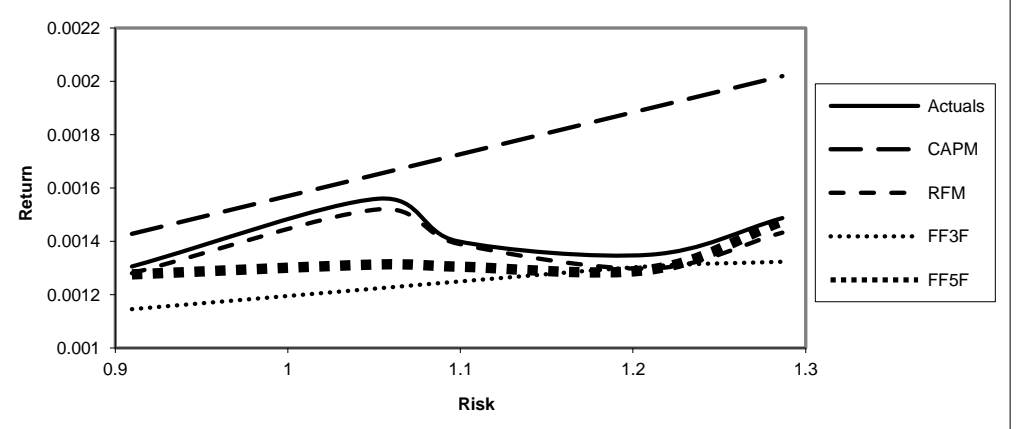

Average Monthly Returns of the Portfolios of S2 from May 2003 to April 2013

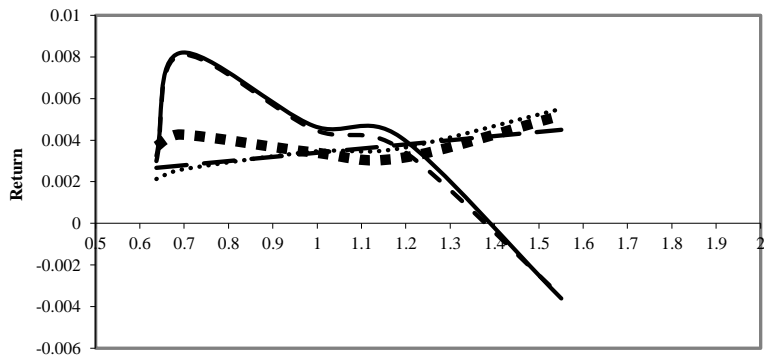

Risk
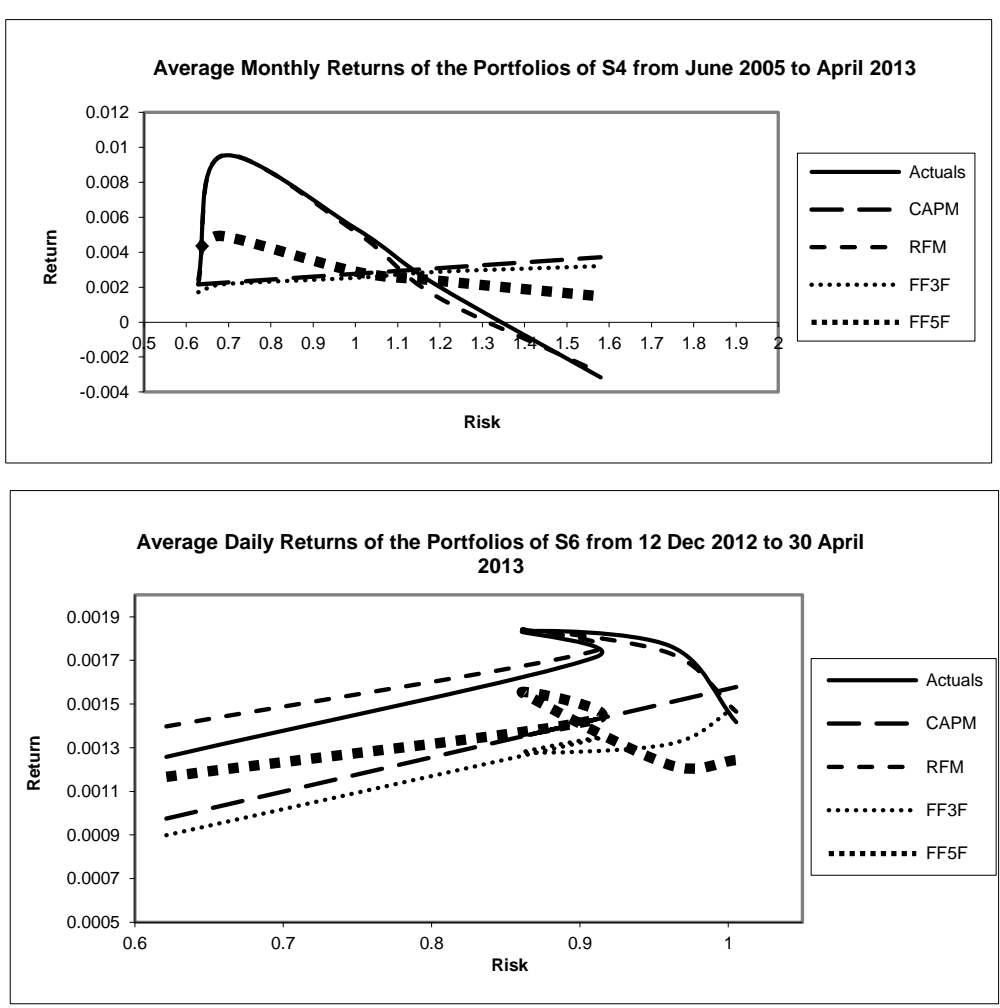

Average Daily Returns of the Portfolios of S8 from 12 Dec 2012 to 30 April 2013

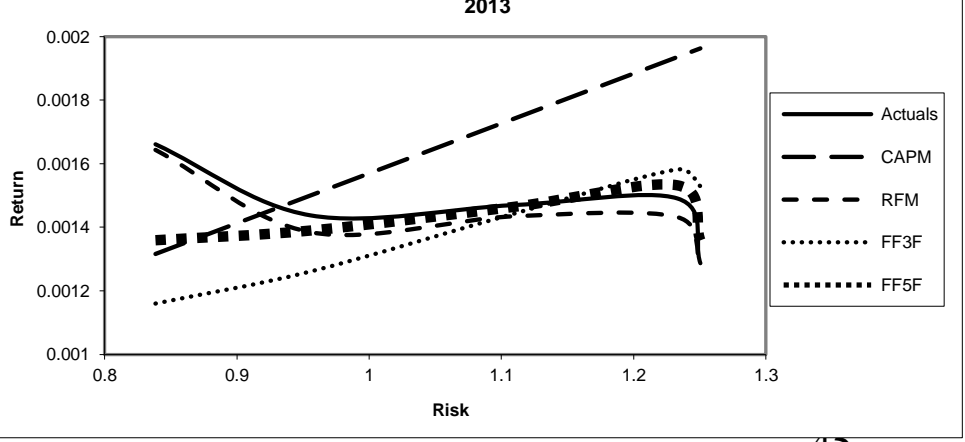


Figure 2: Increasing Risk according to CAPM, FF3F, FF5F and RF $1 \mathrm{~b}$ Equation (27b):

Following Figure 1: Charts of the Actual ${ }_{1}$ Average Returns and the Estimated Average Returns across Increasing Risk according to CAPM, FF3F, FF5F and $\mathbf{R F}_{1 \mathrm{~b}}$ Equation (17b):

Average Monthly Returns of the Portfolios of S9 from May 2003 to April 2013

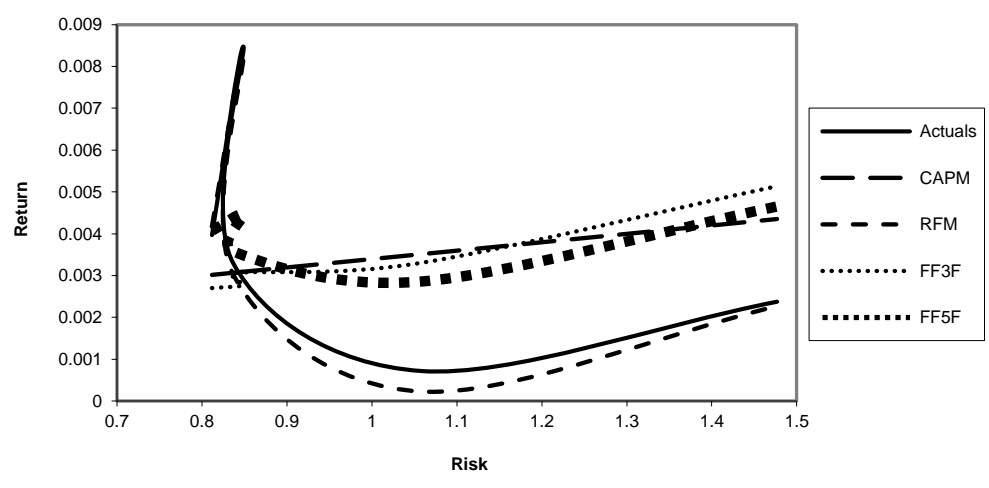

Average Daily Returns of the Portfolios of S11 from 12 Dec 2012 to 30 April 2013

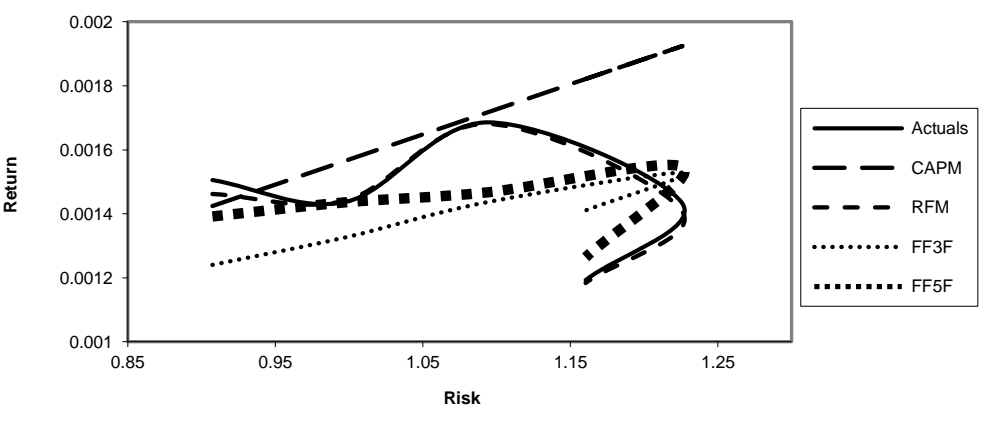

Average Monthly Returns of the Portfolios of S13 from May 2003 to April 2013

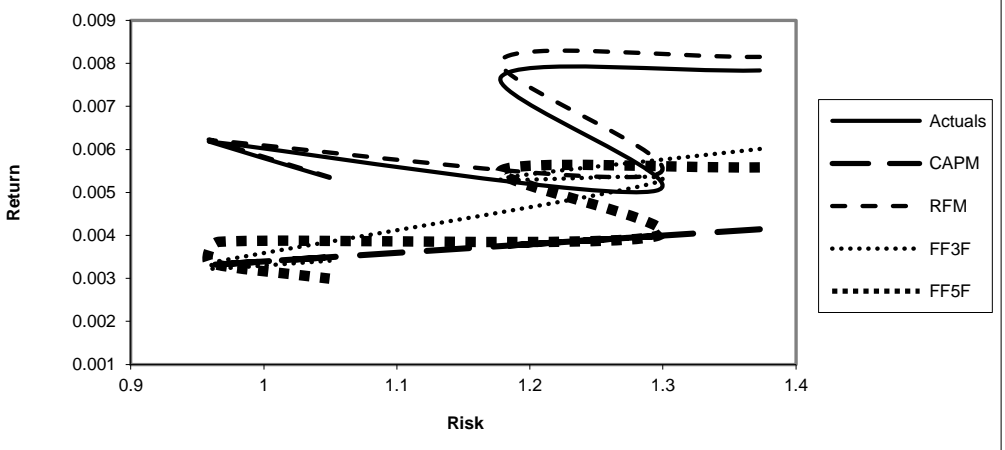

Average Monthly Returns of the Portfolios of S15 from May 2003 to April 2013

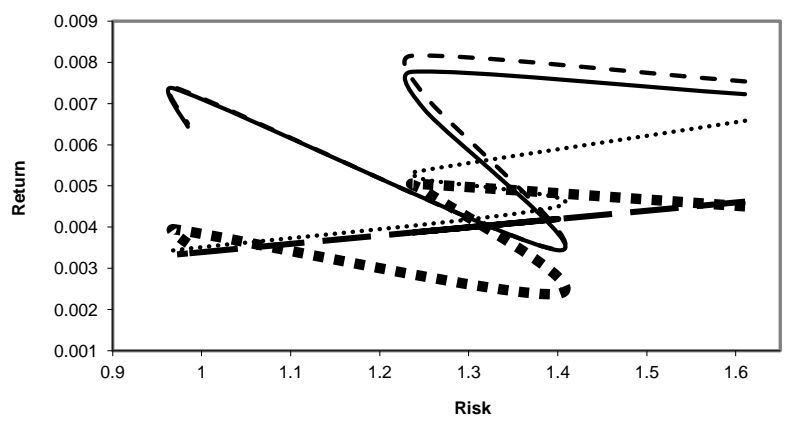

Average Daily Returns of the Portfolios of S10 from 12 Dec 2012 to 30 April 2013

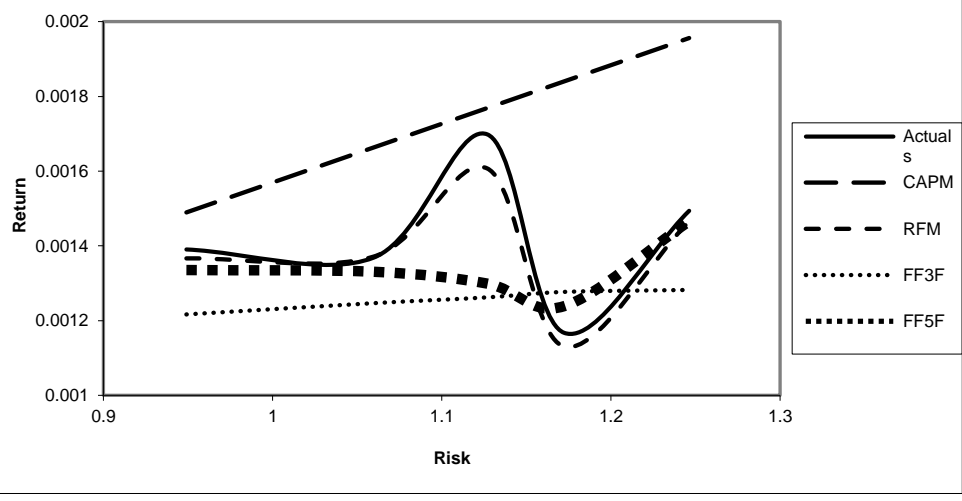

Average Daily Returns of the Portfolios of S12 from 20 May 13 to 30 Sep 13

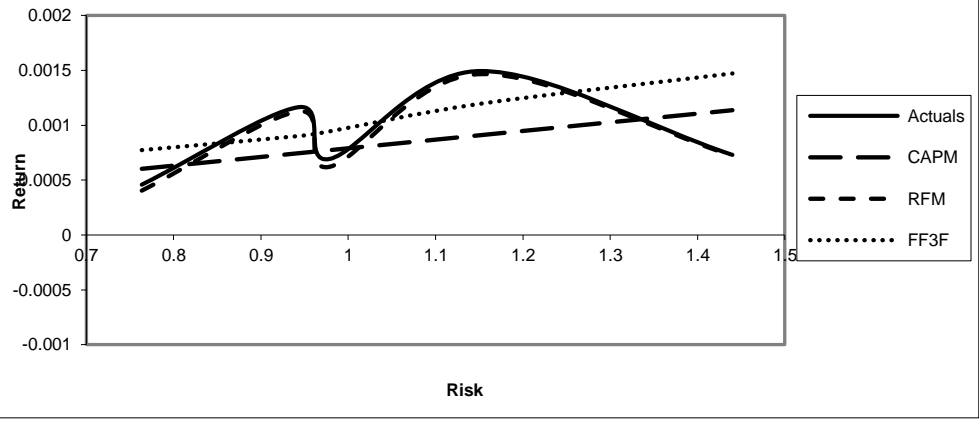

Average Monthly Returns of the Portfolios of S14 from May 2003 to April 2013

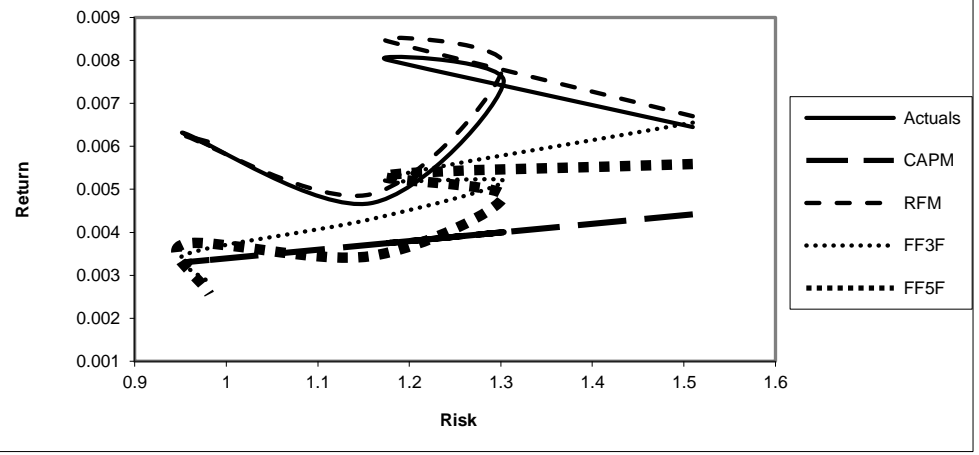

Average Monthly Returns of the Portfolios of S16 from May 2003 to April 2013

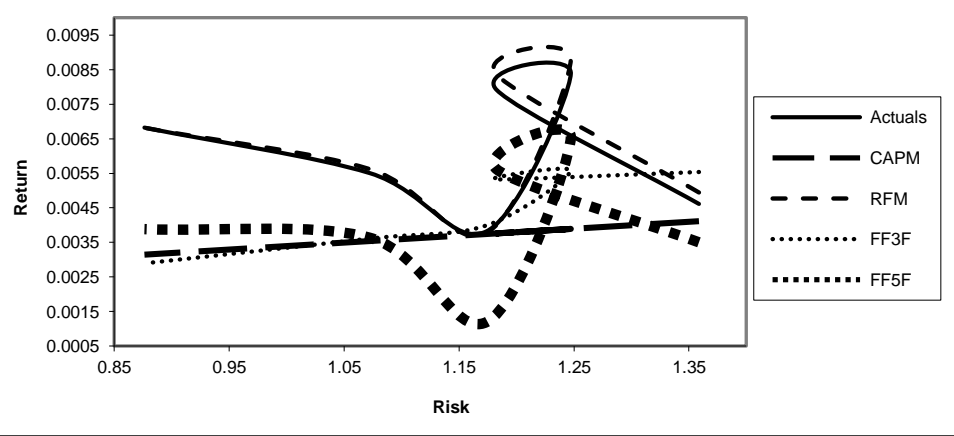


Following Figure 1: Charts of the Actual ${ }_{1}$ Average Returns and the Estimated Average Returns across increasing Risk according to CAPM, FF3F, FF5F and RF ${ }_{1 b}$ Equation (17b):

Average Monthly Returns of the Portfolios of S17 from May 2003 to April 2013

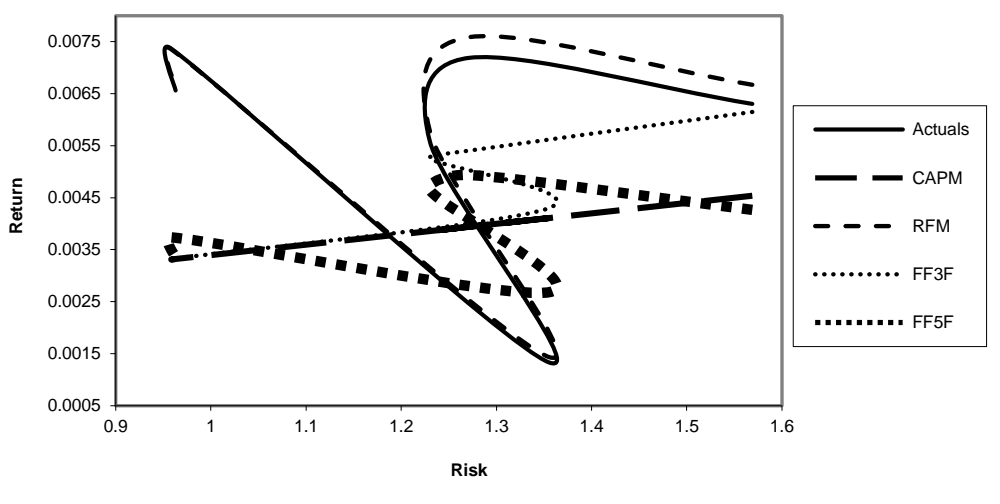

Average Daily Returns of the Portfolios of S19 from 20 May 13 to 30 Sep 13

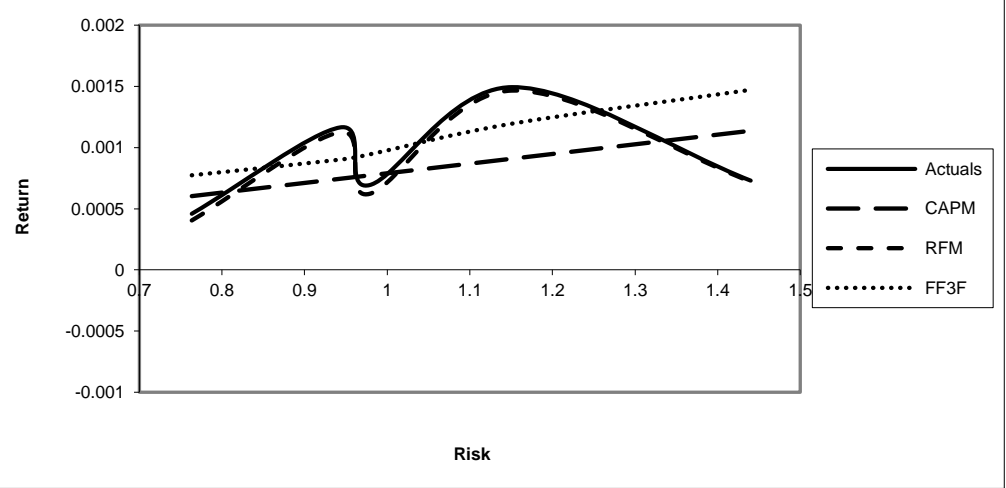

Average Monthly Returns of the Portfolios of S18 from May 2003 to April 2013
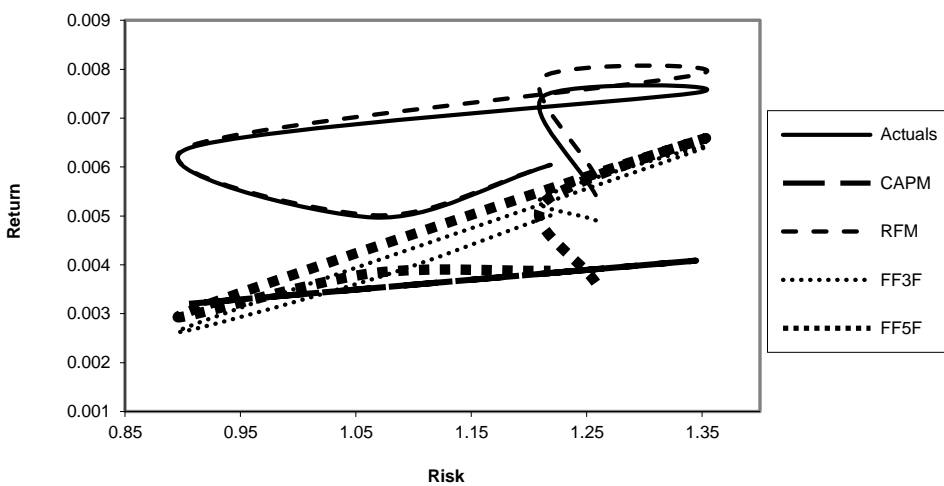

Risk
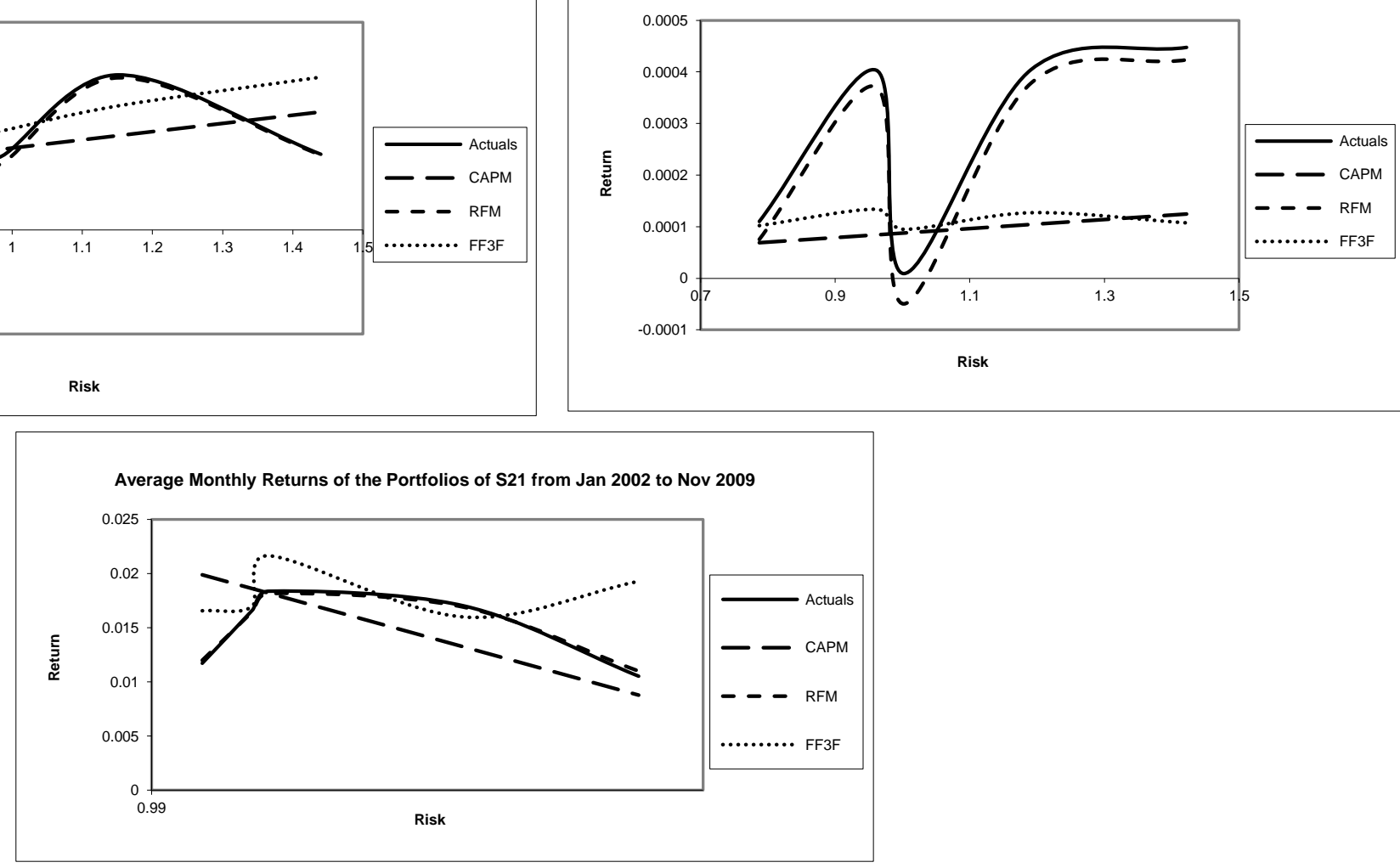